\title{
The Influence of Particulate Matter on the Environmental Burden of Disease in Canada
}

\author{
by \\ Ahmed Almaskut \\ B. Math. Carleton University, 2006 \\ A thesis submitted to \\ the Faculty of Graduate Studies and Research \\ in partial fulfilment of the requirements for the degree of \\ Master of Science
}

School of Mathematics and Statistics

Ottawa-Carleton Institute for Mathematics and Statistics

Carleton University Ottawa, Ontario

September, 2009

(C) Copyright

2009, Ahmed Almaskut 
Library and Archives

Canada

Published Heritage

Branch

395 Wellington Street

Ottawa ON K1A ON4

Canada
Bibliothèque et

Archives Canada

Direction du

Patrimoine de l'édition

395 , rue Wellington

Ottawa ON K1A ON4

Canada
Your file Votre référence
ISBN: $978-0-494-81686-8$
Our file Notre référence
ISBN: $978-0-494-81686-8$
NOTICE:

The author has granted a nonexclusive license allowing Library and Archives Canada to reproduce, publish, archive, preserve, conserve, communicate to the public by telecommunication or on the Internet, loan, distribute and sell theses worldwide, for commercial or noncommercial purposes, in microform, paper, electronic and/or any other formats.

The author retains copyright ownership and moral rights in this thesis. Neither the thesis nor substantial extracts from it may be printed or otherwise reproduced without the author's permission.
AVIS:

L'auteur a accordé une licence non exclusive permettant à la Bibliothèque et Archives Canada de reproduire, publier, archiver, sauvegarder, conserver, transmettre au public par télécommunication ou par l'Internet, prêter, distribuer et vendre des thèses partout dans le monde, à des fins commerciales ou autres, sur support microforme, papier, électronique et/ou autres formats.

L'auteur conserve la propriété du droit d'auteur et des droits moraux qui protège cette thèse. Ni la thèse ni des extraits substantiels de celle-ci ne doivent être imprimés ou autrement reproduits sans son autorisation.
In compliance with the Canadian Privacy Act some supporting forms may have been removed from this thesis.

While these forms may be included in the document page count, their removal does not represent any loss of content from the thesis.
Conformément à la loi canadienne sur la protection de la vie privée, quelques formulaires secondaires ont été enlevés de cette thèse.

Bien que ces formulaires aient inclus dans la pagination, il n'y aura aucun contenu manquant. 


\section{Abstract}

In this thesis we investigate the environmental burden of disease in Canada. Particulate matter (PM2.5) is the environmental risk factor of interest. We study its impact on mortalities from all causes, lung cancer and cardiopulmonary disease. We first start by reviewing some of the results from some of previous environmental burden of disease studies in Chapter 2. In Chapter 3 we introduce all the methodology needed for estimating the burden of disease (BoD) and environmental burden of disease (EBD). Chapter 4 is a simulation study to verify some of the methodology developed in Chapter 3. In Chapter 5 we estimate the EBD for the 1996 Canadian population in terms of years of life lost (YLL). We also estimate the population attributable fractions using PM2.5 concentrations data set. In Chapter 6 we investigate the correlation between years of life lost, death rates and potential years of life lost and discuss our findings. 


\section{Acknowledgements}

I would like to express my sincere gratitude to my two supervisors, Dr. Patrick Farrell and Dr. Daniel Krewski. I have been very fortunate to have worked with both of you and I am forever grateful for all the support you have given me. Dr. Farrell, thank you for taking me under your wings ever since my first undergraduate course with you back in 2005. You have since encouraged and supported me in so many different ways and I am eternally thankful. Dr. Daniel Krewski. thank you for accepting to be my supervisor and for proposing such an interesting topic for my research. I have learned so much from working with you and I look forward to many future projects with you and the McLaughlin Centre.

I would also like to thank my parents for their unconditional love, support and patience. To my friends, thank you for everything you have done for me.

Finally, I would like to thank all my professors, everyone at the School of Mathematics and Statistics and at the McLaughlin Centre for Population Health Risk Assessment who helped me throughout my studies. 


\section{Contents}

Abstract

Acknowledgements

Table of Contents iv

List of Tables vii

List of Figures $\quad x$

1 Introduction 1

2 Literature Review 3

3 Statistical Methods for Calculating EBD $\quad 7$

3.1 Life Tables . . . . . . . . . . . . . . . . . . 8

3.1.1 The Construction of an Abridged Life Table . . . . . 8 
3.1.2 Variance of the Estimate of Life Expectancy, $\hat{e}_{i} \ldots \ldots 11$

3.2 Health Indicators . . . . . . . . . . . . . . . . . . 18

3.2 .1 Years of Life Lost, YLL . . . . . . . . . . . . . . . . 19

3.3 Sensitivity Analysis for YLL . . . . . . . . . . . . . 23

3.3.1 Age Weighting and Discounting .......... . 24

3.3.2 Variance of $Y L L_{1} \ldots \ldots \ldots$. . . . . . . . . . . . . 29

3.4 Population Attributable Fraction $(\mathrm{PAF}) \ldots \ldots . . . . . .30$

3.5 Sensitivity Analysis for Relative Risk Models . . . . . . . . . 32

3.6 Proof of the Effect of the Choice of the Radix on Life Expectancy Calculations ............... 35

\section{Simulation Study}

4.1 Approach 1: Deaths from all Causes and Deaths from Lung Cancer are two Independent Binomial Random Variables . . . 37

4.2 Approach 2: Death from all Causes and Deaths from Lung Cancer are two Dependent Binomial random Variables . . . 40

4.3 Approach 3: Deaths from all Causes and Deaths from Lung Cancer are a Bivariate Normal Random Variable . . . . . . . . 42

\section{Application}


5.11996 Life Expectancy In Canada . . . . . . . . . . . . . . . 44

5.2 Burden of Disease for the 1996 Canadian Population . . . . . 49

5.3 Particulate Matter (PM2.5) . . . . . . . . . 55

5.4 Discussion ..................... 60

6 Health Indicators and Their Correlation 63

$\begin{array}{lll}7 & \text { Conclusion and Discussion } & 68\end{array}$

$\begin{array}{ll}\text { Bibliography } & 69\end{array}$

$\begin{array}{ll}\text { Appendices } & 73\end{array}$

$\begin{array}{ll}\text { A R Programs } & \mathbf{7 4}\end{array}$

A.1 Life Expectancy Function . . . . . . . . . . . . . 74

A.2 YLL Function . . . . . . . . . . . . . . . . 77

A.3 Generating Total Deaths as a Binomial Random Variable . . 78

A.4 Generating Bivariate Normal Data for Approach $3 \ldots . . .79$

A.5 Approach 1 Program . . . . . . . . . . . . . . . . 81

A.6 YLL and Variance of YLL Calculations . . . . . . . . . . . . . 84

A.7 PAF Calculation . . . . . . . . . . . . . . 86

A.8 Health Indicators Comparison . . . . . . . . . . . . . 88 
C.1 WHO Regions . . . . . . . . . . . . . . . . . 95

C.2 World Bank Regions . . . . . . . . . . . . . . . . . . . 97 


\section{List of Tables}

2.1 Population attributable fraction estimates from Lopez et al. study .............................. 4

2.2 Environmental attributable fraction estimates from Prüss- ̈̈stün and Corvalán study . . . . . . . . . . . . . 5

3.1 Abridged life table for 1991 Canadian male population . . . . 12

3.2 The variance estimates for $\hat{e}$, for the 1991 Canadian male pop-

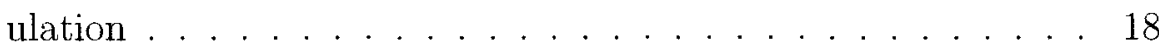

3.3 The impact of different $\beta$ values on the age-weighting function 24

3.4 Effect of $r$ and 3 on the difference betwern male-female YLL. 28

3.5 WHO recommended models for estimating relative risks . . . . 32

3.6 Estimates of relative risk mortality, coefficients of concentrationresponse functions and study types . . . . . . . . . . 33 
4.1 Results from 1000 samples when deaths from cancer and deaths from all causes are independent . . . . . . . . . . . . . . 39

4.2 Results from 1000 samples when deaths from lung cancer and deaths from all causes are dependent . . . . . . . . . . . 41

4.3 Results from 1000 bivariate normal samples . . . . . . . . 43

5.11996 population and deaths estimates for Canada. . . . . . . 45

5.2 Abridged life table for the 1996 Canadian population . . . . 47

5.3 Life expectancy variance estimates for for the 1996 Canadian

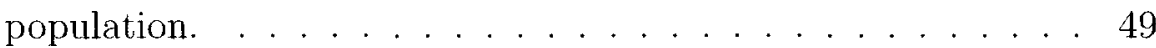

5.4 Life expectancy estimates by sex for the 1996 Canadian pop-

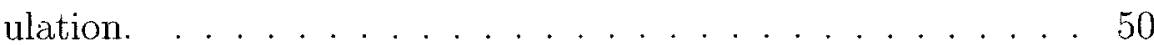

5.51996 deaths from lung cancer and cardiopulmonary disease. . . 51

5.6 Years of life lost from all causes by sex and by age group. . . . 52

5.7 Years of life lost from lung cancer by sex and by age group . . 53

5.8 Years of life lost from cardiopulmonary disease by sex and by

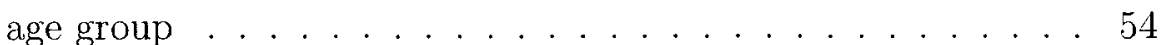

5.9 PM2.5 concentrations, all causes RR. lung cancer RR and cardiopulmonary RR . . . . . . . . . . . . . . . . . 59 
5.10 Populations of the 12 cities and the proportions they represent of the total ....................... 60

5.11 Population attributable fractions . . . . . . . . . 6 60

B.1 The 20 diseases used for the analysis . . . . . . . . . . . . . 92

B.2 Death for both genders combined from 10 diseases in the 1996 Canadian population .................. 93

B.3 Death for both genders combined from 10 diseases in the 1996 Canadian population ................. . . 94 


\section{List of Figures}

3.1 Reported preferences and modeling for relative value of a year of life lived. . . . . . . . . . . . . . . . . . 22

3.2 Age-weighting function. . . . . . . . . . . . . . . . . 25

3.3 Effect of $r$ and $\beta$ on YLL. . . . . . . . . . 26

3.4 Effect of $r$ and $\beta$ on the difference between male-female YLL. 27

3.5 Comparison between different relative risk functions . . . . . . 34

5.1 Yearly average for PM2.5 in $\mu \mathrm{g} / \mathrm{m}^{3} \ldots \ldots . \ldots 57$

6.1 Health indicators comparison plot. . . . . . . . . . . 65 


\section{Chapter 1}

\section{Introduction}

Quantification of a disease, or a number of diseases, and the risk factors that cause them is very crucial to health-related interventions and decisionmaking. The quantity obtained from quantifying a disease, or a number of diseases, is called burden of disease (BoD). The proportion of $\mathrm{BoD}$ that is caused by an environmental factor is known as the environmental burden of disease (EBD). Over the years, numerous studies to assess EBD have been conducted locally and globally by many different organizations. These studies have demonstrated that the impact of enviromment is very significant. Although estimates for both BoD and EBD for Canada were given by some studies such as the global burden of disease (GBD) investigations conducted 
by the World Health Organization (WHO), these estimates were very approximate and were not obtained from detailed Canadian data. The purpose of this thesis is to estimate. for the 1996 Canadian population, the BoD for all causes of death, for lung cancer and for cardiopulmonary disease. In this research we also develop an expression for the variance of one of the health indicators used to quantify the BoD, estimate confidence intervals, and perform a simulation study for the verification of the methodology developed. We will also estimate for all causes, for lung cancer, and for cardiopulmonary disease, the percentages that are attributable to air pollution. More specifically. we will assess the impact of particulate matter (PM2.5) on deaths from all causes, lung cancer and cardiopulmonary disease. 


\section{Chapter 2}

\section{Literature Review}

Studies aimed at estimating the burden of disease began in 1992 when World Bank commissioned the initial global burden of disease (GBD) study for the 1990 world population (see Lopez et al. 2006). Since then, many investigations haven been conducted and in this chapter we will review the results from some of those studies.

Lopez et al. (1996) conducted a GBD study for the World Bank regions

for 1990-2001 (see Appendix C.2). This study reported the BoD in terms of disability adjusted life years (DALYs) that made use of a formula that incorporates time discounting Only. This formula will be discussed in Chapter 3 . The authors reported the BoD estimates for the different World Bank regions 
as opposed to counties separately. Canada was in the high-income countries region. The study estimated that $45 \%$ of the total deaths are attributed to leading risk factors. The population attributable fraction estimates for urban air pollution for all causes of death, lung cancer and cardiopulmonary disease were as shown in Table 2.1.

Table 2.1: Population attributable fraction estimates from Lopez et al. study

\begin{tabular}{|ccc|}
\hline Caise & High-incone counrrics & World \\
\hline Hll causes & $1 \%$ & $1 \%$ \\
Lung cancer & $3 \%$ & $5 \%$ \\
Cardiopulmonaty disease & $2 \%$ & $3 \%$ \\
\hline
\end{tabular}

The methods used to estimate relative risks were those developed by Pope et al. (2002). We will study the models that Pope et al. proposed in Chapter 3 and make use of them for our application study in Chapter 5 .

The World Health organization (WHO) is one of the leading organizations on BoD and EBD studies. The WHO publishes BoD and EBD reports frequently (Prüss-Üstün et al. 2003; Ostro 2004; Prüss-Üstün and Corvalán 2006). These studies provide estimates for the global burden of disease for different regions as specified by WHO (see Appendix C. 1 for WHO regions). The estimates are in terms of DALYs using a formula that incorporates both time discounting and age weights. For the calculation of relative risks in 
the studies mentioned above, WHO uses Pope et al. approach. The WHO studies estimate that $23 \%$ of all deaths are attributable to environmental factors. They estimated that this number is higher for developing countries $(25 \%)$ than in developed ones (17\% only). The environmental attributable fraction estimates for lung cancer and cardiopulmonary disease for developed countries are shown in Table 2.2 (see Prüss-Üstün and Corvalán 2006).

Table 2.2: Environmental attributable fraction estimates from Prüss-Üstün and Corvalán study

\begin{tabular}{|cc|}
\hline Canse & $\begin{array}{c}\text { Artributiable cnvironmental traction } \\
(95 \% \mathrm{CI})\end{array}$ \\
\hline Lung cancer & 30 \\
\hline Men & $(6,55)$ \\
& 30 \\
Women & $(6,55)$ \\
\hline Cardiopulmonary disease & \\
\hline Metu & 22 \\
& $(15.29)$ \\
Women & 6 \\
& $(4.8)$ \\
\hline
\end{tabular}

The WHO estimates that outdoor air pollution is attributable for $5 \%$ of the deaths caused by lung cancer and $2 \%$ of the deaths caused by cardiopulmonary disease. Regarding all deaths. the WHO categorizes Canada, the United States of America and Cuba into a group referred to as AMR-A (see 
Appendix C.1). For this group they estimated that $1 \%$ of the total deaths ( $1.4 \%$ for the world) are attributable to outdoor air pollution.

There have also been studies conducted for BoD or EBD at the local level. Boyd and Genuis (2008) performed a study to investigate the EBD in Canada. This study relied on the WHO estimates for the environmental attributable fractions and reported the BoD in terms of the number of deaths. The authors studied the impact of particulate matter on lung cancer by using an attributable fraction of $5-15 \%$.

From the review of the literature, it became evident that there is a lack of EBD studies for Canada. We therefore focus our attention on such an investigation here, as such studies will help to improve the health of Canadians, and the economy in general. 


\section{Chapter 3}

\section{Statistical Methods for}

\section{Calculating EBD}

To evaluate the EBD. BoD is first calculated for a given disease. or for a number of diseases of interest. The EBD is then a percentage of the BoD attributable to a certain environmental risk factor. Quantifying the BoD always starts by life table analysis of the population of interest. From life tables, life expectancies are obtained and subsequently used to evaluate the BoD in the form of an appropriate health indicator. The population attributable fraction (PAF) is then determined. Generally speaking,the PAF represents the $\mathrm{BoD}$ percentage attributable to a risk factor. 
In this chapter a detailed explanation of life tables, a health indicator, and the population attributable fraction will be given.

\subsection{Life Tables}

There are two different kinds of life tables; complete and abridged. In a complete life table, life expectancies are obtained for each age, whereas an abridged life table provides life expectancies for age intervals. For this study. because of data availability, the abridged life table will be used(see Chiang 1984).

\subsubsection{The Construction of an Abridged Life Table}

For a given year, an abridged life table typically consists of the following quantities for the $i$-th age interval, $i=1, \ldots, w$. and usually in the following order:

1. Age interval $\left(x_{\imath}, x_{\imath+1}\right)$. A commonly used convention is to have all intervals of width five years, expect for the first one, $<1$. second one, $1-<5$, and the last one, $85+$. 
2. Interval $\left(x_{\imath}, x_{\imath+1}\right)$ width. $n_{\imath}$.

$$
n_{\iota}=x_{\imath+1}-x_{\imath}
$$

3. Midyear population, $\mathrm{P}_{\imath}$, in interval $\left(x_{\imath}, x_{\imath+1}\right)$.

4. Number of deaths, $\mathrm{D}_{\imath}$, in the interval $\left(x_{\imath}, x_{\imath+1}\right)$.

5. Death Rate, $\mathrm{M}_{\imath}$, in the interval $\left(x_{\imath}, x_{\imath+1}\right)$.

$$
M_{\iota}=\frac{D_{\imath}}{P_{\iota}}
$$

6. Fraction, $a_{l}$, of last age interval of life. It is defined as the expected fraction of the interval $\left(x_{1}, x_{\imath+1}\right)$ lived by an individual who dies in that interval. The value of $a_{\imath}$ is the same for all individuals falling in age interval $i$.

7. An estimate. $\hat{q}_{\imath}$, of the probability of death in the interval $\left(x_{\imath}, x_{\imath+1}\right)$.

$$
\hat{q}_{1}=\frac{n_{\imath} M_{\imath}}{1+\left(1-a_{\imath}\right) n_{\imath} M_{\imath}}
$$

8. An estimate, $\hat{p}_{\imath}$, of the probability of surviving in the interval $\left(x_{\imath}, x_{\imath+1}\right)$.

$$
\hat{p}_{\imath}=1-\hat{q}_{2}
$$

9. Number of people alive, $l_{\imath}$. at exact age $x_{\imath}$. An arbitrary value, $l_{0}$, called the "radix" or "root" is required to determine $l_{\imath}$ for each of the age intervals. This number effectively represents the size of a population that is going to 
CHAPTER 3. STATISTICAL METHODS FOR CALCULATING EBD 10

be subjected to the same mortality conditions as the real population under study. The radix is usually a convenient round number like 1000,10000 , 100000 etc. Note, however, that the choice of radix does not affect the results obtained in a life table. A proof is given at the end of this chapter. 10. Number of individuals dying, $d_{i}$, in the interval $\left(x_{i}, x_{i+1}\right)$.

$$
d_{i}=l_{i} \hat{q}_{i}
$$

Therefore,

$$
l_{i+1}=l_{i}-d_{i}
$$

Note that it is assumed that every individual dies in the last interval, so that

$$
d_{w}=l_{w}
$$

where $w$ references the last age interval in the table.

11. Number of years lived, $L_{i}$ in the interval $\left(x_{i}, x_{i+1}\right)$.

$$
L_{i}=n_{i}\left(l_{i}-d_{i}\right)+a_{i} n_{i} d_{i}
$$

Note that for the last interval,

$$
L_{w}=\frac{l_{w}}{M_{w}}
$$


12. Total number of years lived, $T_{\imath}$ after age $x_{\imath}$.

$$
T_{b}=L_{\imath}+L_{\imath+1}+\ldots+L_{w}
$$

13. Life expectancy, $\hat{e}_{\imath}$ at age $x_{\imath}$.

$$
\hat{e}_{\iota}=\frac{T_{r}}{l_{r}}
$$

Table 3.1 is an example of an abridged life table for the 1991 Canadian male population.

\subsubsection{Variance of the Estimate of Life Expectancy, $\hat{e}_{b}$}

Chiang (1984) proposes an expression for the variance in $\hat{e}_{2}$. We elaborate on the development of this expression in further detail here.

From equation (3.4) we know that

$$
\hat{p}_{\imath}=1-\hat{q}_{\imath}
$$

Therefore

$$
\operatorname{Var}\left(\hat{p}_{l}\right)=\operatorname{Var}\left(\hat{q}_{l}\right)
$$


Table 3.1: Abridged life talsle for 1991 Canadian male population

\begin{tabular}{|c|c|c|c|c|c|c|c|c|c|c|c|c|}
\hline$\left(x_{1} \cdot x_{1,+1}\right)$ & $\mathrm{n}_{\ell}$ & $\mathrm{P}_{2}$ & $\mathrm{D}_{t}$ & $\mathrm{M}_{2}$ & $a_{2}$ & $\hat{q}_{2}$ & $\hat{p}_{\iota}$ & $l_{\iota}$ & $d_{2}$ & $\mathrm{~L}_{\iota}$ & $\mathrm{T}_{b}$ & $\hat{e}_{\imath}$ \\
\hline$<1$ & 1 & 201595 & 1432 & 0.0071033508 & 01 & 0.007058227 & 0.9929418 & 100000 & 706 & 99364 & 7433183 & 74.381830 \\
\hline $1-<5$ & 4 & 774170 & 298 & 0.0003849284 & 0.4 & 0.001538292 & 0.9984617 & 99294 & 153 & 396808 & 7333819 & 73859639 \\
\hline $5-<10$ & 5 & 978220 & 197 & 0.0002013862 & 0.5 & 0.001006424 & 0.9989936 & 99141 & 100 & 495455 & 6937011 & 69.071162 \\
\hline $10-<15$ & 5 & 962930 & 253 & (1) 0002627398 & 0.5 & 0001312836 & 0.9986872 & 99041 & 131 & 494877 & 6441556 & 65030287 \\
\hline $15-<20$ & 5 & 958404 & 913 & 00009526254 & 05 & 0.004751810 & 0.9952482 & 98910 & 471 & $4 y 3372$ & 5940679 & 60.122121 \\
\hline $201<<25$ & 5 & 985220 & 1256 & 0.0012748422 & 05 & 0.006353960 & 0.9936460 & 98439 & 626 & 490630 & 5453307 & 55.397830 \\
\hline $25-<30$ & 5 & 1182575 & 1502 & 0.0012701097 & 05 & 0.006330448 & 0.9936696 & 97813 & 620 & 487515 & 4962677 & 50736375 \\
\hline $30-<35$ & 5 & 1237690 & 1684 & 0.0013605992 & 0.5 & 0.006779934 & 0.9932201 & 97193 & 659 & 484317 & 4475.162 & 46044077 \\
\hline $35-<40$ & 5 & $11: 33670$ & 1849 & 00016309861 & 0.5 & 0.008121814 & 0.9918782 & 96534 & 785 & 480707 & 3990845 & 41341341 \\
\hline $40-<45$ & 5 & $10421 \times 5$ & $22+8$ & 0.0021570067 & 05 & 0010727187 & 09892728 & 95749 & 1028 & 476175 & 3510138 & 36659788 \\
\hline $45-<50$ & 5 & 824205 & 2904 & 0.0035233953 & 0.5 & $0.017 \pm 63152$ & 0.9825368 & 94721 & 1655 & 469467 & 3033963 & 32030521 \\
\hline $50-<55$ & 5 & 663285 & 3712 & 0.0055963877 & 0.5 & 0.027505846 & 0.9724042 & 93066 & 2569 & 458907 & 2564496 & 27.555670 \\
\hline $55-<60$ & 5 & 608085 & 5705 & 00094805825 & 0.5 & 0046305407 & U 9536946 & 90497 & 4191 & 442007 & 2105589 & 23.266948 \\
\hline $601-<65$ & 5 & 571940 & 9073 & 00158635521 & 05 & 0.076292101 & 0.9237079 & 86306 & 6585 & 415067 & 1663582 & 19275392 \\
\hline $65-<70$ & 5 & 492500 & 12553 & 0.0254883249 & 05 & 0.119807400 & 0.8801926 & 79721 & 9552 & 374725 & 1248515 & 15.661055 \\
\hline $70-<75$ & 5 & 358955 & 14144 & 00394032678 & 05 & 0179348998 & 0.8206510 & 70169 & 12585 & 310382 & 873790 & 12.452650 \\
\hline $75-<80$ & 5 & 252530 & 16081 & 00636795628 & 0.5 & 0.274670561 & 0.7253294 & 57584 & 15817 & 248377 & 554408 & $9.627 \triangleleft 13$ \\
\hline $80-<85$ & 5 & 140135 & 14004 & 0.0999322082 & 0.5 & 0.399783037 & 0.6002170 & 41767 & 16698 & 167090 & 306031 & 7.327100 \\
\hline $85+$ & 5 & 86300 & 15571 & 0.1804287370 & 0.5 & 1.000000000 & 0.0000000 & 25069 & 25069 & 138941 & 138941 & 5.542343 \\
\hline
\end{tabular}


CHAPTER 3. STATISTICAL METHODS FOR CALCULATING EBD 13

We also know from equation 3.2

$$
M_{\iota}=\frac{D_{\iota}}{P_{\iota}}
$$

This. treating $P$, as constant, variance of $M$, is

$$
\operatorname{Var}\left(M_{\imath}\right)=\frac{1}{P_{\imath}^{2}} \operatorname{Var}\left(D_{\imath}\right)
$$

Since $D_{\iota}$ is a binomial random variable with $N$, trials, and probability of success $q_{\imath}$

$$
\operatorname{Var}\left(D_{1}\right)=N_{\imath} q_{2}\left(1-q_{\imath}\right)
$$

Here $N_{\imath}$ is the population at the beginning of interval $\left(x_{2}, x_{\imath+1}\right)$. which is unknown and needs to be estimated. Since

$$
q_{\imath}=\frac{D_{\imath}}{N_{\imath}}
$$

Treating $N_{\imath}$ as an unknown constant, we can estimate $N_{\imath} q_{\imath}$ by $D_{\imath}$ and get

$$
\operatorname{Var}\left(D_{\imath}\right)=D_{\imath}\left(1-q_{\imath}\right)
$$


CHAPTER 3. STATISTICAL METHODS FOR CALCULATING EBD 14

Substituting equation 3.16 into equation 3.13 we get

$$
\operatorname{Var}\left(M_{\imath}\right)=\frac{1}{P_{\imath}^{2}} D_{\imath}\left(1-q_{\imath}\right)=\frac{M_{\iota}}{P_{\iota}}\left(1-q_{\imath}\right)
$$

Since $q_{1}=\frac{D_{1}}{N_{1}}$

$$
\operatorname{Var}\left(q_{\imath}\right)=\frac{1}{N_{1}^{2}} \operatorname{Var}\left(D_{\imath}\right)=\frac{D_{\imath}}{N_{\imath}^{2}}\left(1-q_{\imath}\right)=\frac{q_{\imath}^{2}\left(1-q_{\imath}\right)}{D_{\imath}}
$$

Therefore

$$
\operatorname{Var}\left(\hat{q}_{\imath}\right)=\frac{\hat{q}_{\iota}^{2}\left(1-\hat{q}_{\imath}\right)}{D_{\iota}}
$$

Now

$$
\hat{e}_{r}=\frac{T_{\imath}}{l_{\imath}}=\frac{L_{\imath}+L_{\imath+1}+\ldots \ldots+L_{u}}{l_{l}}=\frac{1}{l_{\imath}} \sum_{\jmath=\iota}^{w} L_{\jmath}
$$

since 


$$
\begin{array}{r}
L_{\jmath}=n_{\jmath} l_{\jmath+1}+a_{\jmath} n_{\jmath}\left(l_{\jmath}-l_{\jmath+1}\right) \\
=a_{\jmath} n_{\jmath} l_{\jmath}+\left(1-a_{\jmath}\right) n_{\jmath} l_{\jmath+1}
\end{array}
$$

Substituting equation 3.20 into equation 3.19 gives,

$$
\begin{aligned}
\hat{e}_{\imath} & =\frac{1}{l_{\imath}} \sum_{\jmath=\imath}^{w}\left[a_{\jmath} n_{\jmath} l_{\jmath}+\left(1-a_{\jmath}\right) n_{\jmath} l_{\jmath+1}\right] \\
& =a_{\imath} n_{\imath}+\left(1-a_{\imath}\right) n_{\imath} \frac{l_{\imath+1}}{l_{\imath}}+\frac{1}{l_{\iota}} \sum_{\jmath=\imath+1}^{w}\left[a_{\jmath} n_{\jmath} l_{\jmath}+\left(1-a_{\jmath}\right) n_{\jmath} l_{\jmath}+1\right] \\
& =a_{\imath} n_{\imath}+\frac{1}{l_{\imath}} \sum_{\jmath=\imath+1}^{w}\left(a_{\jmath} n_{\jmath} l_{\jmath}\right)+\frac{1}{l_{\imath}} \sum_{\jmath=\imath}^{w}\left(1-a_{\jmath}\right) n_{\jmath} l_{\jmath}+1
\end{aligned}
$$

Let $\imath=\jmath-1$, then $\jmath=\imath+1$ and

$$
\hat{e}_{\imath}=a_{\imath} n_{\imath}+\sum_{\jmath=\imath+1}^{w}\left[a_{\jmath} n_{\jmath}+\left(1-a_{\jmath-1}\right) n_{\jmath-1}\right] \frac{l_{\jmath}}{l_{\iota}}
$$

Now

$$
\frac{l_{J}}{l_{\imath}}=\frac{l_{\imath} \hat{p}_{\imath} \hat{p}_{\imath+1} \ldots \hat{p}_{J-1}}{l_{\iota}}=\hat{p}_{\imath} \hat{p}_{\imath+1} \ldots \hat{p}_{\jmath-1}=\hat{p}_{\imath \jmath}
$$


CHAPTER 3. STATISTICAL METHODS FOR CALCULATING EBD 16

where $\hat{p}_{\imath \jmath}$ is defined as the probability of survival from age $x_{\imath}$ to age $x_{\jmath}$.

Substituting equation 3.23 into equation 3.21 gives

$$
\hat{e}_{\imath}=a_{\imath} n_{\imath}+\sum_{\jmath=\imath+1}^{w} C_{\jmath} \hat{p}_{\imath \jmath}
$$

where

$$
C_{\jmath}=\left(1-a_{\jmath-1}\right) n_{\jmath-1}+a_{\jmath} n_{\jmath}
$$

The only source of variation in the life expectancy. $\hat{e}_{2}$, is due to variation in $\hat{p}_{\imath \jmath}$. The delta method can therefore be used to derive the variance for $\hat{e}_{\imath}$. First we take the derivative of $\hat{p}_{\imath \jmath}$ with respect to $\hat{p}_{k}$. If $k<\jmath$ then $\hat{p}_{\imath k}$ and $\hat{p}_{k \jmath}$ have $\hat{p}_{\iota} \hat{p}_{l+1} \ldots \hat{p}_{k-1}$ in common and therefore, are dependent.

$$
\frac{\partial}{\partial \hat{p}_{k}} \hat{p}_{\imath \jmath}= \begin{cases}\hat{p}_{\imath k} \hat{p}_{k+1, \jmath} & \text { for } i \leq k<\jmath \\ 0 & \text { otherwise }\end{cases}
$$




$$
\begin{aligned}
\frac{\partial}{\partial \hat{p}_{k}} \hat{e}_{i} & =\sum_{\jmath=i+1}^{w} C_{j} \frac{\partial}{\partial \hat{p}_{k}} \hat{p}_{i j} \\
& =\sum_{\jmath=k+1}^{w} C_{\jmath} \hat{p}_{i k} \hat{p}_{k+1, j} \\
& =\hat{p}_{2 k}\left[C_{k+1}+\sum_{j=k+2}^{w} C_{j} \hat{p}_{k+1, j}\right] \\
& =\hat{p}_{2 k}\left[\left(1-a_{k}\right) n_{k}+a_{k+1} n_{k+1}+\sum_{j=k+2}^{w} C_{j} \hat{p}_{k+1, j}\right] \\
& =\hat{p}_{i k}\left[\left(1-a_{k}\right) n_{k}+\hat{e}_{k+1}\right]
\end{aligned}
$$

Since all age groups are distinct and do not overlap, the probabilities of surviving, $p_{i}$, are not correlated assuming that $p_{\imath} \neq 0$ for $i<w$. Therefore

$$
\operatorname{Var}\left(\hat{e}_{i}\right)=\sum_{k=\imath}^{w-1}\left(\frac{\partial}{\partial \hat{p}_{k}} \hat{e}_{i}\right)^{2} \operatorname{Var}\left(\hat{p}_{k}\right)
$$

Substituting equation 3.25 and equation 3.18 into equation 3.26 . gives the formula for the variance of $\hat{e}_{i}$ :

$$
\operatorname{Var}\left(\hat{e}_{i}\right)=\sum_{k=1}^{w-1} \hat{p}_{i k}^{2}\left[\left(1-a_{k}\right) n_{k}+\hat{e}_{k+1}\right]^{2} \frac{\hat{q}_{k}^{2}\left(1-\hat{q}_{k}\right)}{D_{k}}
$$

Table 3.2 contains the variance estimates for the 1991 Canadian male 
population. As expected, the variance is very small due to the fact that the variance of probability of death is very small.

Table 3.2: The variance estimates for $\hat{e}_{i}$ for the 1991 Canadian male population

\begin{tabular}{|c|c|c|c|c|}
\hline Age interval & $\operatorname{Var}\left(\hat{p}_{1}\right)$ & $l_{t}^{2}\left[\left(1-a_{2}\right) n_{2}+\dot{e}_{2+1}\right]^{2} \operatorname{Var}\left(\hat{p}_{1}\right)$ & $\sum_{k \geq \geq_{l}} l_{k=}^{2}\left[\left(1-a_{k}\right) n_{1}+\hat{e}_{k+1}\right]^{2} \operatorname{Var}\left(\hat{p}_{k}\right)$ & $\operatorname{Var}\left(\hat{C}_{2}\right)$ \\
\hline$<1$ & $3454395 \times 10^{-8}$ & 1930662.9 & 161267140 & $16126714 \times 10^{-3}$ \\
\hline $1-<5$ & $7.928535 \times 10^{-9}$ & 409420.9 & 14196051.1 & $1.4398642 \times 10^{-3}$ \\
\hline $5-<10$ & $5.136398 \times 10^{-9}$ & 2302916 & 13786630.2 & $14026572 \times 10^{-3}$ \\
\hline $10-<15$ & $6.803466 \times 10^{-9}$ & 261707.3 & 13556338.5 & $13820138 \times 10^{-3}$ \\
\hline $15-<20$ & $2.461381 \times 10^{-8}$ & 807204.9 & 13294631.3 & $1.3589263 \times 10^{-3}$ \\
\hline $20-<25$ & $3.193971 \times 10^{-8}$ & 8771672 & 12487426.4 & $1.2886606 \times 10^{-3}$ \\
\hline $25-<30$ & $2.651190 \times 10^{-8}$ & 597732.1 & 11610259.2 & $1.2135251 \times 10^{-3}$ \\
\hline $30-<35$ & $2.711155 \times 10^{-8}$ & 4922571 & 110125271 & $1.1657811 \times 10^{-3}$ \\
\hline $35-<40$ & $3.538568 \times 10^{-8}$ & 505671.8 & 10520270.1 & $1.1289281 \times 10^{-3}$ \\
\hline $10-<\mathbf{4 5}$ & $5.063974 \times 10^{-8}$ & 553561.9 & 10014598.2 & $1.0923581 \times 10^{-3}$ \\
\hline $45-<50$ & $1.031805 \times 10^{-7}$ & 836263.0 & 9461036.3 & $10544990 \times 10^{-3}$ \\
\hline $50-<55$ & $1.994924 \times 10^{-7}$ & 11471873 & 8624773.3 & $9.957850 \times 10^{-4}$ \\
\hline $5.5-<60$ & $3.547100 \times 10^{-7}$ & 1377443.4 & 74775860 & $0.130468 \times 10^{-4}$ \\
\hline $60-<65$ & $5.925744 \times 10^{-7}$ & 14558179 & 61001426 & $8.189512 \times 10^{-4}$ \\
\hline $65-<70$ & $1.006462 \times 10^{-6}$ & 1430142.4 & 46443247 & $7.307639 \times 10^{-4}$ \\
\hline $70-<75$ & $1.866312 \times 10^{-6}$ & 1351573.7 & 3214182.4 & $6.527997 \times 10^{-4}$ \\
\hline $75-<80$ & $3.402879 \times 10^{-6}$ & 10896849 & 186226086 & $5617175 \times 10^{-4}$ \\
\hline $80-<85$ & $6.850226 \times 10^{-6}$ & 772923.7 & 772923.7 & $4.430677 \times 10^{-4}$ \\
\hline $85+$ & 0.0 & 00 & 0.0 & 00 \\
\hline
\end{tabular}

\subsection{Health Indicators}

Health indicators are summary measures of population health. They can be as simple as number of deaths due to a specific disease, $D_{i}$, or as complex 
CHAPTER 3. STATISTICAL METHODS FOR CALCULATING EBD 19

as the number of years of life lost due to premature mortality, YLL, over the entire population. Although many health indicators have been developed. YLL will be the main focus in this study. In chapter 6 , a comparison study will compare YLL with death rates, $M_{\iota}$, and potential years of life lost, PYLL.

\subsubsection{Years of Life Lost, YLL}

The years of life lost measure, YLL. is usually combined with a second measure reflecting the number of years lived with a disability, YLD, to create an indicator that combines both mortality and morbidity. This indicator is called the disability adjusted life years or DALY and is written as

$$
D A L Y=Y L L+Y L D
$$

The DALY measures health gaps as opposed to health expectancies. It considers the differences between a current situation and an ideal situation where everyone lives up to their life expectancy (see Prüss-Üstün et al. 2003).

The YLL is the part of the DALY that accounts for mortality. It can be broken down by age group. Specifically, the years of life lost for a particular age group, $\mathrm{YLL}_{\imath}$, is essentially the number of deaths multiplied by life 
CHAPTER 3. STATISTICAL METHODS FOR CALCULATING EBD 20

expectancy for that group

$$
Y L L_{1}=D_{1} e_{2}
$$

where $Y L L_{\iota}$ is the number of years of life lost for age group $i, \mathrm{D}_{\imath}$ is number of deaths for age group $i$, and $e_{\imath}$ is the life expectancy estimate for group $i$

Equation 3.30 is the simplest for calculating $\mathrm{YLL}_{\imath}$ and does not incorporate any time or age discounting. However, some studies showed the need to include a time discount rate to account for the preference of a healthy life year now as opposed to in the future (see Lopez et. al 2006; Prüss-Üstün et al. 2003). These studies showed that the value of a year of life is decreased by a fixed percentage, $r$. For example, the following equation was used by Prüss-Üstün et al. (2003) to include the discount rate, $r$

$$
Y L L_{i}=\frac{D_{\imath}}{r}\left(1-e^{-r e_{2}}\right)
$$

where the discount rate, $r$, is usually taken to be $3 \%$

Notice that the previous equation simplifies to equation 3.30 when $r$ approaches zero. 


$$
\lim _{r \rightarrow 0} \frac{D_{i}}{r}\left(1-e^{-r e_{2}}\right)=D_{i} e_{i}
$$

The expression for YLL was further developed by including age weighting (see Murray and Acharya 1997). Age weighting is included so that healthy life lived at young ages and old ages are given lower weights. This choice was based on a number of studies that indicated a social preference to value a year lived by a younger adult more than a year lived by a young child or an older adult. Not all studies agree and age weights are the most controversial value choice built into the $\mathrm{YLL}_{i}$ (see Lopez et al.2006).

Lopez et al. (2006) used the following function to model the relative age weight

$$
X_{a d j}=C x e^{-\beta x}
$$

where $X_{\text {adj }}$ is the weighted age, $\mathrm{C}$ is the adjustment constant for age-weights $(\mathrm{C}=0.1658), \beta=$ age weighting constant (e.g. $\beta=0.04$ ), and $x=$ age (years)

Figure 3.1 shows a general pattern of the valuation of health according to age.

With the age weights and time discounting, the general formula for calculating $\mathrm{YLL}_{i j}$ for individual $j$ within age group $i$ is (Murray and Acharya, 
CHAPTER 3. STATISTICAL METHODS FOR CALCULATING EBD 22

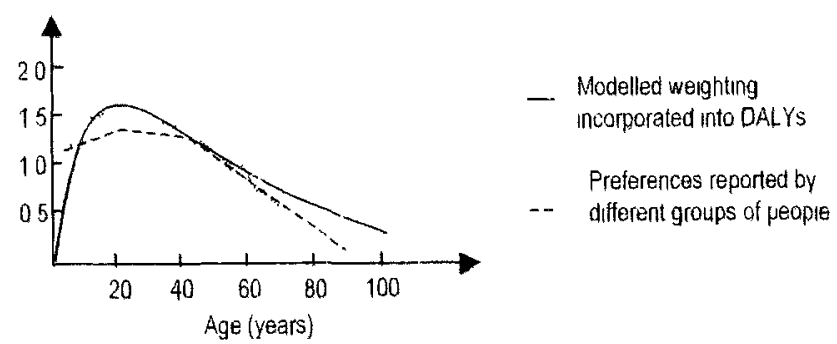

Figure 3.1: Reported preferences and modeling for relative value of a year of life lived.

1997)

$$
Y L L_{\imath \jmath}=\int_{a_{\imath}}^{\rho_{\imath}+a_{2}} C x e^{-\beta x} e^{-r\left(x-a_{\imath}\right)} d x
$$

Equation 3.33 can be solved using integration by parts. First rearrange the equation into the following form,

$$
Y L L_{\vartheta \jmath}=C e^{r a_{\imath}} \int_{a_{\imath}}^{e_{2}+a_{2}} x e^{-x(r+3)} d x
$$

Letting $u=x$ and $d v=e^{-x(\beta+r)}$ then $d u=d x$ and $v=\frac{-1}{(r+3)} e^{-x(\beta+r)}$ so that

$$
\begin{aligned}
Y L L_{\imath \jmath} & =C e^{r a_{\imath}}\left[\left.\frac{-x}{(r+\beta)} e^{-(r+\beta) x}\right|_{a_{\imath}} ^{e_{\imath}+a_{\imath}}+\frac{1}{(r+\beta)} \int_{a_{\imath}}^{e_{\imath}+a_{\imath}} e^{-(r+\beta) x} d x\right] \\
& =C e^{r a_{\imath}}\left[\frac{-\left(e_{\imath}+a_{\imath}\right)}{(r+\beta)} e^{-(r+\beta)\left(e_{\imath}+a_{\imath}\right)}+\frac{a_{\imath}}{(r+\beta)} e^{-(r+\beta) a_{\imath}}+\left.\frac{-1}{(r+\beta)^{2}} e^{-(r+3) x}\right|_{a_{\imath}} ^{e_{\imath}+a_{\imath}}\right] \\
& =\frac{C e^{r a_{\imath}}}{\alpha^{2}}\left\{e^{-\alpha \gamma_{\imath}}\left[-\alpha \gamma_{\imath}-1\right]-e^{-\alpha a_{\imath}}\left[-\alpha a_{\imath}-1\right]\right\}
\end{aligned}
$$


where $a_{\imath}$ is the age of death (years) in the age interval $\left(x_{\iota}, x_{\imath+1}\right), \alpha=(r+\beta)$. $\gamma_{\iota}=\left(e_{\imath}+a_{\imath}\right), \imath=1 \ldots . w$, and $j=1 \ldots . D_{\iota}$

Since the exact age of death is not known and is taken as the midpoint of the interval. YLL $\iota_{\jmath}$ will be the same for all $\jmath=1 \ldots D_{\imath}$ in the $\imath$-th age interval(i.e., $\left.Y L L_{\imath 1}=Y L L_{\imath 2}=\ldots=Y L L_{\imath D_{\imath}}\right)$. Thus. we drop the $\jmath$ subscript.

To calculate $\mathrm{YLL}_{\imath}$ for age interval $\left(x_{\imath} \cdot x_{\imath+1}\right)$. equation 3.33 should be multiplied by the number of deaths for that interval. $\mathrm{D}_{\imath}$.

$$
Y L L_{\imath}=D_{\imath} Y L L_{\imath \jmath}
$$

The years of life lost for the whole population. YLL can be then calculated by summing over all age intervals.

$$
Y L L=\sum_{\imath=1}^{w} \sum_{\jmath=1}^{D_{\imath}} Y L L_{\imath \jmath}=\sum_{\imath=\imath}^{w} D_{\imath} Y L L_{\imath \jmath}=\sum_{i=1}^{w} Y L L_{\imath}
$$

\subsection{Sensitivity Analysis for YLL}

In this section the YLL formula will be studied further by investigating the effect of age weighting and discounting. Also, an approximate closed form for the variance of YLL will be derived. 


\subsubsection{Age Weighting and Discounting}

Equation 3.32 is the weighting function that was used to assign different weights for different ages. We can determine the age that yields the maximum weight by taking the first derivative and finding the critical point.

$$
\frac{\partial}{\partial x} X_{w}=C e^{-\beta x}-C \beta x e^{-\beta x}=0
$$

Therefore, $\mathrm{X}_{w}$ is maximized when $x=\frac{1}{\beta}$.

To make sure that the area under the curve from age 0 to 100 stays the same, the constant $\mathrm{C}$ should vary depending on the value of 3 . Table 3.3 and Figure 3.2 show the impact of different choires of 3 on the age-weighting function.

Table 3.3: The impact of different, 3 values on the age-weighting function

\begin{tabular}{|ccccc|}
\hline 3 & $\mathrm{C}$ & Maximum age wcight & Age of maximum age wcight & Age range for which agc waght is $>1$ \\
\hline 002 & 00634 & 117 & 500 & $272-831$ \\
003 & 01051 & 129 & 333 & $149-630$ \\
004 & 01658 & 152 & 250 & $84-542$ \\
005 & 02487 & 183 & 200 & $52-507$ \\
006 & 03560 & 218 & 167 & $35-469$ \\
\hline
\end{tabular}

Most studies choose $\beta$ to be 0.04 (See Prüss-Üstün et al. 2003). For this value, the maximum weight of 1.52 is given to a person who is 25 years old. 


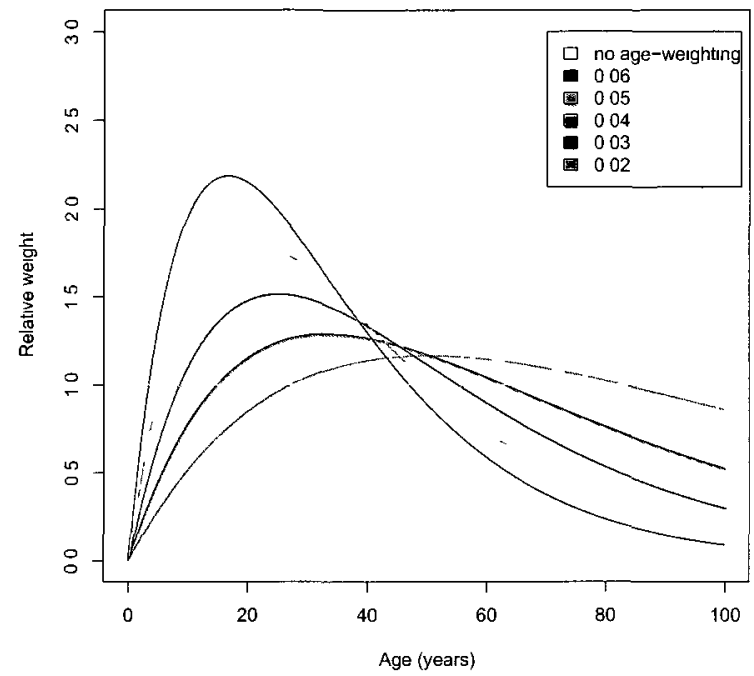

Figure 3.2: Age-weighting function.

The age range that is given weights higher than 1 is $(8.4,54.2)$. It appears that a value of 0.03 could be a better choice than 0.04 for the following reasons:

1. The age that is given the highest weight is 33.3 . This age is an age of a person who is most likely in the work force longer than a person who is 25 . This means, economically, more valuable.

2. The age range for which age weights are higher than 1 is (14.9.63). This age range is better than the one for $\beta=0.04$ since a person can start work at the age of 16 and retire around 62 . 
However, the value of 0.04 is the choice for most studies because it corresponds to the curve that best described the results obtained in previous investigations, Figure 3.1.

Figure 3.3 shows the difference in YLL for the 1991 Canadian male population using all different formulae. Here $\operatorname{YLL}$ is denoted $\operatorname{YLL}(r, \beta)$ so that all four formulae are used. For example. YLL $(3,4)$ means years of life lost when using both time discounting and age-weighting.

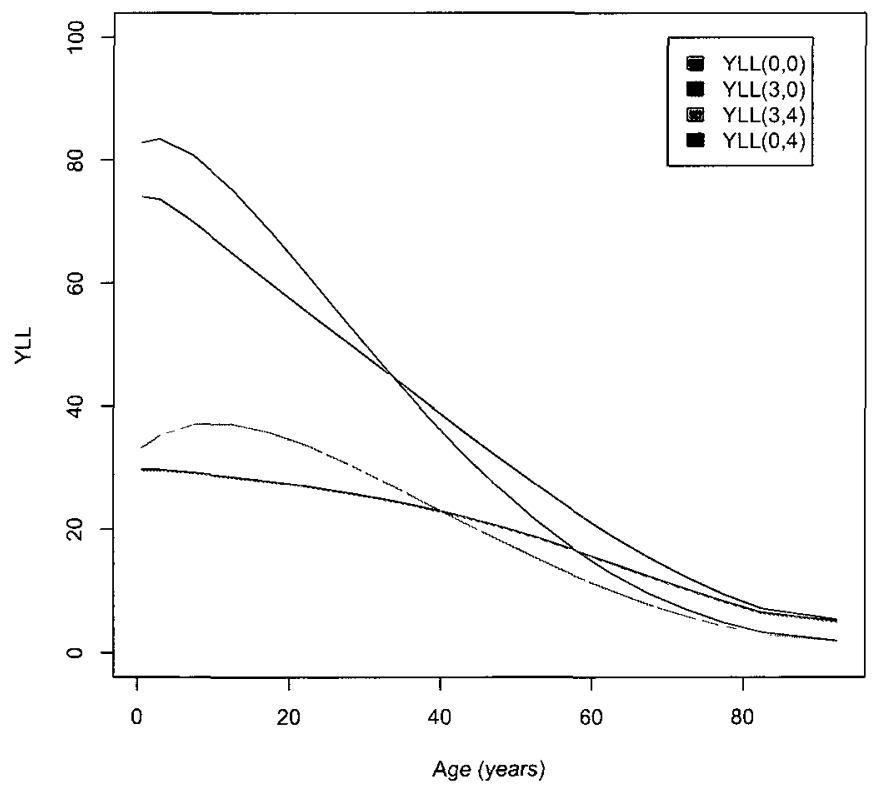

Figure 3.3: Effect of $r$ and $\beta$ on YLL. 
CHAPTER 3. STATISTICAL METHODS FOR CALCULATING EBD 27

We notice from Figure 3.3 that $Y L L(0,0)$ and $\operatorname{YLL}(0,4)$ are close in behavior except for the fact that the presence of $\beta$ changes the weights depending on age. the quantity YLL(3.0) which uses only time discounting reduces the value of YLL but it does not change the weights. This causes the curve to change very slightly between age 0 and 60 . $\operatorname{YLL}(3,4)$, on the other hand. does change the weight by putting more weights between ages 0 and just before 40 and less weights after that.

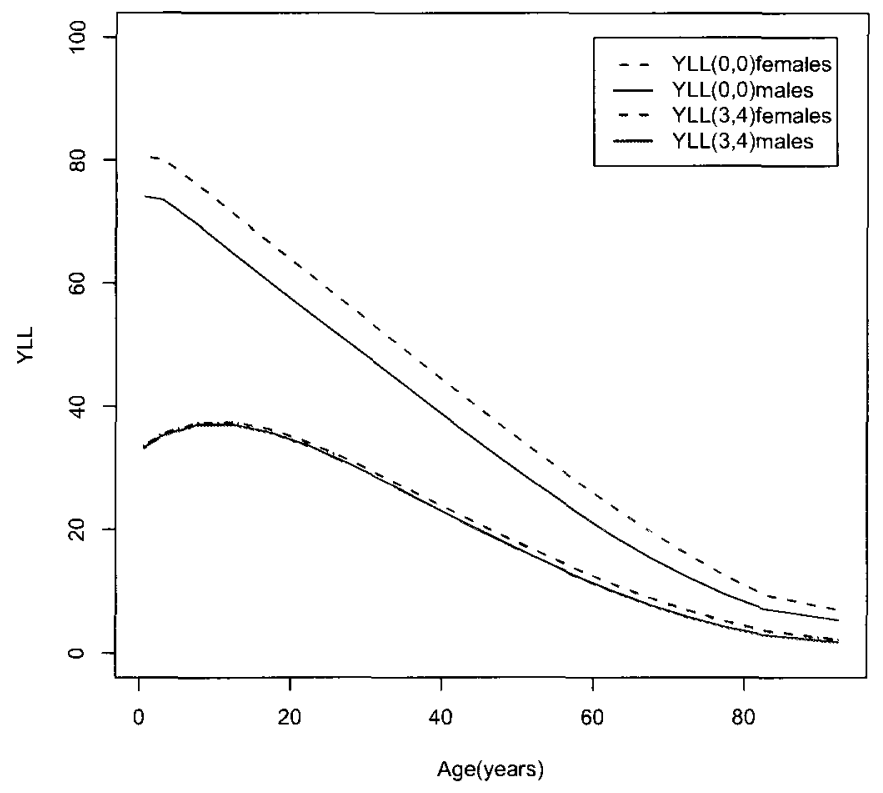

Figure 3.4: Effect of $r$ and $\beta$ on the difference between male-female YLL. 
Table 3.4: Effect of $r$ and $\beta$ on the difference between male-female YLL.

\begin{tabular}{|c|c|c|c|c|c|c|}
\hline Age & YLL(O O) maks & YLL $(00)$ fomalcs & YLL $(30)$ males & YLL $(30)$ temales & YLL $(34)$ male, & YLL $(34)$ temales \\
\hline 05 & $74331 \$ 30$ & 80851220 & $299^{7} 48891$ & 30385645 & 33189850 & 33553988 \\
\hline 30 & 73859639 & 80332116 & 29697753 & 30339381 & 35224448 & 35571803 \\
\hline 75 & $6997+162$ & 76419334 & 29247919 & 29966482 & 37025624 & 37408253 \\
\hline 125 & 65039287 & 71481177 & 28596450 & 29428861 & 37090493 & 37532948 \\
\hline 175 & 60122121 & 66538938 & 27843520 & 288048.38 & 35779036 & 36289004 \\
\hline 225 & 55397830 & 61660616 & 37007619 & 28091143 & 33587089 & 341586.37 \\
\hline 275 & 50736375 & 56770243 & 26058167 & 27262775 & 30852925 & 31484251 \\
\hline 325 & 46044077 & 51896920 & 24958463 & 26307105 & 27813857 & 28516291 \\
\hline 375 & 41341341 & 47031650 & 23689510 & 25202947 & 24644037 & 25427461 \\
\hline 425 & 36659788 & 42214128 & 22235340 & 23938743 & 21464671 & 22310195 \\
\hline 475 & 32030521 & 37469400 & 20581918 & 22501645 & 18357779 & 19335826 \\
\hline 525 & $27>55070$ & 32826532 & 18719877 & 20882819 & 15394848 & 16468069 \\
\hline 575 & 23266948 & 28321258 & $1674^{-491}$ & 19081007 & 12618600 & 13772886 \\
\hline 625 & 19275392 & 24018456 & 14637585 & 17117239 & 10083773 & 11281015 \\
\hline 675 & 15661055 & 19932862 & 12496417 & 15002720 & 7836071 & 9007111 \\
\hline 725 & 12452650 & 16138485 & 10391124 & 12792735 & 5901137 & 6976061 \\
\hline 775 & 962781.3 & 12655752 & 8362125 & 10530488 & 4278329 & 5198548 \\
\hline 825 & 7327100 & 9649079 & 6577704 & 8378050 & 3009329 & 3723070 \\
\hline 925 & 5542343 & 7185281 & 5106090 & 6463628 & 1790644 & 2217282 \\
\hline
\end{tabular}

Figure 3.4 is a comparison between the $\operatorname{YLL}(0,0)$ and $\mathrm{YLL}(3.4)$ for 1991 the male and female Canadian populations. We notice that besides the effects mentioned before. incorporating time discounting and age-weights reduces the difference between YLL for males and females.

Table 3.4 contains the YLL estimates for both male and female populations. The first two columns are estimates when using neither time discounting nor age-weights which are equivalent to life expectancy estimates. 
CHAPTER 3. STATISTICAL METHODS FOR CALCULATING EBD 29

\subsubsection{Variance of $Y L L_{2}$}

From equation 3.35 we know that $Y L L_{\imath}=D_{\imath} Y L L_{\imath}$. Where $D_{\imath}$ and $Y L L_{\imath}$ are two dependent random variables. Bohrnstedt and Glodberger (1969)derived the variance of the multiplication of two dependent random variables as follows

$$
\begin{aligned}
\operatorname{Var}\left(Y L L_{\imath}\right) & =\operatorname{Var}\left(D_{\imath} Y L L_{\imath \jmath}\right) \\
& =E\left[D_{\imath} Y L L-E\left(D_{\imath} Y L L_{\imath \jmath}\right)\right]^{2}
\end{aligned}
$$

For simplicity, let $D_{\imath}=x, Y L L_{\imath \jmath}=y, \Delta x=x-E(x)$, and $\Delta y=y-E(y)$, then

$$
\begin{aligned}
& \qquad \begin{aligned}
x y & =[\Delta x+E(x)][\Delta y+E(y)] \\
& =(\Delta x)(\Delta y)+(\Delta x) E(y)+(\Delta y) E(x)+E(x) E(y)
\end{aligned} \\
& E(x y)=E[(\Delta x)(\Delta y)]+E(x) E(y) \\
& \text { and } \\
& x y-E(x y)=(\Delta x)(\Delta y)+(\Delta x) E(y)+(\Delta y) E(x)-E[(\Delta x)(\Delta y)]
\end{aligned}
$$


Square both sides and take expectations to get the variance

$$
\begin{aligned}
\operatorname{Var}(x y)= & E^{2}(x) \operatorname{Var}(y)+E^{2}(y) \operatorname{Var}(x)+E\left[(\Delta x)^{2}(\Delta y)^{2}\right] \\
& +2 E(x) E\left[(\Delta x)(\Delta y)^{2}\right]+2 E(y) E\left[(\Delta x)^{2}(\Delta y)\right] \\
& +2 E(x) E(y) E[(\Delta x)(\Delta y)]-E^{2}[(\Delta x)(\Delta y)]
\end{aligned}
$$

This is a rather complicated equation and an approximate one would be more practical. Since the variance of the number of deaths, $D_{i}$, is much larger than the variance of the life expectancy. $\hat{e}_{2}$. we can consider the number of deaths, $D_{i}$, as the only source of variation. Under this assumption, the variance of $Y L L_{i}$ becomes,

$$
\operatorname{Var}\left(Y L L_{i}\right)=D_{i}\left(1-q_{i}\right) Y L L_{i j}^{2}
$$

In chapter 4 we will test equation 3.38 by performing a simulation study.

\subsection{Population Attributable Fraction (PAF)}

The population attributable fraction is defined as "the proportion of disease cases over a specified time that would be prevented following elimination of the exposure of interest, assuming the exposure is causal" (see Rockhill et al. 1998). There are different formulae available for calculating PAF (see 
CHAPTER 3. STATISTICAL METHODS FOR CALCULATING EBD 31

Rockhill et al. 1998). For this study, however, two formulae are relevant; single category exposure for level of exposure and multi-level of exposure formulae. The following formula is for calculating PAF when there is one level of exposure and one relative risk in the population of interest.

$$
P A F=\frac{p_{e}(R R-1)}{R R}
$$

where $p_{e}$ is the proportion of population exposed to the risk factor of interest and $\mathrm{RR}$ is the relative risk

In the case of multiple levels of exposure exposure and different relative risks, PAF can be calculated as follows.

$$
P A F=\sum_{\imath=1}^{n} p_{e_{\imath}} \frac{R R_{\imath}-1}{R R_{\iota}}
$$

where $p_{e_{2}}$ is the proportion of population exposed to the risk factor of interest in the $i$-th exposure category and $R R_{\imath}$ is the relative risk from exposure in the $i$-th category.

Estimating PAF requires estimating the relative risk for the risk factor understudy. In this study we will adopt the World health Organization (WHO) approach for calculating relative risks. The following table contains the different WHO recommended expressions used to estimate the relative risks for 
CHAPTER 3. STATISTICAL METHODS FOR CALCULATING EBD 32

the diseases that will be studied(Prüss-Üstün et al. 2004; Pope et al. 2002).

Table 3.5: WHO recommended models for estimating relative risks

\begin{tabular}{|cccc|}
\hline Outcono & Relative risk function & $\begin{array}{c}\text { Suggested } \Gamma \text { coefticient } \\
(95 \% \mathrm{CI})\end{array}$ & Subgroup \\
\hline All-cause mortality & $R R=e^{\left[\Gamma\left(X-X_{0}\right)\right.}$ & 0.004 & All ages \\
Cardiopulmonary mortality & $R R=\left[\frac{(X+1)}{\left(X_{0}+1\right)}\right]^{1}$ & $(0.001-0.0077)$ & \\
& & 0.15515 & Age $>30$ years \\
Lung cancer mortality & $R R=\left[\frac{(X+1)}{\left(X_{0}+1\right)}\right]^{T}$ & $0.0562 .0 .2541)$ & \\
& & 0.23218 & Age $>30$ ycars \\
& & $(0.08563,0.37873)$ & \\
\end{tabular}

where $\mathrm{X}$ is the current annual mean concentration of the risk factor of interest, $\mathrm{X}_{0}$ is target or threshold concentration of the risk factor of interest, and $\Gamma$ is the model coefficient.

\subsection{Sensitivity Analysis for Relative Risk Mod- els}

In this section we investigate further why the WHO recommended the functions given in Table 3.5 for estimating relative risks. In addition to these functions, Table 3.6 provides others that have been considered (Cohen et al. 2003). 
Table 3.6: Estimates of relative risk mortality, coefficients of concentrationresponse functions and study types

\begin{tabular}{|c|c|c|c|}
\hline Health outcome & Rclative risk function & $\begin{array}{l}\text { Relative mosk } \\
\text { per } 10 \mu \mathrm{g} / \mathrm{m}^{3}\end{array}$ & $\begin{array}{c}\text { Гi Concentration- } \\
\text { itsponse slope) } \\
\text { pei } \mu \mathrm{g} / \mathrm{m}^{3} \\
\text { (standard enor) }\end{array}$ \\
\hline C ${ }_{1}$ diopulmonary (Log-linedr) & $R R=\left[\frac{(x+1)}{\left(x_{0}+1\right)}\right]^{\Gamma}$ & 1093441 & $011605(0044790)$ \\
\hline Cardiopulmonary (Log lineaz aver age) & $R R=\left[\frac{(\mathrm{Y}+1)}{\left(X_{0}+L\right)}\right]^{\complement}$ & 1128240 & $0155148(0050460)$ \\
\hline Car diopulmonary (Lincas) & $R R=e^{\left[\Gamma\left(\mathrm{Y}-X_{0}\right)\right]}$ & 1059185 & $000575(0002160)$ \\
\hline Cardiopulmonary(Lineds avel dge & $R R=e^{\left[\Gamma\left(X-Y_{0}\right)\right]}$ & 1093441 & $0008933(0002907)$ \\
\hline Lung cancor(Log-lincas) & $R R=\left[\frac{(x+1)}{\left(x_{0}+1\right)}\right]^{1}$ & 1142360 & $017114(0071968)$ \\
\hline Luing cancol (Log-linear avorago) & $R R=\left[\frac{(X+1)}{\left(Y_{0}+1\right)}\right]^{\Gamma}$ & 1197896 & $0232179(0074770)$ \\
\hline Ling cancor(Lincar) & $R R=e^{\left[\Gamma\left(x-x_{0}\right)\right]}$ & 1082096 & $000789(0003417)$ \\
\hline Lung cancer(Linear aver age) & $R R=e^{\left[\Gamma\left(X-x_{0}\right)\right]}$ & 1135110 & $0012673(000426)$ \\
\hline
\end{tabular}

The difference between linear average and linear. and between log-linear average and log-linear is the value of $X$ used. For the former function in each pair, the average of the vearly averages is used as $X$, while for the latter function in each pair, it is the annual average that is employed. The graph in Figure 3.5 shows the four relative risk functions for cardiopulmonary calculated for different values of $X$.

It is easy to notice that the log-linear function is more stable for higher values of concentration. More specifically, it barely changes for a concentrations above $50 \mathrm{\mu g} / \mathrm{m}^{3}$. This is desirable since concentrations above $50 \mu \mathrm{g} / \mathrm{m}^{3}$ do not add to the overall impact of exposure to PM2.5. For this reason. the WHO recommends log-linear relative risks functions, and not linear ones. 
CHAPTER 3. STATISTICAL METHODS FOR CALCULATING EBD 34

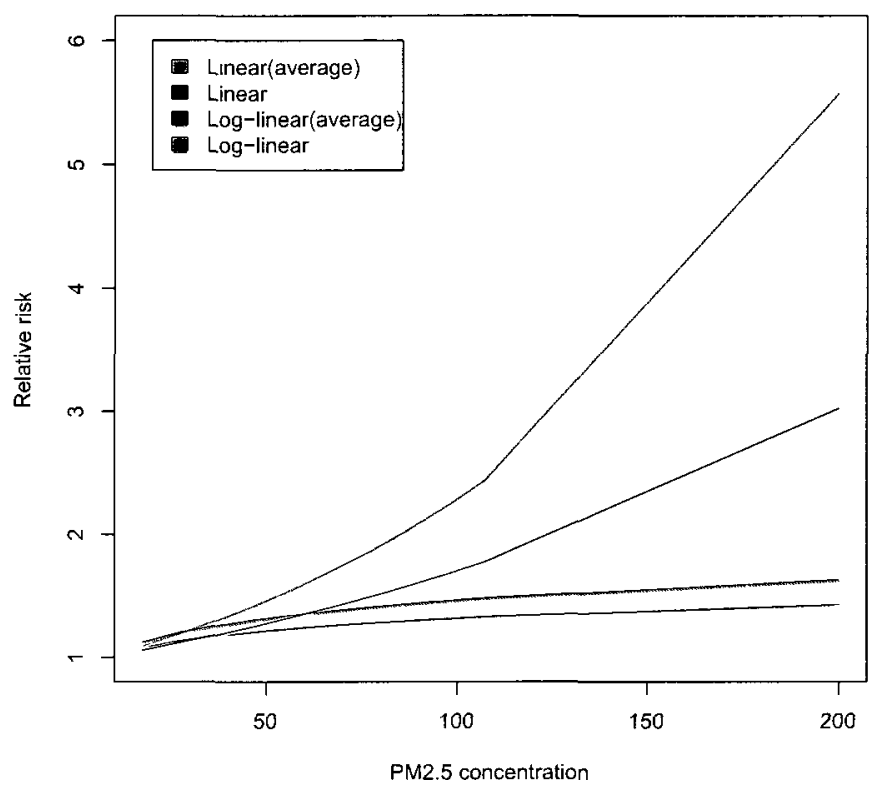

Figure 3.5: Comparison between different relative risk functions

In Chapter 5, an application study will make use of all the methodology covered in this chapter and more explanations will be given on how to use the different formulae. 


\subsection{Proof of the Effect of the Choice of the Radix on Life Expectancy Calculations}

Proof. In this proof we show that the choice of the value of the radix has no impact on life expectancy calculations.

$$
\begin{gathered}
\hat{e}_{\imath}=\frac{1}{l_{\imath}}\left[L_{\imath}+L_{\imath+1}+\ldots+L_{w}\right] \\
L_{\imath}=n_{\imath} l_{\imath+1}+a_{\imath} n_{\imath}\left(l_{\imath}+l_{\imath}+1\right) \\
d_{\imath}=l_{\imath} \hat{q}_{\imath} \\
l_{\imath+1}=l_{\iota}-d_{\imath} \\
\therefore l_{\imath+1}=l_{\imath}-l_{\imath} \hat{q}_{\imath}=l_{\imath}\left(1-\hat{q}_{\imath}=l_{\imath} \hat{p}_{\imath}\right. \\
L_{\imath}=n_{\imath} l_{\imath} \hat{p}_{\imath}+a_{\iota} n_{\imath}\left(l_{\iota}-l_{\imath}+l_{\imath} \hat{q}_{\imath}\right) \\
L_{\imath}=l_{\imath}\left(n_{\imath} \hat{p}_{\imath}+a_{\imath} n_{\imath} \hat{q}_{\imath}\right) \\
\therefore \hat{e}_{\iota}=\left(n_{\imath} \hat{p}_{\imath}+a_{\imath} n_{\imath} \hat{q}_{\imath}\right)+\ldots+\hat{p}_{\imath} \hat{p}_{\imath+1} \ldots \hat{p}_{w-1}\left(n_{w} \hat{p}_{w}+a_{w} n_{w} \hat{q}_{w}\right) \\
\therefore L_{\imath+1}=l_{\imath+1}\left(n_{\imath+1} \hat{p}_{\imath+1}+a_{\imath+1} n_{\imath+1} \hat{q}_{\imath+1}\right) \\
L_{\imath+1}=l_{\imath} \hat{p}_{\imath}\left(n_{\imath+1} \grave{p}_{\imath+1}+a_{\imath+1} n_{\imath+1} \hat{q}_{\imath+1}\right) \\
L_{\imath+1} \ldots \hat{p}_{w-1}\left(n_{w} \hat{p}_{w}+a_{w} n_{w} \hat{q}_{w}\right)
\end{gathered}
$$


CHAPTER 3. STATISTICAL METHODS FOR CALCULATING EBD 36

Since the result is not a function of $l_{0}$, then the choice of the radix does not effect the estimates of the life expectancy obtained. 


\section{Chapter 4}

\section{Simulation Study}

In this chapter. we present the results of a simulation study aimed at assessing the formula derived for the variance of the estimator of years of life lost. Three different approaches were followed, which we now describe in turn.

\subsection{Approach 1: Deaths from all Causes and Deaths from Lung Cancer are two Inde- pendent Binomial Random Variables}

Under this first approach, we conducted a simulation where it is assumed that the number of deaths from all causes and from lung cancer are two 
independent binomial random variables. Specifically. we created a simulated data set. call it $\jmath$-th, by generating an outcome, $x_{\imath \jmath}$, for the total number of deaths in age group $\imath$ for $i=1.2 \ldots \ldots I$ and an outcome, $y_{\imath \jmath}$, for the number of deaths in age group $\imath$ due to lung cancer. These outcomes were generated according to the binomial distributions

$$
\begin{gathered}
x_{\imath \jmath} \sim \operatorname{b\imath nom}\left(D_{\imath} . D_{\imath}\left(1-M_{\iota}\right)\right) \\
y_{\imath \jmath} \sim \operatorname{binom}\left(D_{C \imath}, D_{C \imath}\left(1-M_{C_{\imath}}\right)\right)
\end{gathered}
$$

where $D_{\iota}$ is the number of deaths from all causes in the $\imath$-th age group, $M_{\imath}$ is the death rate for all causes, $D_{C \imath}$ is the number of deaths from lung cancer, $M_{C \imath}$ is the death rate for lung cancer. The parameter values used for $D_{1}, D_{C \imath}, M_{\imath}$ and $M_{C \imath}$ are taken from Table 5.1 and Table 5.5.

For the $j$-th simulated data set, it is then possible to compute, for each age group, a point estimate for $Y L L_{\iota}, \widehat{Y L L_{\iota}}$, and an estimate of the variance of $\widehat{Y L L_{\imath}}$ and an approximate $95 \%$ confidence interval using formulas 3.34. 3.35, and 3.38. We then repeated for 1000 simulated data sets. thereby producing 1000 point estimates and confidence intervals for $Y L L_{l}$.

Table 4.1 contains the results summarized over the 1000 simulated data sets. Column 3 presents the $Y L L_{\imath}$ for the 1996 Canadian population. while 
Column 4 shows the means of the point estimates of $Y L L_{2}$ obtained through the simulation. Note that the means are close to the true values

Table 4.1: Results from 1000 samples when deaths from cancer and deaths from all causes are independent

\begin{tabular}{|c|c|c|c|c|c|c|c|c|}
\hline $\begin{array}{l}\text { Age } \\
\text { gioup }\end{array}$ & $\begin{array}{l}\text { Cancel } \\
\text { deaths }\end{array}$ & YLL & $\begin{array}{l}\text { Average } \\
\widehat{I L L}\end{array}$ & $\vec{V}(\mathrm{~L} L L)$ & $\begin{array}{l}\text { Avetage } \\
\widehat{V}(\widehat{Y L L})\end{array}$ & $S^{2}(\widehat{Y L L})$ & $\begin{array}{l}\text { twerage } \\
\text { halt width }\end{array}$ & $\begin{array}{c}\text { Coverag } \\
\%\end{array}$ \\
\hline$<1$ & 0 & $a$ & 0 & 0 & 0 & 0 & 0 & - \\
\hline $1<5$ & 0 & 0 & 0 & 0 & 0 & 0 & 0 & \\
\hline $5-<10$ & 0 & 0 & 0 & 0 & 0 & 0 & 0 & - \\
\hline $10-<15$ & 0 & 0 & 0 & 0 & 0 & 0 & 0 & \\
\hline $15<20$ & 1 & 3609764 & 3531426 & 1303039 & 1310859 & 1392084 & 7096334 & 625 \\
\hline $20-<25$ & 2 & 6788339 & 6723832 & 2304075 & 2282173 & $23.30 \quad 154$ & 936331 & 86 \\
\hline $25-<30$ & 4 & 12497268 & 12369099 & $390+535$ & 3864467 & 3794240 & 12184308 & 902 \\
\hline $30<35$ & 22 & 62140976 & $61965: 39$ & 17559848 & 17502586 & 16263326 & 25930278 & 947 \\
\hline $35<40$ & 88 & 221120686 & 222248588 & 55559848 & 55843141 & 53249362 & 16317061 & 956 \\
\hline $40<45$ & 231 & 508361188 & 509117286 & 111863783 & 112029893 & 109572946 & 65602899 & 057 \\
\hline $45-<50$ & 476 & 902873351 & 901345667 & 1712174.31 & 170927937 & 163290599 & 81033127 & 955 \\
\hline $50<5.5$ & 800 & 1284826945 & 1284336783 & 206245117 & 206167648 & 199.282492 & 88995148 & 948 \\
\hline $55<60$ & 1240 & 1653309018 & 1657413585 & 220227972 & 220775736 & 22931071 & 92094086 & 949 \\
\hline $60-<65$ & 1949 & 2108676311 & 2112079691 & 227769083 & 228136967 & 236596923 & 93616824 & 943 \\
\hline $65<70$ & 2746 & 2346824531 & 2347258931 & 200069569 & 200105933 & 196179542 & 87677075 & 955 \\
\hline $70<75$ & 3071 & 2010760458 & 2012389618 & 131233132 & 131339532 & 12412171 & 71031961 & 956 \\
\hline $75-<80$ & 2442 & 1180736021 & 1179798898 & 56884441 & 56840347 & 57314535 & $46^{*} 28779$ & 948 \\
\hline $80<85$ & 1611 & 551418218 & 551168869 & 18806637 & 18797783 & 18621084 & 26872581 & 949 \\
\hline $85+$ & 1025 & 207800412 & 20788985 & 4203610 & 4203835 & 4264597 & 12708049 & $95 \pm$ \\
\hline
\end{tabular}

Column 5 gives the estimated variance of $Y L L_{\imath}$ obtained by applying equation 3.38 to the 1996 Canadian population. while Column 6 represents the means of the estimates of the variance of $\widehat{Y L L}$ over the 1000 simulated data sets. In addition, Column 7 gives the sample variance of the estimates 
of $\widehat{Y L L}$, Column 5 very close agreement with columns 6 and 7 , suggesting that equation 3.38 appears to be appropriate for estimating the variance of $Y L L_{\iota}$. As additional verification for the appropriateness of equation 3.38, we computed approximate $95 \%$ large sample confidence intervals based on normal theory for $Y L L_{2}$, and determined the percentage of intervals over the 1000 simulated data sets that covered the true value of $Y L L_{2}$. These percentages, referred to as coverages, are presented in Column 9. Provided that $D_{C_{2}}$ is sufficiently large so that the normal approximation to binomial be valid, the coverage percentages are very close to $95 \%$ nominal rate.

\subsection{Approach 2: Death from all Causes and Deaths from Lung Cancer are two De- pendent Binomial random Variables}

For this approach, we repeated the simulation of Approach 1: however under the assumption that the number of deaths from all causes and from lung cancer are two dependent binomial random variables. Therefore, in this case. the $j$-th simulated data set $(j=1,2, \ldots, 1000)$ is obtained by generating 
an outcome for the number of lung cancer deaths, $y_{2 j}$, for the $i$-th age group as given in Approach 1, and an outcome for $z_{\imath \jmath}$ according to

$$
z_{\imath \jmath} \sim \operatorname{binom}\left(D_{\iota}-D_{C_{\imath}} \cdot\left[D_{\imath}-D_{C_{\imath}}\right]\left[1-\left(M_{\iota}-M_{C \imath}\right)\right]\right)
$$

So that $y_{\imath,}+z_{1 j}$ represents ontcomes for deaths from all causes.

Table 4.2: Results from 1000 samples when deaths from lung cancer and deaths from all causes are dependent

\begin{tabular}{|c|c|c|c|c|c|c|c|c|}
\hline $\begin{array}{l}\text { Agc } \\
\text { group }\end{array}$ & $\begin{array}{l}\text { Cancer } \\
\text { deatho }\end{array}$ & YLL & $\begin{array}{c}\text { Average } \\
\widehat{Y L L}\end{array}$ & $\widehat{V}(Y L L)$ & $\begin{array}{l}\text { Average } \\
\widehat{V}(\widehat{\Gamma L L})\end{array}$ & $S^{2}(\widehat{Y L L})$ & $\begin{array}{l}\text { Average } \\
\text { half width }\end{array}$ & $\begin{array}{c}\text { Coverage } \\
\%\end{array}$ \\
\hline$<1$ & 0 & 0 & 0 & 0 & 0 & 0 & 0 & - \\
\hline $1-<5$ & & 00 & 0 & 0 & 0 & 0 & 0 & - \\
\hline $5-<10$ & 0 & 0 & 0 & 0 & 0 & 0 & 0 & - \\
\hline $10-<15$ & 0 & 0 & 0 & 0 & 0 & 0 & 0 & - \\
\hline $15-<20$ & 1 & 3609764 & 3631418 & 1303039 & 1310853 & 1392993 & 7096319 & 625 \\
\hline $20-<25$ & 2 & 6788339 & 6723821 & 2304075 & 2282165 & 2330135 & 9363315 & 86 \\
\hline $25-<30$ & 4 & 12497268 & 1236915 & 3904535 & 3864499 & 3794428 & 12184358 & 902 \\
\hline $30-<35$ & 22 & 62140976 & 61965756 & 17559848 & 17502595 & 16264193 & 25930285 & 947 \\
\hline $35-<40$ & 88 & 221120686 & 22224858 & 35559818 & 5584.3137 & 53246044 & 46317059 & 956 \\
\hline $40-<45$ & 231 & 508361188 & 509118085 & 111863783 & 112030245 & 109580704 & 65603002 & 957 \\
\hline $45-<50$ & 476 & 902873351 & 901344299 & 171217431 & 170927419 & 163096709 & 81033004 & 956 \\
\hline $50-<55$ & 800 & 1284826945 & 1284328785 & 206245417 & 20616508 & 198880301 & 88904594 & 95 \\
\hline $55-<60$ & 1240 & 1653309018 & 1657389966 & 220227972 & 220769444 & 228910696 & 92092774 & 949 \\
\hline $60-<65$ & 1949 & 2108676311 & 2112069563 & 227769083 & 228134783 & 234909052 & 93616376 & 943 \\
\hline $65-<70$ & 2746 & $23468 \quad 24531$ & 2347289006 & 200069569 & 200111062 & 193795109 & 87678199 & 959 \\
\hline $70<75$ & $30 \pi 1$ & 2010760458 & 2012412621 & 131233132 & 131342537 & 122140324 & 71032774 & 959 \\
\hline $75-<80$ & 24.42 & 1180736021 & 1179814166 & 56884441 & 56841714 & 55527534 & 46730574 & 949 \\
\hline $80-<85$ & 1611 & 551418218 & 55119604 & 18806637 & 18799643 & 1805837 & 26873911 & 952 \\
\hline $85+$ & 1025 & 207890412 & 207891113 & 4203610 & 4203889 & $4168+16$ & 12708131 & 959 \\
\hline
\end{tabular}

Table 4.2 contains the results of the simulation study. From the results, it is evident that the variance expression still works really well. As a matter of 
fact, this simulation shows that the variation in the total number of deaths (deaths from all causes) does not have a significant effect on the variance of $Y L L_{2}$. The coverages here are still very close to the $95 \%$ nominal rate whenever $D_{C \imath}$ is large enough.

\subsection{Approach 3: Deaths from all Causes and}

\section{Deaths from Lung Cancer are a Bivariate}

\section{Normal Random Variable}

Finally,we repeated the simulation study using an approach where number of deaths from all causes and from lung cancer are bivariate normal.

Here we generated $x_{i j}$ and $y_{\imath \jmath}$ as defined in approach 1 according to a bivariate normal distribution as follows

$$
\left.\left(\begin{array}{c}
x_{\imath \jmath} \\
y_{i \jmath}
\end{array}\right) \sim \mathbf{N}_{\mathbf{2}}\left(\begin{array}{c}
D_{c \imath} \\
D_{\iota}
\end{array}\right),\left(\begin{array}{cc}
D_{C i}\left(1-M_{C \imath}\right) & -P_{\imath} M_{C_{\imath}} M_{\imath} \\
-P_{\imath} M_{C i} M_{\imath} & D_{\imath}\left(1-M_{\imath}\right)
\end{array}\right)\right)
$$

Where $P_{\imath}$ is mid-year population associated with the $i$-th age group for the 1996 Canadian population given in Table 5.1.

From the results in Table 4.3 we can see that the results of this simulation study still show that the variance expression is a good approximation. 
In addition, the coverage percentages are still very close to the $95 \%$ nominal rate. This confirms that the variance formula we developed is a valid approximation for the variance of $Y L L_{\text {r }}$

Table 4.3: Results from 1000 bivariate normal samples

\begin{tabular}{|c|c|c|c|c|c|c|c|c|}
\hline $\begin{array}{l}\text { Age } \\
\text { group } \\
\end{array}$ & $\begin{array}{l}\text { Cancer } \\
\text { deaths }\end{array}$ & YLL & $\begin{array}{c}\text { Average } \\
\widehat{\Gamma L L} \\
\end{array}$ & $\widehat{V}(1 L L)$ & $\begin{array}{l}\text { Avelnge } \\
\hat{V}(\widehat{Y L L})\end{array}$ & $S^{2}(\widehat{I L L})$ & $\begin{array}{l}\text { Average } \\
\text { halt wadth }\end{array}$ & $\begin{array}{c}\text { Coverage } \\
\%\end{array}$ \\
\hline$<1$ & 0 & 0 & 0 & 0 & 0 & 0 & 0 & - \\
\hline $1-<5$ & 0 & 0 & 0 & 0 & 0 & 0 & 0 & - \\
\hline $5-<10$ & 0 & 0 & 0 & 0 & 0 & 0 & 0 & - \\
\hline $10-<15$ & 0 & 0 & 0 & 0 & 0 & 0 & 0 & \\
\hline $15-<20$ & 1 & 3609764 & 4164381 & 1303039 & 1503241 & 865896 & 7599245 & 915 \\
\hline $20-<25$ & 2 & 6788339 & 742616 & 2304075 & 2520557 & 1991975 & 984021 & 88 \\
\hline $25-<30$ & 4 & 12497268 & 12672169 & 3904535 & 3959173 & 3289835 & 12332704 & 919 \\
\hline $30-<35$ & 22 & 62140976 & 61920412 & 1735984.8 & 174898 & 17042473 & 25920805 & 931 \\
\hline $35<<0$ & 88 & 221120686 & 22080414 & 55559848 & 55480286 & 54283135 & 16166337 & 945 \\
\hline $40-<45$ & 231 & 508361188 & 507680375 & 111863783 & 111713921 & 104949636 & 6551032 & 955 \\
\hline $45<50$ & 476 & 902873351 & 903184905 & 171217431 & 171276352 & 172908816 & 81115673 & 949 \\
\hline $50-<55$ & 800 & $12848 \quad 26945$ & 12839105 & 206245417 & 206098577 & 186630997 & 88980239 & 964 \\
\hline $55-<60$ & 1240 & 1653309018 & 1652016992 & 220227972 & 220055605 & 210819119 & 91943766 & 954 \\
\hline $60-<65$ & 1949 & $210867631 \mathrm{~L}$ & 2109359069 & 227769083 & 227841854 & 227181974 & 93556254 & 947 \\
\hline $65-<70$ & 2746 & 2346824531 & 2346549160 & 200069569 & 200045401 & 203562314 & 87663813 & 95 \\
\hline $70-<75$ & 3071 & 2010760458 & $20095 \pm 7015$ & 131233132 & 131151308 & 13417996 & 70981044 & 95 \\
\hline $7 \overline{0}-<80$ & 2442 & 1180736021 & 1181019831 & 56884441 & 56897319 & 5330852 & 46752191 & 963 \\
\hline $80-<85$ & 1611 & 551418218 & 551596365 & 18806637 & 18812259 & 18899914 & 26882926 & 946 \\
\hline $85+$ & 1025 & 207890412 & 208185595 & 1203610 & 4209391 & 4034432 & 12716444 & 953 \\
\hline
\end{tabular}




\section{Chapter 5}

\section{Application}

In this chapter the methodology discussed in Chapter 3 and verified by simulation in chapter 4 will be applied to the 1996 Canadian population. All calculations are carried out using R (see Appendix A).

\subsection{Life Expectancy In Canada}

Life expectancy was estimated using life table analysis. Two data sets were used; the 1996 population data provided by Statistics Canada and deaths by selected causes, also provided by Statistics Canada. Table 5.1 summarizes both data sets, with deaths accumulated over all causes. 
Table 5.1: 1996 population and deaths estimates for Canada.

\begin{tabular}{|ccccccc|}
\hline Age group & \multicolumn{3}{c}{ Nid-year population $P_{i}$} & \multicolumn{3}{c|}{ Deaths from all caluses $D_{i}$} \\
& Both & Nale & Fenale & Both & Male & Female \\
\hline$<1$ & 366690 & 187370 & 179320 & 2051 & 1155 & 896 \\
$1-<5$ & 1551135 & 795190 & 755045 & 461 & 257 & 204 \\
$5-<10$ & 1990015 & 1019290 & 970725 & 297 & 458 & 139 \\
$10-<15$ & 1993440 & 1023360 & 970080 & 330 & 206 & 133 \\
$15-<20$ & 1959120 & 1003355 & 955765 & 1049 & 730 & 319 \\
$20-<25$ & 1898050 & 951825 & 946225 & 1352 & 1034 & 318 \\
$25-<30$ & 2030680 & 1005285 & 1025395 & 1505 & 1112 & 393 \\
$30-<35$ & 2468235 & 1221685 & 1246550 & 2323 & 1641 & 682 \\
$35-<40$ & 2544035 & 1258020 & 1286015 & 3120 & 2104 & 1016 \\
$40-<45$ & 2317670 & 1144995 & 1172675 & 4106 & 2564 & 1542 \\
$45-<50$ & 2093855 & 1040830 & 1053025 & 5244 & 3210 & 2034 \\
$50-<55$ & 1616545 & 806685 & 809860 & 6673 & 4141 & 2532 \\
$55-<60$ & 1301705 & 643445 & 658260 & 8783 & 5412 & 3371 \\
$60-<65$ & 1187750 & 580870 & 606880 & 12915 & 8158 & 4757 \\
$65-<70$ & 1105945 & 523070 & 582875 & 19612 & 12237 & 7375 \\
$70-<75$ & 955990 & 420295 & 535695 & 26831 & 15935 & 10896 \\
$75-<80$ & 678250 & 276935 & 401315 & 30320 & 16416 & 13904 \\
$80-<85$ & 450585 & 167245 & 283340 & 33531 & 16344 & 17187 \\
$85+$ & 337075 & 100280 & 236795 & 52368 & 18590 & 33778 \\
\hline
\end{tabular}

We now analyze the previous summarized data for both genders combined and estimate life expectancy associated with each age group. The abridged results are given in Table 5.2. Note that the calculations for age groups $<1$ through $80-<85$ are carried out in same manner; as an illustration we demonstrate the procedure for age group $15-<20$.

Columns 1 through 4 in Table 5.2 obtained directly from data in Table 
4.1. Columns 5 through 13 are obtained as follows

$$
\begin{aligned}
& M_{5}=\frac{D_{5}}{P_{5}}=\frac{1049}{1959120} \cong 0.000535444 \\
& a_{5}=0.5 \\
& \hat{q}_{5}=\frac{n_{5} M_{5}}{1+\left(1-a_{5}\right) n_{5} M_{5}}=\frac{5 \times 0.000535444}{1+(1-0.5) \times 5 \times 0.000535444} \cong 0.0026736435 \\
& \hat{p}_{5}=1-\hat{q}_{5}=1-0.0026736435 \cong 0.9964448 \\
& l_{5}=l_{4}-d_{4}=99249-85=99164 \\
& d_{5}=l_{5} \hat{q}_{5}=99164 \times 0.00267364448 \cong 266 \\
& L_{5}=n_{5}\left(l_{5}-d_{5}\right)+a_{5} n_{5} d_{5}=5 \times(99164-266)+0.5 \times 5 \times 266=495155 \\
& T_{5}=L_{5}+L_{6}+\ldots+L_{19}=495155+493610+\ldots+239263=6331170 \\
& \hat{e}_{5}=\frac{T_{5}}{l_{5}}=\frac{6331170}{99164} \cong 63.845448
\end{aligned}
$$

Note that for the last age group, 85+; The life expectancy estimates are obtained differently. specifically, for this group $\hat{q}_{19}=1\left(\hat{p}_{19}=0\right)$ since everyone is assumed to die. the life expectancy estimate is then calculated as follows.

$$
\begin{aligned}
& l_{19}=l_{18}-d_{18}=54165-16993=37172=d_{19} \\
& L_{19}=\frac{l_{19}}{M_{19}}=\frac{37172}{0.1553600831} \cong 239263=T_{19} \\
& \hat{e}_{19}=\frac{T_{19}}{l_{19}}=\frac{239263}{37172} \cong 6.436646
\end{aligned}
$$

We next demonstrate the calculation of the variance of the life expectancy estimate for each age group. The procedure is the same for all age groups 
Table 5.2: Abridged life table for the 1996 Canadian population

\begin{tabular}{|c|c|c|c|c|c|c|c|c|c|c|c|c|}
\hline$\left(\nu_{1}, x_{2}+1\right)$ & $\mathrm{n}_{2}$ & $\mathrm{P}_{\mathrm{r}}$ & $\mathrm{D}_{\iota}$ & $\mathrm{M}_{2}$ & $a_{2}$ & $\hat{q}_{e}$ & $\hat{p}_{z}$ & $l_{\iota}$ & $d$ & $\mathrm{~L}_{\iota}$ & $T_{2}$ & $\hat{e}_{2}$ \\
\hline$<1$ & 1 & 366690 & $205]$ & 6) 0055932804 & 0.1 & 0.0055652651 & 0.9944347 & 100000 & 557 & 99498 & $78: 20618$ & 78206180 \\
\hline $1-<5$ & 4 & 1551135 & 461 & 0 (1002972017 & 0.4 & 0.0011879596 & 0.9988120 & 99443 & 119 & 397486 & $772112 n$ & 77.643675 \\
\hline $5-<10$ & 5 & 1990015 & 297 & 0.0001492451 & 0.5 & 0.0007459472 & 0.9992541 & 99324 & 75 & 496432 & 7323634 & 73734787 \\
\hline $10-<15$ & 5 & 1998440 & 339 & 6) 0001700578 & 05 & 00008499276 & 09991501 & 99249 & 85 & 496032 & 6827202 & 687886223 \\
\hline $15-<20$ & 5 & 1959120 & 1049 & 00005354445 & 0.5 & $0.0026736+35$ & 0.9973264 & 99164 & 266 & 495155 & 6331170 & $63.8454+8$ \\
\hline $20-<25$ & 5 & 1898050 & 1352 & $00007 \perp 23100$ & 0.5 & 0.0035552190 & 0.9964448 & 98898 & 352 & 493610 & 5836015 & 59010445 \\
\hline $25-<30$ & 5 & 2030680 & 1505 & $0.0007+11310$ & 0.5 & 00036988020 & 0.9963012 & 98546 & 365 & 491817 & 5342405 & 54212297 \\
\hline $30-<35$ & 5 & 2468235 & 2323 & 0.0009411584 & 0.5 & 0.0046947455 & 09953053 & 98181 & 461 & 489752 & 4850588 & 49404549 \\
\hline $35-<40$ & 5 & 2544035 & 3120 & 0.0012263982 & 0.5 & 0.0061132479 & 0.9938868 & 97720 & 598 & 487105 & 4360836 & 44625829 \\
\hline $40-<45$ & 5 & 2317670 & 4106 & 00017716068 & 05 & 0.0088189748 & 09911810 & $y 7122$ & 857 & 483467 & 3873731 & 39885206 \\
\hline $45-<50$ & 5 & 2093855 & 5244 & $000250+4714$ & 0.5 & 0.0124444402 & 0.9875556 & 96265 & 1198 & 478330 & 3390264 & 35.218034 \\
\hline $50-<55$ & 5 & 1616545 & 6673 & 0.0041279395 & 0.5 & 0.0204288747 & 0.9795711 & 95067 & 1943 & 470477 & 2911934 & 30.630334 \\
\hline $55-<60$ & 5 & 130170.5 & 8783 & 0.0067473045 & 05 & 0.0331768861 & 09668231 & 43124 & 3090 & 457895 & 2441457 & 26.217260 \\
\hline $60-<65$ & 5 & 1187750 & 12915 & 0.0108735003 & 0.5 & 00529287010 & 0.9470713 & 90034 & 4766 & 438255 & 1983562 & 22.031255 \\
\hline $65-<70$ & 5 & 1105945 & 19612 & 0.0177332507 & 0.5 & 0.0849022706 & 0.9150977 & 85268 & 7240 & 408240 & 1545307 & 18.122042 \\
\hline $70-<75$ & 5 & 955990 & 26831 & 0.0280661932 & 0.5 & 0.1311301551 & 0.8688648 & 78028 & 10232 & 364560 & 1137067 & 14.572551 \\
\hline $75-<80$ & 5 & 678250 & 30320 & 00447032805 & 0.5 & 0.2010476759 & 0.7989523 & 67796 & 13631 & 304902 & 772507 & 11394581 \\
\hline $80-<85$ & 5 & 450585 & 33531 & 0.0744165918 & 0.5 & 0.3137183356 & 0.6862817 & 54165 & 36993 & 228342 & 467605 & 8.632973 \\
\hline $85+$ & 5 & 337075 & 52368 & 0.1553660831 & 0.5 & 1.0000000000 & 0.0000000 & 37172 & 37172 & 2.39263 & 239203 & 6.436646 \\
\hline
\end{tabular}


except for the 85+ age group where the life expectancy does not vary. As an example, we now show the calculations for age group $15-<20$.

$$
\begin{aligned}
& \operatorname{Var}\left(\hat{p}_{5}\right)=\frac{\hat{q}_{5}^{2}\left(1-\hat{p}_{5}\right)}{D_{5}}=\frac{0.0026736435^{2} \times 0.9973264}{1049}=6.796241 \times 10^{-9} \\
& \begin{aligned}
l_{5}^{2}\left[\left(1-a_{5}\right) n_{5}+\hat{e}_{6}\right]^{2} \operatorname{Var}\left(\hat{p}_{5}\right) & =99164^{2} \times[0.5 \times 5+59.010445]^{2} \times 6.796241 \times 10^{-9} \\
& =252856.78
\end{aligned}
\end{aligned}
$$

If we let $l_{\imath}^{2}\left[\left(1-a_{\iota}\right) n_{\imath}+\hat{e}_{\ell+1}\right]^{2} \operatorname{Var}\left(\hat{p}_{\imath}\right)=\eta_{l}$, then

$$
\begin{aligned}
& \eta_{5}+\eta_{6}+\ldots+\eta_{19}=252856.78+293047.99+\ldots+0=5728198.2 \\
& \operatorname{Var}\left(\hat{e}_{5}\right)=\frac{\eta_{5}+\eta_{6}+\ldots+\eta_{19}}{l_{5}^{2}}=\frac{5728198.2}{l_{5}^{2}}=\frac{5728198.2}{99164^{2}} \cong 6.082326 \times 10^{-4}
\end{aligned}
$$

Table 5.3 contains the variance estimates for all age groups. As was the case before, the variance estimates are very small since the estimates for the probability of dying, $\hat{q}_{t}$ are small.

The analysis conducted above by pooling over both genders was repeated separately for males and females. Table 5.4 contains estimates for the life expectancy for the 1996 Canadian population for males, females and both combined. From this table. one can observe that the life expectancy for a female is about six years longer than that of a male in the 1996 Canadian population. 
Table 5.3: Life expectancy variance estimates for for the 1996 Canadian population.

\begin{tabular}{|c|c|c|c|c|}
\hline Age interval & $\operatorname{Var}\left(\hat{p}_{2}\right)$ & $l_{7}^{2}\left[\left(1-a_{1}\right) n_{2}+\hat{e}_{1+1}\right]^{2} \operatorname{Var}\left(\hat{p}_{2}\right)$ & $\sum_{k \geq 1}, l_{k}^{2}\left[\left(1-a_{k}\right) n,+\left.\hat{e}_{k+1}\right|^{2} \operatorname{Var}\left(\hat{p}_{k}\right)\right.$ & $\operatorname{Var}\left(\hat{e}_{t}\right)$ \\
\hline$<1$ & $1.501697 \times 10^{-8}$ & 926413.31 & 7268910.9 & $7268911 \times 10^{-4}$ \\
\hline $1-<5$ & $3.057639 \times 10^{-9}$ & 175267.29 & 63424975 & $6.413748 \times 10^{-4}$ \\
\hline $5-<10$ & 1. $872129 \times-9$ & 93860.85 & 6167230.3 & $6.251464 \times 10^{-1}$ \\
\hline $10-<15$ & $2.129094 \times-9$ & $923+4.40$ & 6073369.4 & $6.165629 \times 10^{-4}$ \\
\hline $15-<20$ & $6.796241 \times-9$ & 25285678 & 5981055.0 & $6.082326 \times 10^{-1}$ \\
\hline $20-<25$ & $9315566 \times-9$ & 293047.99 & 5728198.2 & $5.856566 \times 10^{-4}$ \\
\hline $25-<30$ & $9.056832 \times-9$ & 23695461 & 54351502 & $5.596720 \times 10^{-4}$ \\
\hline $30-<35$ & $9443461 \times-9$ & 202164.13 & $519 \$ 1956$ & $5.392594 \times 10^{-1}$ \\
\hline $35-<40$ & $1.190492 \times-8$ & 20.1231 .08 & 4996031.5 & $5.231886 \times 10^{-4}$ \\
\hline $40-<45$ & $1877458 \times-8$ & 25194373 & 4791800.4 & $5.079997 \times 10^{-4}$ \\
\hline $45-<50$ & $2916417 \times-8$ & 296645.70 & 4539856.7 & $4.898976 \times 10^{-1}$ \\
\hline $50-<55$ & $6.126377 \times-8$ & 456614.40 & $42+32110$ & $4.694994 \times 10^{-4}$ \\
\hline $55-<60$ & $1.211645 \times-7$ & 632321.81 & 37865966 & $4366423 \times 10^{-4}$ \\
\hline $60-<65$ & $205-1332 \times-7$ & 70824751 & 31542748 & $3.891226 \times 10^{-4}$ \\
\hline $65-<70$ & $3363444 \times-7$ & 712776.20 & 24160273 & $3364257 \times 10^{-4}$ \\
\hline $70-<75$ & $5.568305 \times-7$ & 654507.86 & 1733251.1 & $2.846823 \times 10^{-1}$ \\
\hline $75-<80$ & $1065099 \times-6$ & 606764.64 & 10787432 & $2.346983 \times 10^{-4}$ \\
\hline $80-<85$ & $2014354 \times-6$ & 47197858 & 471978.6 & $1608736 \times 10^{-4}$ \\
\hline $85+$ & 0 & 0 & 0 & 0 \\
\hline
\end{tabular}

\subsection{Burden of Disease for the 1996 Canadian}

\section{Population}

In this section. we use the data from the 1996 Canadian population to illustrate the estimation of burden of disease $(\mathrm{B} \circ \mathrm{D})$. Specifically, we consider the 
Table 5.4: Life expectancy estimates by sex for the 1996 Canadian population.

\begin{tabular}{|cccc|}
\hline & \multicolumn{3}{c|}{ Lite Expectancv Estumate } \\
Age ninterval & Male & Female & Both \\
\hline$<1$ & 75192240 & 81147230 & 78206180 \\
$1-<5$ & 74656159 & 80552873 & 77643675 \\
$5-<10$ & 70751111 & 76638670 & 73734787 \\
$10-<15$ & 65804104 & 71692415 & 68788623 \\
$15-<20$ & 60867990 & 66710522 & 63845448 \\
$20-<25$ & 56080845 & 61848144 & 59010445 \\
$25-<30$ & 51372806 & 56948342 & 54212297 \\
$30-<35$ & 46644091 & 52053125 & 49404549 \\
$35-<40$ & 41941756 & 47189011 & 44625829 \\
$40-<45$ & 37273100 & 42366275 & 39885206 \\
$45-<50$ & 32664672 & 37629388 & 35218034 \\
$50-<55$ & 28133630 & 32970526 & 30630334 \\
$55-<60$ & 23800307 & 28450713 & 26217269 \\
$60-<65$ & 19715402 & 24123920 & 22031255 \\
$65<70$ & 15968137 & 19988566 & 18122942 \\
$70-<75$ & 12641830 & 16131144 & 14572551 \\
$75-<80$ & 97658667 & 12591702 & 11394581 \\
$80-<85$ & 7294264 & 9505705 & 8632973 \\
$85+$ & 5394273 & 7010312 & 6436646 \\
\hline
\end{tabular}

estimation of BoD for all causes of death. lung cancer(ICD-9:162) and cardiopulmonary disease (ICD-9:400-440,460-519) mortality. The years of life lost (YLL) will be the health indicator used. The mortality data for lung cancer and cardiopulmonary disease was obtained from Statistics Canada and is given in Table 5.5 . 
Table 5.5: 1996 deaths from lung cancer and cardiopulmonary disease.

\begin{tabular}{|c|c|c|c|c|c|c|}
\hline \multirow[t]{2}{*}{ Ago group } & \multicolumn{3}{|c|}{ Deaths from lunger cancer } & \multicolumn{3}{|c|}{ Deaths from cardiopulmonary } \\
\hline & Both & Male & Female & Both & Male & Fomale \\
\hline$<1$ & 0 & 0 & 0 & 68 & 30 & 38 \\
\hline $1-<5$ & 0 & 0 & 0 & 50 & 29 & 21 \\
\hline $5-<10$ & 0 & 0 & 0 & 14 & 10 & 4 \\
\hline $10-<15$ & 0 & a & 0 & 22 & 10 & 12 \\
\hline $15-<20$ & 1 & 1 & 0 & 45 & 25 & 20 \\
\hline $20-<25$ & 2 & 1 & 1 & 49 & 36 & 13 \\
\hline $25-<30$ & 4 & 2 & 2 & 110 & 65 & 45 \\
\hline $30-<35$ & 22 & 11 & 11 & 201 & 119 & 82 \\
\hline $35-<40$ & 88 & 36 & 32 & 380 & 250 & 130 \\
\hline $40-<45$ & 231 & 94 & 137 & 684 & 477 & 207 \\
\hline $45-<50$ & 476 & 229 & 247 & 1147 & 867 & 280 \\
\hline $50-<55$ & 800 & 441 & 359 & 1787 & 1310 & 477 \\
\hline $55-<60$ & 1240 & 742 & 498 & 2696 & 1915 & 781 \\
\hline $60-<65$ & 1949 & 1259 & 690 & 4369 & 3071 & 1298 \\
\hline $65-<70$ & 2746 & 1799 & 947 & 7385 & 4907 & 2478 \\
\hline $70-<75$ & 3071 & 2022 & 1049 & 11589 & 7224 & 4365 \\
\hline $75-<80$ & 2442 & 1592 & 850 & 14747 & 8135 & 6612 \\
\hline $80-<85$ & 1611 & 1054 & 557 & 18163 & 8903 & 9260 \\
\hline $85+$ & 1025 & 632 & 393 & 21580 & 7959 & 13621 \\
\hline
\end{tabular}

Table 5.6 table presents, for both genders combined, the estimates of burden of disease for all causes using year of life lost, YLL. Equations 3.34 and 3.35 were used to estimate YLL and equation 3.38 to obtain estimates for the standard deviation. In terms of YLL, the point estimate for the total burden of disease due to premature mortality for all causes of death is 1648104.6 years. The $95 \%$ confidence interval is $(1607638.6,1688570.6)$. Similar YLL calculations for BoD across all causes of death were performed 
by gender. From these, we can also observe that the burden of disease for the male population is about 1.3 of that for the female population.

Table 5.6: Years of life lost from all causes by sex and by age group.

\begin{tabular}{|c|c|c|c|c|c|c|}
\hline Age group & Both & $\mathrm{SD}$ & Male & $\mathrm{SD}$ & Fomale & SD \\
\hline$<1$ & 6854032 & 15093930 & 38399139 & 11263874 & 30076486 & 10022714 \\
\hline $1-<5$ & 1633023 & 7608808 & 9065539 & 5654014 & 7258629 & $508 \quad 1371$ \\
\hline $5<10$ & 1106800 & 6421827 & 5858606 & 4660496 & 5201231 & 4411310 \\
\hline $10-<15$ & 1266766 & 6879545 & $76 \overline{33} 309$ & 53.31776 & 4993465 & 4329587 \\
\hline $15-<20$ & 3786641 & 11688265 & 26160346 & 9682185 & 1.1580389 & 6482691 \\
\hline $20-<25$ & 4588015 & 12475757 & 34804318 & 10817748 & 10866939 & 6092852 \\
\hline $25<30$ & 4702094 & 12116079 & 34.391516 & 10308524 & 12379399 & 6243384 \\
\hline $30-<35$ & 6561517 & 13607101 & 45779366 & 11293371 & 19458804 & 7149123 \\
\hline $35-<40$ & 7839726 & 14026751 & 52051564 & 11338287 & 25852800 & 8107540 \\
\hline $40<45$ & 9036053 & 14089133 & 55320051 & 10912814 & 34479794 & 8774790 \\
\hline $45-<50$ & 9946764 & 13718479 & 59347284 & 10458697 & 39378617 & 8722985 \\
\hline $50<55$ & 10717038 & 13092301 & 64306036 & 9967392 & 41760347 & 8286140 \\
\hline $55-<60$ & 11710457 & 12453237 & 69040598 & 9345263 & $4651381^{7}$ & 7990753 \\
\hline $60<65$ & 13973028 & 12228389 & 83286767 & 9156148 & 53773407 & 7765907 \\
\hline $65-<70$ & 16760968 & 11861862 & 97044234 & 8669455 & 66526440 & 7697474 \\
\hline $70-<75$ & 17567623 & 10573357 & 95006414 & 7382167 & 75990252 & 7205465 \\
\hline $75-<80$ & 14659840 & 8228718 & 70981739 & 5373333 & 72032864 & 6002112 \\
\hline $80-<85$ & 11476758 & 6029812 & 49007791 & 3641292 & 63278694 & 4678097 \\
\hline $85+$ & 10620618 & 4265330 & 32534219 & 2153664 & 73127236 & 3699305 \\
\hline Total & 1648104603 & 20645901 & 930050840 & 15741050 & 694829611 & 12904360 \\
\hline
\end{tabular}

Relative to the results in Table 5.6 for all causes of death, Table 5.7 contains analogous estimates for BoD due to premature deaths caused by lung cancer. The point estimate for both genders combined is about 130617.3 years and the $95 \%$ confidence interval is $(122946.4,138288.2)$ years. The burden of disease for the male population is about 1.4 of that for the female 
population.

Table 5.7: Years of life lost from lung cancer by sex and by age group

\begin{tabular}{|c|c|c|c|c|c|c|}
\hline Age group & Both & $S D$ & Mazle & $S D$ & Fomale & $\mathrm{SD}$ \\
\hline $0<1$ & 0 & 0 & 0 & 0 & 0 & 0 \\
\hline $1-<5$ & 0 & 0 & 0 & 0 & 0 & 0 \\
\hline $5-<10$ & 0 & 0 & 0 & 0 & 0 & 0 \\
\hline $10<15$ & 0 & 0 & 0 & 0 & 0 & 0 \\
\hline $15-<20$ & 3609762 & 3609761 & 3584842 & 3584840 & 0 & 0 \\
\hline $20-<25$ & 6788335 & 4800075 & 3365988 & 3365986 & 3417276 & 3417274 \\
\hline $25<30$ & 12497261 & 6248624 & 6186064 & 4374204 & 6299949 & 4454732 \\
\hline $30<35$ & 62140929 & 13248432 & 30686961 & 9252125 & 31385168 & 0462942 \\
\hline $35-<40$ & 221120470 & 23571114 & 89061611 & 14843.389 & 132317482 & 18348762 \\
\hline $40-<45$ & 508360533 & $334+6001$ & 202811419 & 20917542 & 306337989 & 26170602 \\
\hline $45-<50$ & $9028 \div 1799$ & 41378357 & 423380936 & 27974722 & 478196575 & 30423351 \\
\hline $50-<55$ & 1284823949 & 15414145 & 684833661 & 32002212 & 592099705 & 31242900 \\
\hline $55<60$ & 1653303695 & 46928302 & 946565482 & 31729470 & $68715161^{-}$ & 30780350 \\
\hline $60-<65$ & 2108666722 & 47724942 & 1285340028 & 30185452 & 779980053 & 29676448 \\
\hline $65<70$ & 2346808978 & 44728840 & 1426677914 & 33578573 & 854244596 & 27736660 \\
\hline $70-<75$ & 2010740168 & 36225748 & 1205541069 & 26745101 & 731587506 & 22565913 \\
\hline $75-<80$ & 1180716632 & 23850068 & 688370667 & 17202791 & 440362014 & 15088288 \\
\hline $80<85$ & 551401914 & 13713324 & 316043898 & 9704078 & 205074955 & 8680760 \\
\hline $85+$ & 2078,7584 & 6483125 & 110605844 & 4385778 & 85431061 & 4305819 \\
\hline Tot $x_{1}$ & 130617287 & 3913709 & 74230564 & 2794466 & 53338859 & 2623549 \\
\hline
\end{tabular}

Analogous estimates of burden of disease due to premature mortalities caused by cardiopulmonary disease are given in Table 5.8. It is estimated that the burden of disease is 492291.3 years and the $95 \%$ confidence interval is $(475448,509134.6)$ years. The male burden of disease is still larger by about the same margin than that of the female. When looking at all three tables we can observe that lung cancer and cardiopulmonary disease account for 
Table 5.8: Years of life lost from cardiopulmonary disease by sex and by age

\begin{tabular}{|c|c|c|c|c|c|c|}
\hline Agr group & Both & SD & Male & $\mathrm{SD}$ & Frmalt & SD \\
\hline $0<1$ & 22727224 & 2755825 & 9973802 & 1820813 & 12755653 & 2069021 \\
\hline $1<5$ & $1772 \quad 1510$ & 2506160 & 10229596 & 1899554 & 7472118 & 1630527 \\
\hline $5<10$ & 5217240 & 1394361 & 3707979 & 1172560 & 1496757 & 748377 \\
\hline $10<15$ & 8220902 & 1752693 & 3715199 & 1174843 & $450538 ?$ & 1300584 \\
\hline $15-<20$ & 16243931 & 2421474 & 8962105 & 1792399 & 7260432 & 1623465 \\
\hline $20<25$ & 16631421 & 2375887 & 12117558 & 2019555 & 4142459 & 1232108 \\
\hline $25-<30$ & 34367467 & 3276721 & 20104708 & 2493602 & 14174884 & 2113021 \\
\hline $30-<35$ & 36774212 & 4004381 & 33197712 & 3043081 & 23396216 & 2583595 \\
\hline $35-<40$ & 95483839 & 4897852 & 61848311 & 3911244 & 3.3079371 & $290 \perp 106$ \\
\hline $40-<45$ & 150527334 & 5754715 & 102916008 & $47 \perp 1219$ & 46296105 & 3216823 \\
\hline $45-<50$ & 217561755 & 6422171 & 160293132 & 5441572 & 54208519 & 3239148 \\
\hline $50<55$ & 280997550 & 6785404 & 203131314 & 5616028 & 78671744 & 3601071 \\
\hline $55<60$ & 359460223 & 6015772 & 244295539 & $557+218$ & 107764139 & 3853816 \\
\hline $60-<65$ & 472691889 & 7138170 & 313524958 & 5642624 & 146726682 & 4068242 \\
\hline $6 \overline{3}-<70$ & 631142910 & 7319773 & 389144443 & 5529121 & 223528839 & 4480823 \\
\hline $70<75$ & 758790876 & 7005686 & 430703694 & 5023715 & 304421303 & 4588876 \\
\hline $75-<80$ & 713023266 & 5807355 & 351752222 & 3842234 & 342549840 & 4177821 \\
\hline $80-<85$ & 621670575 & 4518893 & 266958142 & 2752938 & 340932510 & 3484558 \\
\hline $85+$ & 437658368 & 2882322 & 139289859 & 1498074 & 296095798 & 2462994 \\
\hline Total & 493291269 & 8593561 & 276616631 & 6495939 & 204976875 & 5337597 \\
\hline
\end{tabular}

about 8 and $30 \%$ of the total burden of disease respectively. There are many fatal diseases and the fact that lung cancer and cardiopulmonary account for almost $40 \%$ of the burden makes them two very serious diseases that we try to reduce. In the next section we will focus on particulate matter as one of the environmental risk factors that causes lung cancer and cardiopulmonary diseases. 


\subsection{Particulate Matter (PM2.5)}

Particulate matter, PM2.5, is an air pollutant consisting of a mixture of solid and liquid particles that are less than $2.5 \mu \mathrm{m}$ in diameter. Sources of particulate matter can be natural (e.g. . pollen. bacteria, viruses. fungi, mold, yeast, soil from erosion), or through human activities including diesel trucks, power plants, wood stoves. and industrial processes(see Minnesota Pollution Control Agency website). Among the effects of exposure to particulate matter are the following effects:

- Respiratory symptoms

- Adverse effects on the cardiovascular system

- Increase in hospital admissions

- Reduction in lung function

- Reduction in life expectancy due to cardiopulmonary and lung cancer mortality

To study the effect of PM2.5 on all causes of death, lung cancer and cardiopulmonary disease, a data set that contains PM2.5 concentrations for 

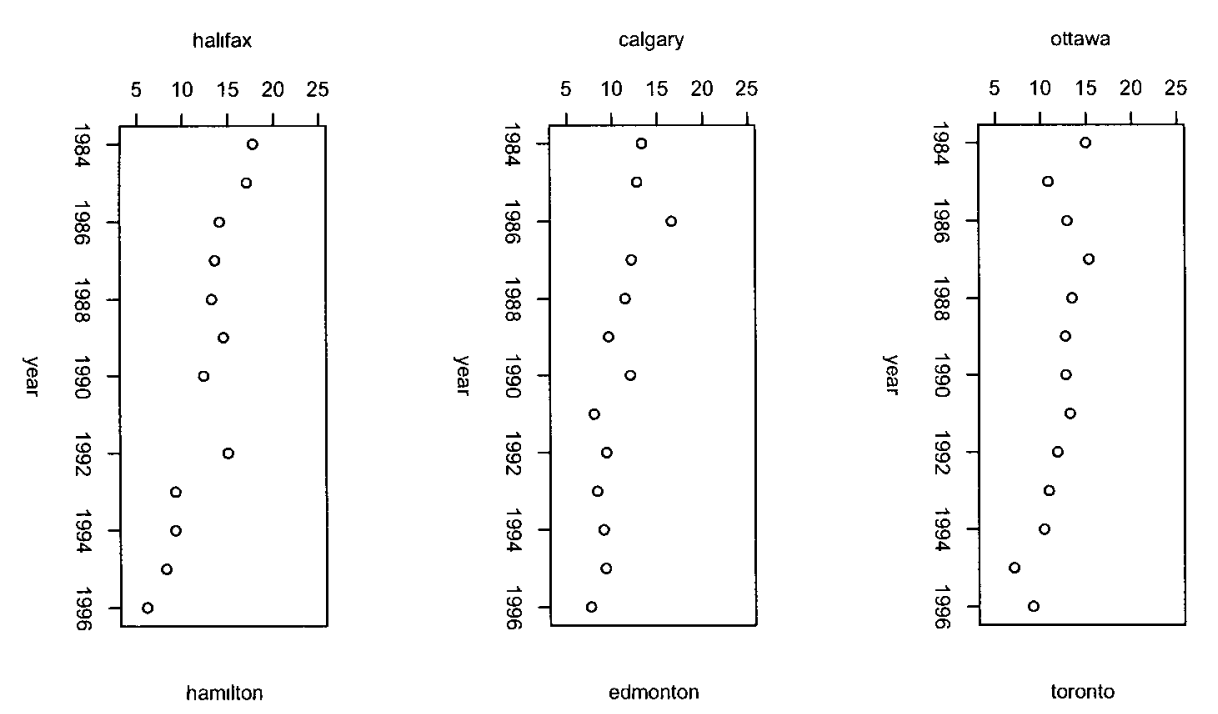

2
2
0
07
0
0
0
0
0
2
0
0
0
2
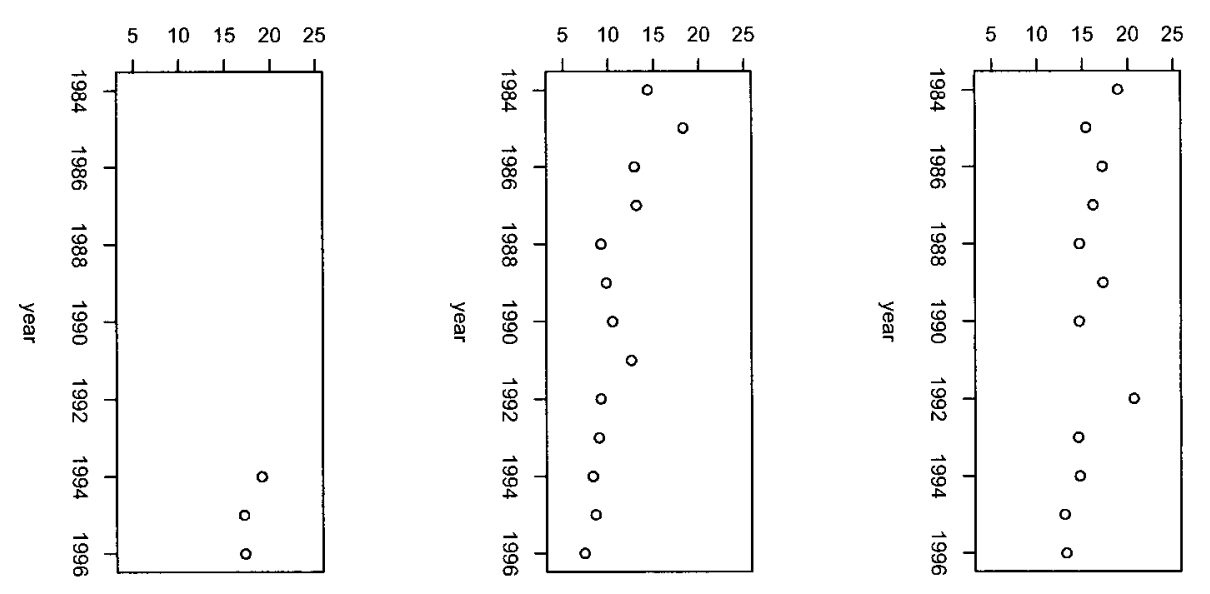

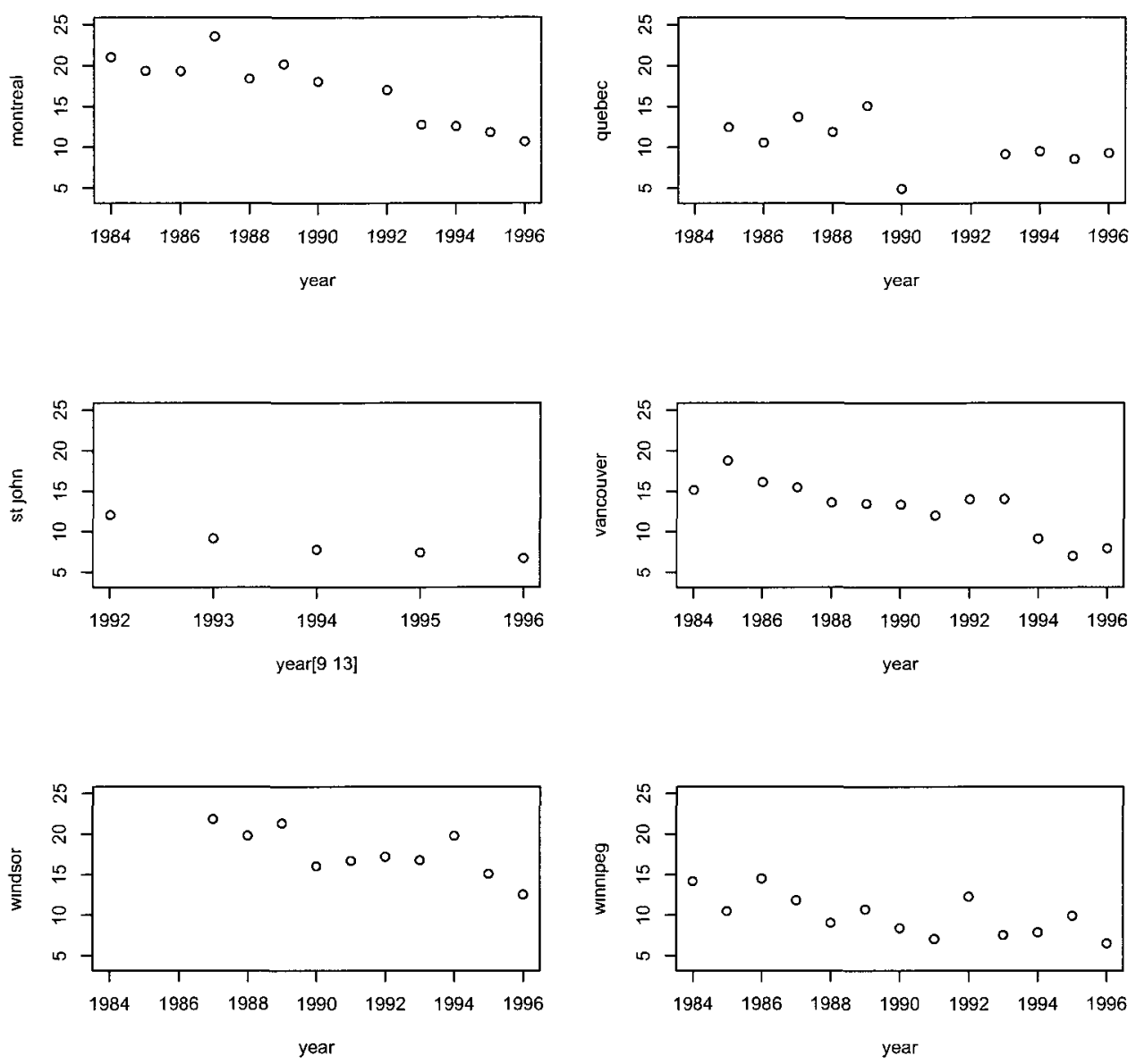

Figure 5.1: Yearly average for PM2.5 in $\mu \mathrm{g} / \mathrm{m}^{3}$.

12 major Canadian cites (Ottawa. Toronto, Calgary, Edmonton, Halifax, Hamilton, Montreal. Quebec, St. John, Vancouver, Windsor, Winnipeg) from 1994 to 1996 was used. This data set was produced by the Canadian 
National Air Pollution Surveillance (NAPS) and we acquired from Health Canada (Burnett et al. 2000). A maximum of thirteen and a minimum of three years of data are available for the 12 cities. For purposes of illustration we made use of the annual concentration for each city over the three year period from 1994 through 1996.

For each city we now estimate the relative risks for all diseases, lung cancer and cardiopulmonary disease using the expressions in Table 3.5 and taking the theoretical minimum level of exposure, $x_{0}$, to be 7.5 (see Lopez et al. 2006). Table 5.9 contains the results obtained. To estimate the population attributable fractions, we use equation 3.40. Table 5.10 contains the population of each of the 12 cities. Please note that our population of study is now the combined populations of the 12 cities only and not the 1996 Canadian population. The proportion of individuals in each of the 12 cities in the population created is also given in Table 5.10 .

We computed the population attributable fraction with equation 3.40 using the relative risks from Table 5.9. Table 5.11 contains the results.

We conclude that over both genders combined particulate matter. PM2.5, attributed about $1.5 \%, 7.4 \%$ and $5 \%$ to the total 1996 burden of disease in the 12 cities due to all causes. lung cancer and cardiopulmonary disease 
Table 5.9. PM2.5 concentrations, all causes RR, lung cancer RR and cardiopulmonary RR

\begin{tabular}{|c|c|c|c|c|}
\hline City & $\begin{array}{l}9496 \text { PM } 25 \text { avel agc } \\
\text { concentration }\end{array}$ & 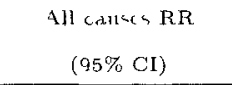 & $\begin{array}{l}\text { Lung Cancer RR } \\
\qquad(95 \% \mathrm{CI})\end{array}$ & $\begin{array}{c}\text { Cardiopulmonary RR } \\
(95 \% \mathrm{CI})\end{array}$ \\
\hline Otrawa & 8826635 & $\begin{array}{c}1005321 \\
(10013281010267)\end{array}$ & $\begin{array}{c}1034247 \\
(10124961056464)\end{array}$ & $\begin{array}{c}1022757 \\
(1008184103754)\end{array}$ \\
\hline Toronto & 1364831 & $\begin{array}{c}1024898 \\
(1006167 \quad 1048481)\end{array}$ & $\begin{array}{c}1134697 \\
(1047708122 \diamond 909)\end{array}$ & $\begin{array}{c}1088109 \\
\left(\begin{array}{llll}1 & 03106 & 1 & 148316\end{array}\right)\end{array}$ \\
\hline Calgary & 8657479 & $\begin{array}{c}1004641 \\
(1001158+008952)\end{array}$ & $\begin{array}{c}1030085 \\
(10109921019539)\end{array}$ & $\begin{array}{c}+020005 \\
(10072011032972)\end{array}$ \\
\hline Edmonton & $80780^{-}$ & $\begin{array}{c}1002315 \\
(10005781004461)\end{array}$ & $\begin{array}{c}1010394 \\
(1006561025232)\end{array}$ & $\begin{array}{c}101020 \\
(10037051016859)\end{array}$ \\
\hline Halitax & 7822505 & $\begin{array}{c}1001291 \\
(10003231002487)\end{array}$ & $\begin{array}{c}1008685 \\
(1003195 \perp 014206)\end{array}$ & $\begin{array}{c}1005796 \\
(10020951009509)\end{array}$ \\
\hline Hamulton & 1782656 & $\begin{array}{c}1042171 \\
(1010381082761)\end{array}$ & $\begin{array}{c}1202773 \\
(10704651351435)\end{array}$ & $\begin{array}{c}1131309 \\
(10457041223923)\end{array}$ \\
\hline Montrual & 1168216 & $\begin{array}{c}1016869 \\
(10041911032727)\end{array}$ & $\begin{array}{c}1097354 \\
(10348571163626)\end{array}$ & $\begin{array}{c}1064048 \\
(10227421107022)\end{array}$ \\
\hline Qub bec & 9092263 & $\begin{array}{c}1006389 \\
(1001594<012336)\end{array}$ & $\begin{array}{c}\perp 040671 \\
(1014812106719)\end{array}$ & $\begin{array}{c}1026998 \\
(10096961044595)\end{array}$ \\
\hline St John & 7332518 & $\begin{array}{c}1 \\
(11)\end{array}$ & 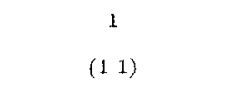 & $\begin{array}{c}1 \\
(11)\end{array}$ \\
\hline Vancouver & 8047693 & $\begin{array}{c}1002193 \\
(10000481004226)\end{array}$ & $\begin{array}{c}1014604 \\
(10053611023931)\end{array}$ & $\begin{array}{c}1009735 \\
(10035151015993)\end{array}$ \\
\hline Windsor & 1579123 & $\begin{array}{c}1033721 \\
(10083261065924)\end{array}$ & $\begin{array}{c}1171243 \\
(10600291294126)\end{array}$ & $\begin{array}{c}1111405 \\
(10390021188853)\end{array}$ \\
\hline Winnipcy & 810779 & $\begin{array}{c}1002434 \\
(10006081004691)\end{array}$ & $\begin{array}{c}1016165 \\
(1005931+026502)\end{array}$ & $\begin{array}{c}1010773 \\
(10038891017704)\end{array}$ \\
\hline
\end{tabular}

respectively. 
Table 5.10: Populations of the 12 cities and the proportions they represent

\begin{tabular}{|c|c|c|c|c|c|c|}
\hline \multirow[t]{2}{*}{ City } & \multicolumn{3}{|c|}{ Population } & \multicolumn{3}{|c|}{ Proportion of total $p_{\imath}$} \\
\hline & Both & Mak & Femrit & Both & Male & Femalt \\
\hline Ortawa & 763435 & 372495 & 390940 & 0052397879 & 0052423032 & 005237376 \\
\hline Toronto & 4263760 & 2076360 & 2187400 & 0292640474 & 0292216236 & 0 293043336 \\
\hline Calgaty & 821630 & 409235 & 412415 & 0056392056 & 0057593631 & 0055250739 \\
\hline Edmonton & 862595 & 426965 & 435635 & 0059203663 & a 06008886 & 0058361495 \\
\hline$H \neq \ln f \mathrm{f} x$ & 332520 & 160755 & 171765 & 00228223 & 0022623833 & 002301115 \\
\hline Hamilton & 624360 & 304030 & 3203.30 & 0042852554 & 004278762 & 0042914223 \\
\hline Montical & 3326510 & 161.1035 & 1713475 & D $22 \$ 312912$ & 0226728787 & 0229820123 \\
\hline Qux bes & 671885 & 323835 & 348050 & 0046114403 & 0045574874 & 0046627838 \\
\hline St John & 125705 & 60730 & 64975 & 0008627683 & 0008546828 & 0008704622 \\
\hline Vancolirer & 1831665 & 900805 & 930860 & 012571517 & 0126774667 & 012170619 \\
\hline Windior & 278685 & 135935 & 142750 & 0019127369 & 0019130793 & 0019124045 \\
\hline Wmmipeg & 667210 & 323380 & 343830 & 0045793537 & 0045510839 & 004606249 \\
\hline
\end{tabular}

Table 5.11: Population attributable fractions

\begin{tabular}{|cccc|}
\hline Gender & $\begin{array}{c}\text { All causes } \\
(95 \% \mathrm{CI})\end{array}$ & $\begin{array}{c}\text { Lung cancer } \\
(95 \% \mathrm{CI})\end{array}$ & $\begin{array}{c}\text { Carchopulmonaly } \\
(95 \% \mathrm{CI})\end{array}$ \\
\hline Both & 001463782 & 00738313 & 005024739 \\
& $(0003691052002788218)$ & $(00281983901163687)$ & $(001863876008038464)$ \\
Malk & 001460439 & 007366726 & 005013548 \\
& $(0003682622,002781853)$ & $(00281354601161114)$ & $(001859712008020617)$ \\
Female & 00146696 & 00739873 & 005035381 \\
& $(000369906700279427)$ & $(00282582301166134)$ & $(001867835008055437)$ \\
\hline
\end{tabular}

\subsection{Discussion}

We now discuss the results obtained by comparing them to results from other studies. The world health organizatıon. WHO, estımates were $1 \%$. $5 \%$ and $3 \%$ for all causes. lung cancer and cardiopulmonary respectively 
(Ostro et al. 2004). The estimates from our study differ from those and we provide explanations as to why this is the case. The WHO studies global burden of disease (GBD) and they cover 3211 urban cities worldwide so it is reasonable to get different results from our investigation. This is true since most Canadian cities have lower pollution than most of other major cities in the world. However, lower estimates would be what is expected which is not the case here.

There are a number of differences between our research and the researches conducted by the WHO which can lead to a difference in the results. First, the concentration levels that were used for the WHO studies were for PM10 and not PM2.5. The PM2.5 estimates were obtained by multiplying PM10 by a factor. Also, the data were for 304 major cities in the world and assumptions were made to estimate concentrations for the rest of the 3211 cities. Moreover, the results for the population attributable fractions that the WHO obtained were assumed to be for the whole world and not the 3211 major cities. This means that further assumptions were made to obtain population attributable fractions for areas or cities other than the 3211 cities. Our research covers 12 major cities in Canada and we did not generalize our results for the rest of Canada. When we assumed that the rest of Canada 
has a concentration that is less or equal to the theoretical minimum ( 7.5 $\mu \mathrm{g} / \mathrm{m}^{3}$ ) the estimates change to about $0.74 \%, 4 \%$ and $3 \%$ for all causes, lung cancer and cardiopulmonary disease respectively. These estimates are much closer to those reported by the WHO which makes us believe that a similar assumption was made by the WHO for areas where data were not available. Also, when estimating relative risks, the WHHO studies used the linear model whereas we used the log-linear model, which the WHO recommends. The linear model gives lower relative risks which, as a result, gives lower estimates for the population attributable fractions.

We also compared our study to a study that was for the environmental burden of disease in Canada (Boyd et al. 2007). This study addressed the effect of particulate matter on lung cancer only. The researchers did not estimate their population attributable fractions but rather made use of previous estimates and expert opinion. The estimate they used was $5-15 \%$ and ours was about $2.8-11.6 \%$. 


\section{Chapter 6}

\section{Health Indicators and Their}

\section{Correlation}

In this study we have used $Y L L$ as the indicator to quantify BoD. There are, however, a number of other indicators that could have been employed. In this chapter, we address the question of whether the choice of indicator to quantify BoD makes any difference. Specifically, we shall investigate, for ages from 0 to 75 , if any correlation exists between death rate, years of life lost and potential years of life lost. We have already discussed death rates, $M$, and years of life lost, YLL. We now describe potential years of of life lost. PYLL. 
CHAPTER 6. HEALTH INDICATORS AND THEIR CORRELATION 64

The concept of PYLL was first introduced in 1947 by Dempsey (see J-M Romeder et al. 1997). For a given individual who died from a particular disease. PYLL is an indicator of the years of life the would have remained had the person lived until 75. Provided that individuals are grouped by age categories. the following expression is for calculating potential years of life lost, $P Y L L_{k}$, for a specific disease, say the $k$-th.

$$
P Y L L_{k}=\sum_{\imath=1}^{16}\left(75-x_{\imath}-0.5\right) D_{\imath k}
$$

where, $k$ denotes the $k$-th disease, $i$ is the age group. $x_{2}$ is the age of death in the $i$-th age group and $D_{\imath k}$ is the total number of deaths in the $i$-th age group.

Death rate and years of life lost for a given disease are calculated as follows.

$$
\begin{aligned}
M_{k} & =\frac{\sum_{l=1}^{16} D_{\imath k}}{\sum_{\imath=1}^{16} P_{\imath}} \\
Y L L_{k} & =\sum_{\imath=1}^{16} Y L L_{\imath k}
\end{aligned}
$$

In order to investigate the extent of correlation between $W, Y L L$, and PYLL, we made use of data on deaths from 20 different diseases in the 1996 
CHAPTER 6. HEALTH INDICATORS AND THEIR CORRELATION 65

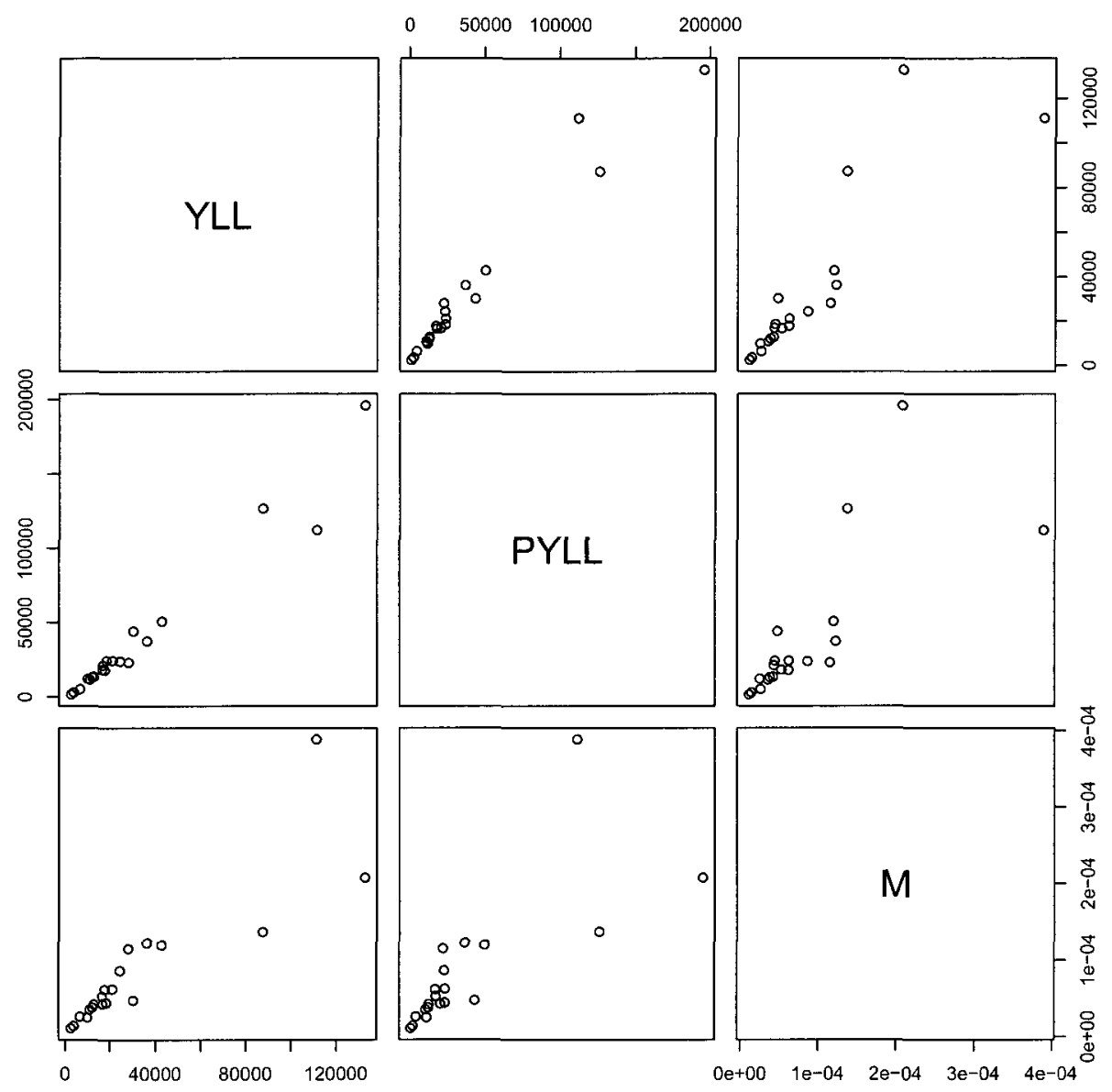

Figure 6.1: Health indicators comparison plot.

Canadian population for both genders combined.

Figure 6.1 shows scatter diagrams of $Y L L_{k}$ vs $P Y L L_{k}, Y L L_{k}$ vs $M_{k}$, and $P Y L L_{k}$ vs $M_{k}$ across the 20 different diseases $(k=1,2, \ldots 20)$. These 
CHAPTER 6. HEALTH INDICATORS AND THEIR CORRELATION 66

plots seem to suggest there is a strong positive correlation between any two of these measures. In addition, the scatter diagrams appear linear. Therefore, three separate pairwise regressions were fit where $Y L L_{k}$ was regressed against $P Y L L_{k}, Y L L_{K}$ was regressed against $M_{k}$, and $P Y L L_{k}$ was regressed against $M_{k}$. However. in each case, the scatter diagrams seem to suggest a possible violation of the assumption of a constant error term variance typically specified for a simple linear regression model. We therefore apply power transformations to remedy the non-constant variance problem.

\section{PYLL vs YLL}

We estimated the best power transformation, $\lambda$, of PYLL using Box-Cox method. The estimate for $\lambda$ was 0.7878788 . The estimate for Pearson correlation coefficient is 0.989 . with associated p-value $<0.0001$.

\section{M vs YLL}

We apply the same procedure to obtain $\lambda$ of 0.3030303 . The correlation coefficient estimate is 0.871 and the p-value is $<0.0001$.

\section{M vs PYLL}


CHAPTER 6. HEALTH INDICATORS AND THEIR CORRELATION 67

The best $\lambda$ is 0.7878788 . The Pearson correlation coefficient estimate is 0.861 and $\mathrm{p}$-value $<0.0001$.

Since a correlation was found between pair of the three health indicators. we can conclude that it does not matter which health indicator, out of the three, to use to quantify the $\mathrm{BoD}$. This is a very important finding since the three health indicators differ in complexity and data required to estimate them. 


\section{Chapter 7}

\section{Conclusion and Discussion}

In this research we shed some light on the influence of PM2.5 on mortalities by all causes, lung cancer and cardiopulmonary disease. This research represents a first Canadian study in this area, as all studies conducted before either were conducted globally or did not use Canadian data. An important conclusion arrived at here is that the WHO estimates are not very applicable at the local level. We therefore hope that this study and its findings will motivate future Canadian studies using more recent data, additional risk factors and more diseases.

An important statistical contribution of our research is the development of a confidence interval for $Y L L$, which was never done before as previous 
studies have only considered point estimates. We first derived an expression for the variance of the estimate of YLL that we subsequently employed in the development of a confidence interval. This confidence interval formula was then verified by a simulation study that demonstrated its usefulness for estimating BoD. 


\section{Bibliography}

[1] Bohrnstedt, G. W., Goldberger. A. S.: On the exact covariance of products of random variables. Journal of American statistical association. Dec., 1969, vol.64, No. 328, pp. 1439-1442.

[2] Boyd, D.R., Genuis, S.J.: The environmental burden of disease in Canada: Respiratory disease, cardiovascular disease, cancer. and congenital affliction. Environmental Research, Sept.. 2008,106, 240-249.

[3] Burnett, R. T., Brook, J., Dann, T., Delocla, C., Philips. O.. Cakmak, S., Vincent, R.. Goldberg, M. S.. Krewski, D.: Association between particulate and gas-phase components of urban air pollution and daily mortality in eight Canadian cities. Inhalation Toxicology. 2000, vol.12(supplement 4). pp. 15-39. 
[4] Chiang, 1. C.: The life table and its applications. Krieger publishing company, 1984 .

[5] Cohen, A.J., Anderson, H. R., Ostro, B., Pandey, K. D., Krzyzanowski. M., Künzli, N., Gutschmidit, K., Pope III, C. A, Romieu, I., Samet, J. M.. Smith, K. R.: Urban Air Pollution from "Comparative qunatification of health risks". World health Organization. 2003.

[6] Krewski, D.: Evaluating the effects of ambient air pollution on life expectancy. The New England Journal of Medicine. 2009. vol.360. pp. 413-415.

[7] Lopez, A. D.. Mathers, C. D., Ezzati, M., Jamison. D. T., Murray, C. J. L.: Global burden of disease and risk factors. Oxford University Press, 2006.

[8] Manuel. D. G.. Goel, V., Williams, J. I., Corey. P.: Health-adjusted life expectancy at the local level in Ontario. Chronic Diseases in Canada. 2000.vol.21, No.2.

[9] Murray, C. J. L., Acharya, A. K.: Understanding DALYs. Journal of Health Ecnomics. 1997. vol.16, pp. 703-730. 
[10] Ostro B.: Outdoor air pollution: Assessing the environmental burden of disease at national and local levels. Geneva, World Health Organization, 2004. (WHO Environmental Burden of Disease Series, No.5)

[11] Pope III, C. A., Burnett. R. T., Thun, M. J.. Calle, E. E., Krewski. D., Ito, K., Thurston, G. D.: Lung cancer, cardiopulmonary mortality. and long exposure to fine particulate air pollutoin. JAMA. 2002, vol.287, No. 9, pp 1132-1141.

[12] Prüss-Üstün, A., Matters, C., Corvalán, C., Woodward, A.: Introduction and methods: Assessing the environmental burden of disease at national and local levels. Geneva, World Health Organization, 2003. (WHO Environmental Burden of Disease Series, No.1)

[13] Prüss-Üstün, A., Corvalán, C.: Preventing disease though healthy environments: Towards an estimate of the environment burden of disease. World Heath Organization. 2006.

[14] Rockhill, B., Newman, B., Weinberg, C.: Use and misuse of population attributable fractions. American Journal of Public Health. 1998,vol.88, No.1. 
[15] Romeder, J-M, McWhinnie, J. R.: Potential Years Of Life Lost Between Ages 1 And 70: An Indicator Of Premature Mortality For Health Plsnning. International Journal Of Epidemiology. 1977, vol.6. No.2. pp.143-151.

[16] Minnesota Pollution Control Agency: www.pca.state.mn.us.

[17] Statistics Canada: www.statcan.gc.ca.

[18] The World Bank: www.worldbank.org.

[19] World Health organization: www.worldbank.org. 


\title{
Appendix A
}

\section{R Programs}

\author{
A.1 Life Expectancy Function \\ leb $<-$ function (age, $p, d$ ) \\ \{ \\ result<-matrix $(\operatorname{rep}(0), 19,17)$ \\ result $[, 1]<$-age \\ result $[, 2]<-c(1,4, \operatorname{rep}(5,17))$ \\ result $[, 3]<-p$ \\ result $[, 4]<-d$ \\ result $[, 6]<-c(0.1,0.4, \operatorname{rep}(0.5,17))$
}




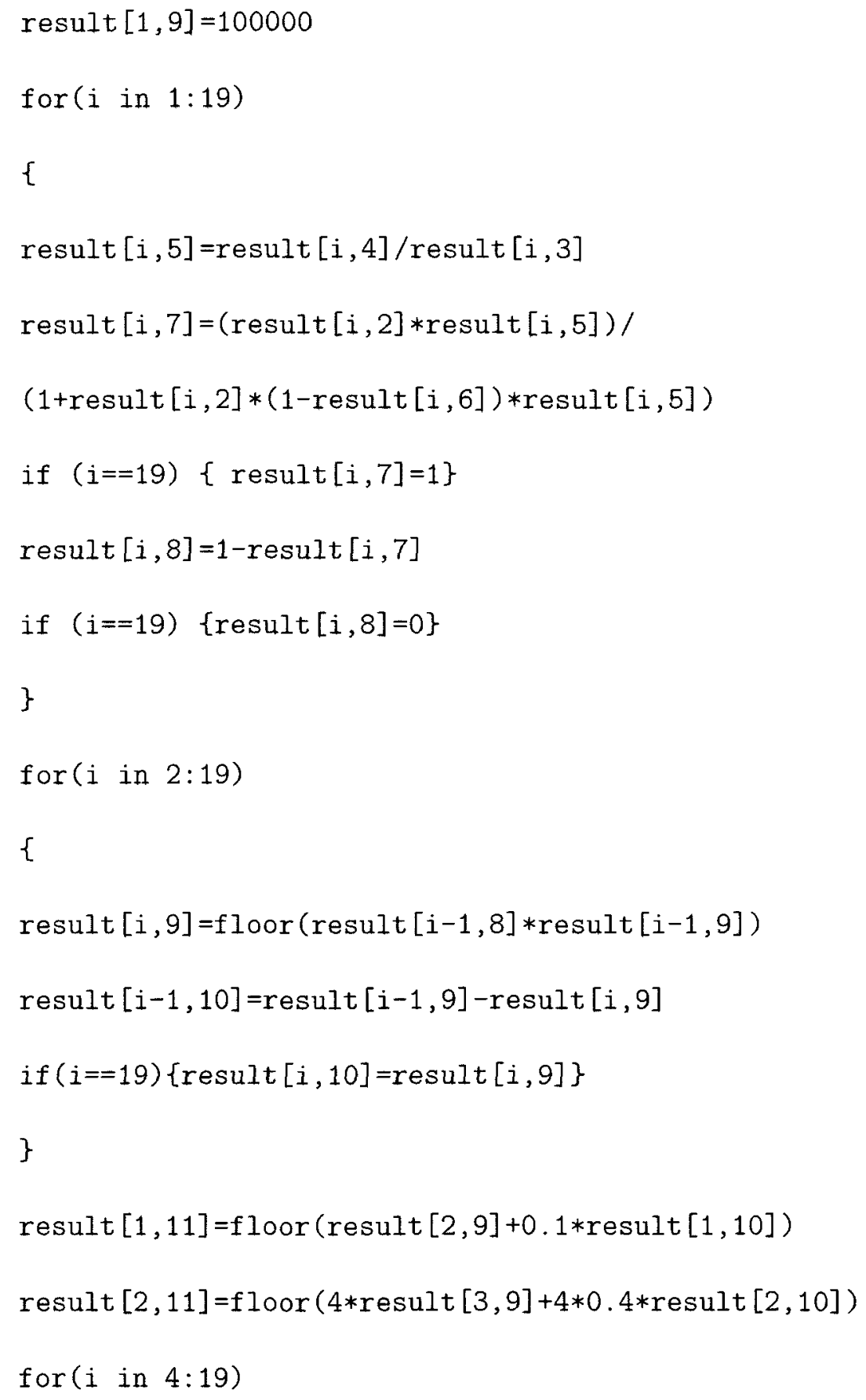




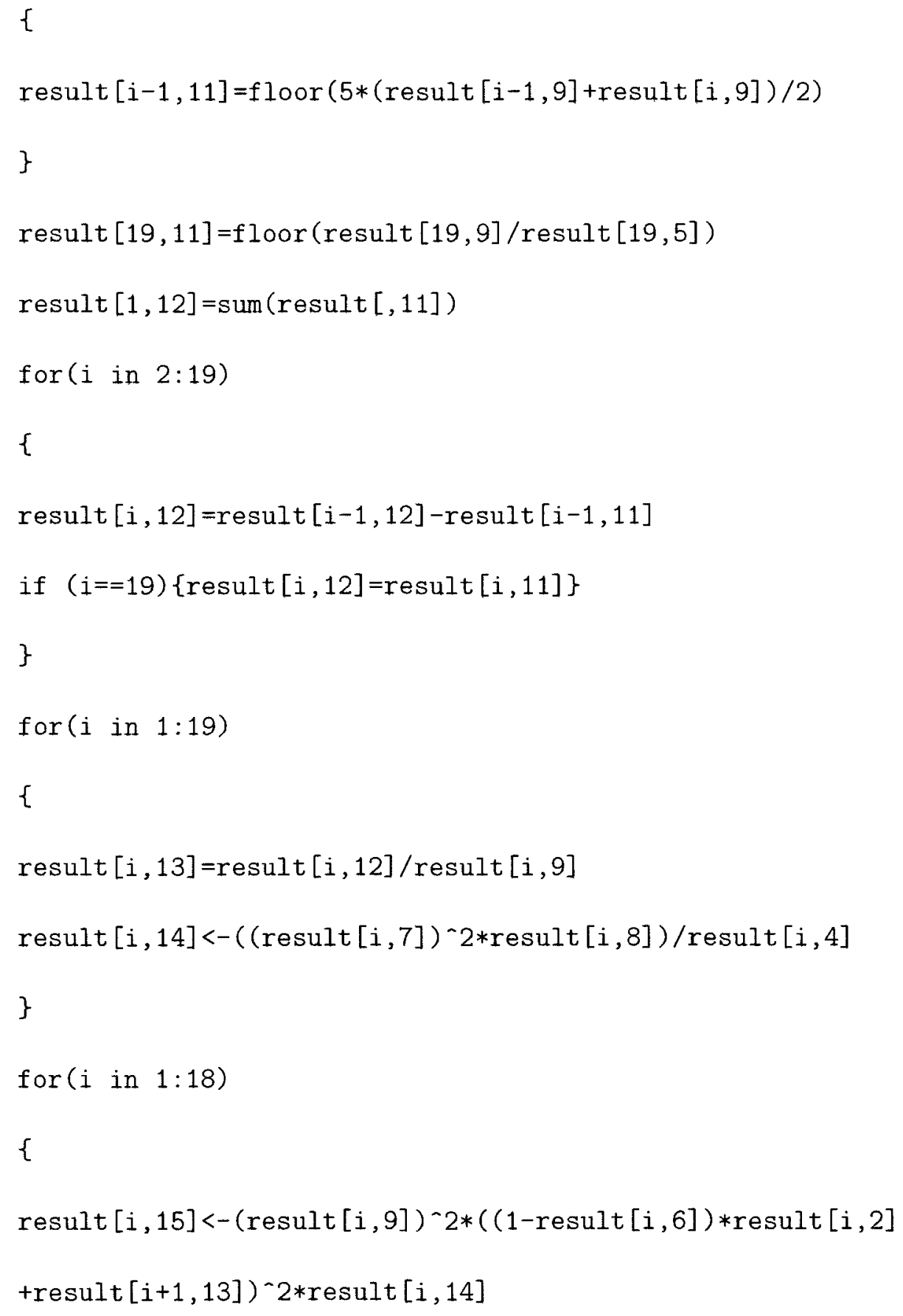




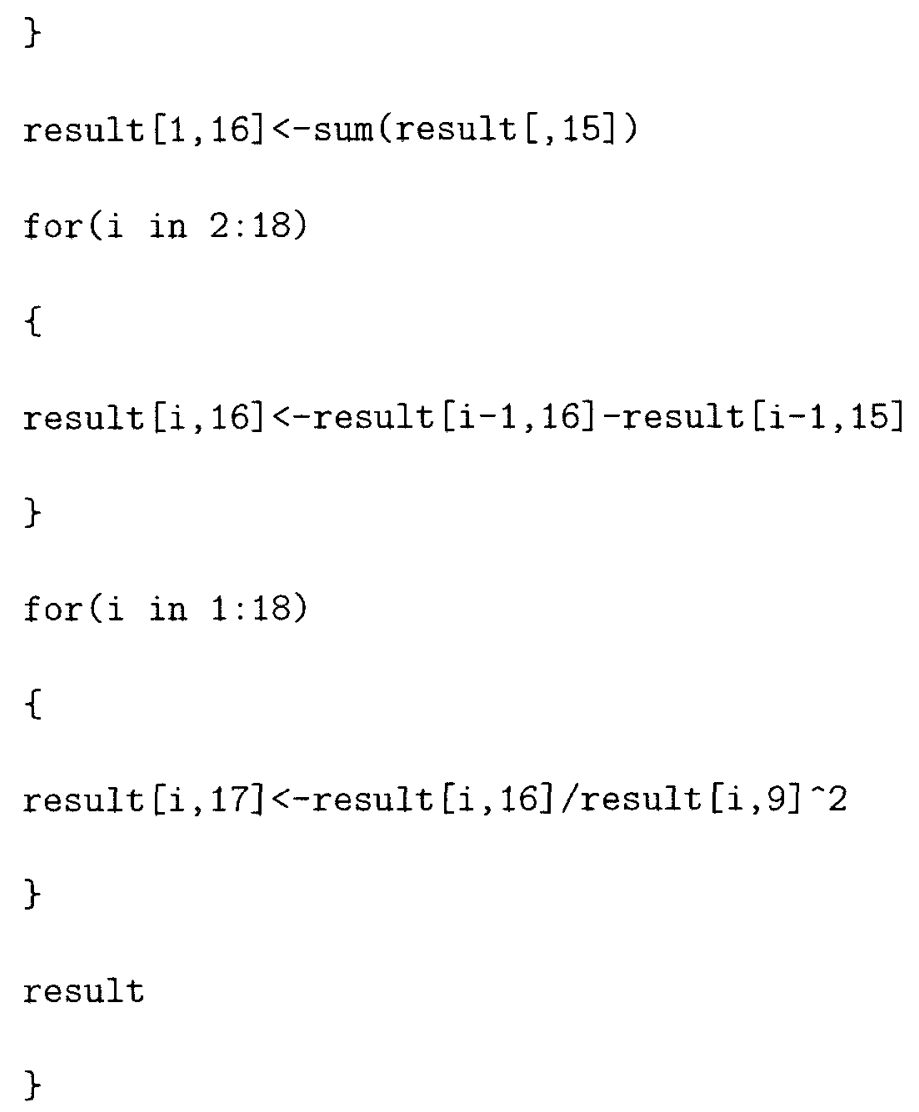

A.2 YLL Function

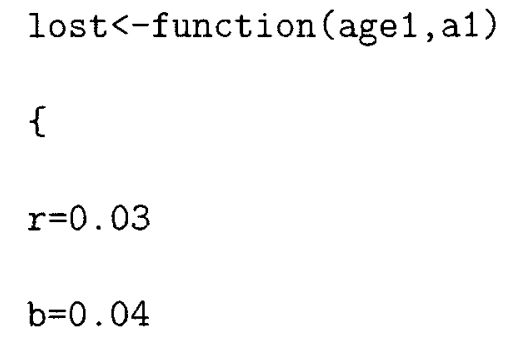




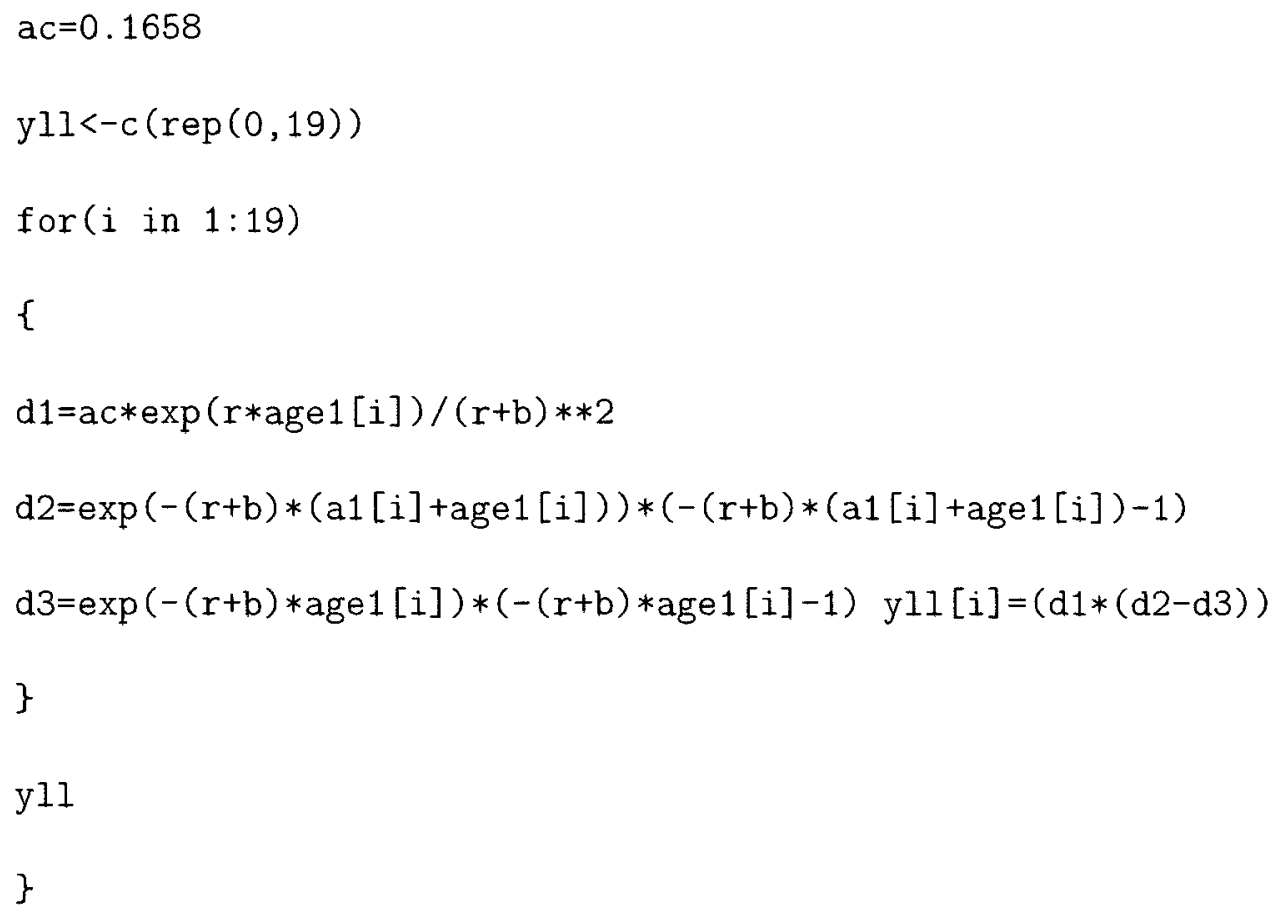




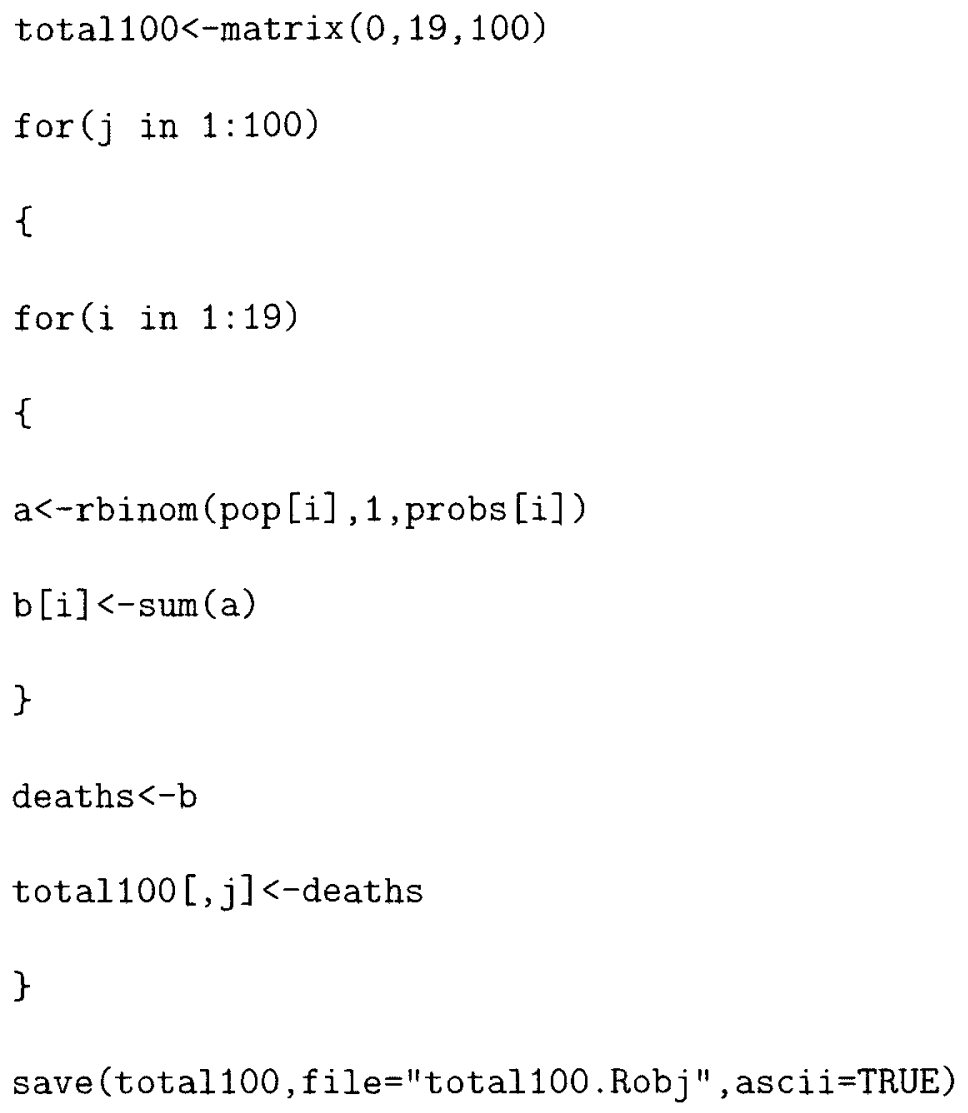

\section{A.4 Generating Bivariate Normal Data for}

\section{Approach 3}

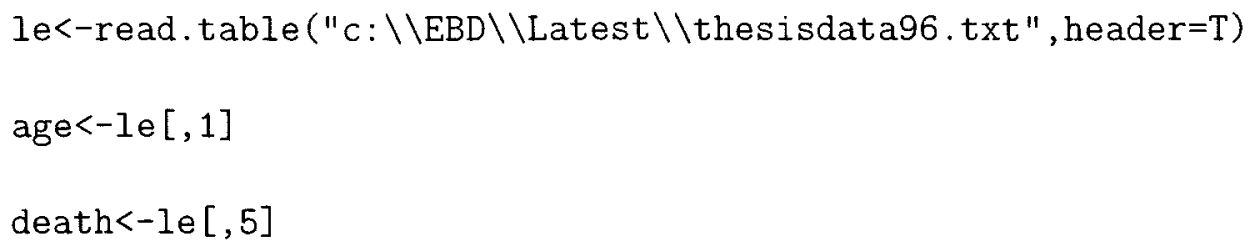




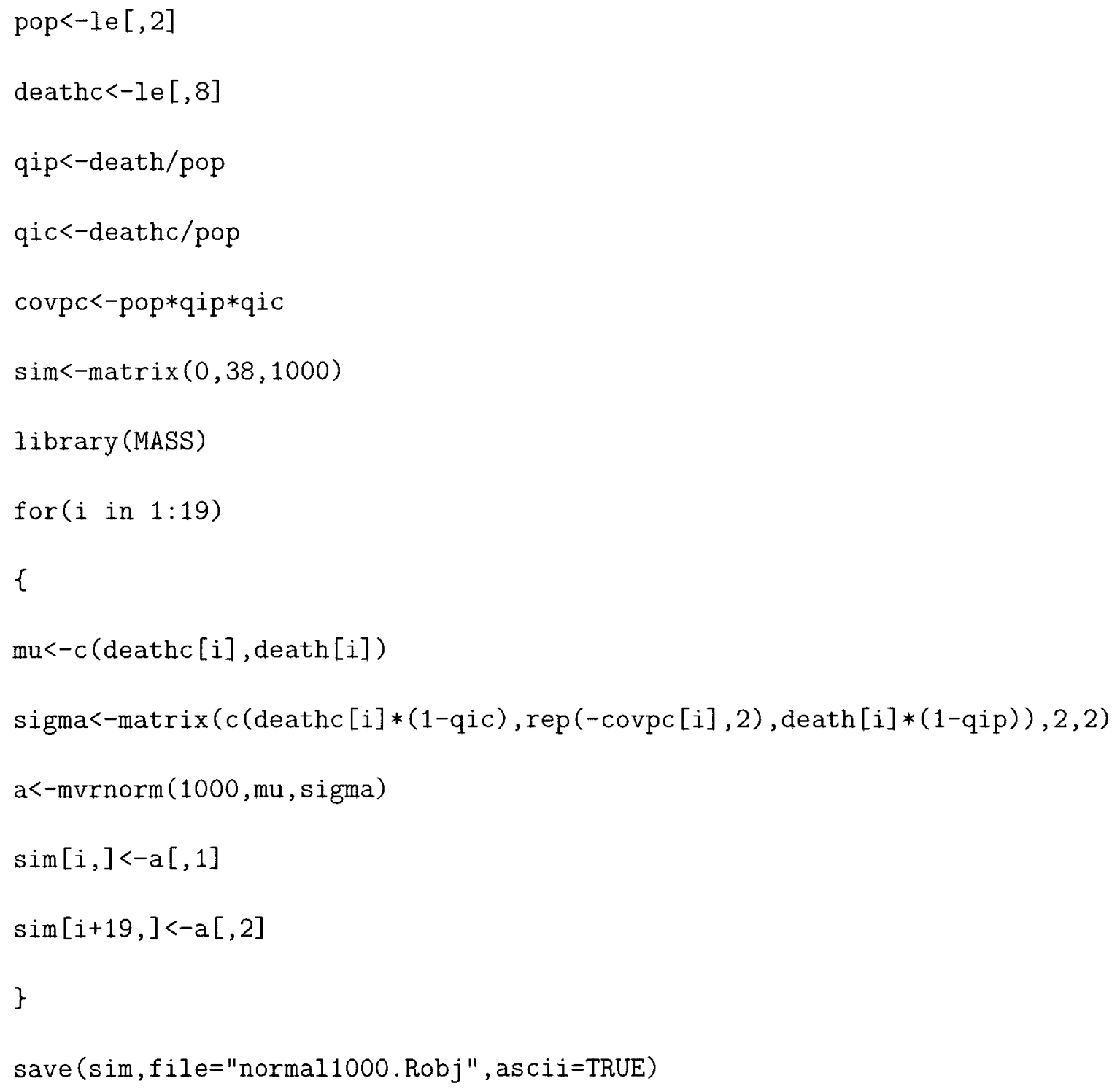




\section{A.5 Approach 1 Program}

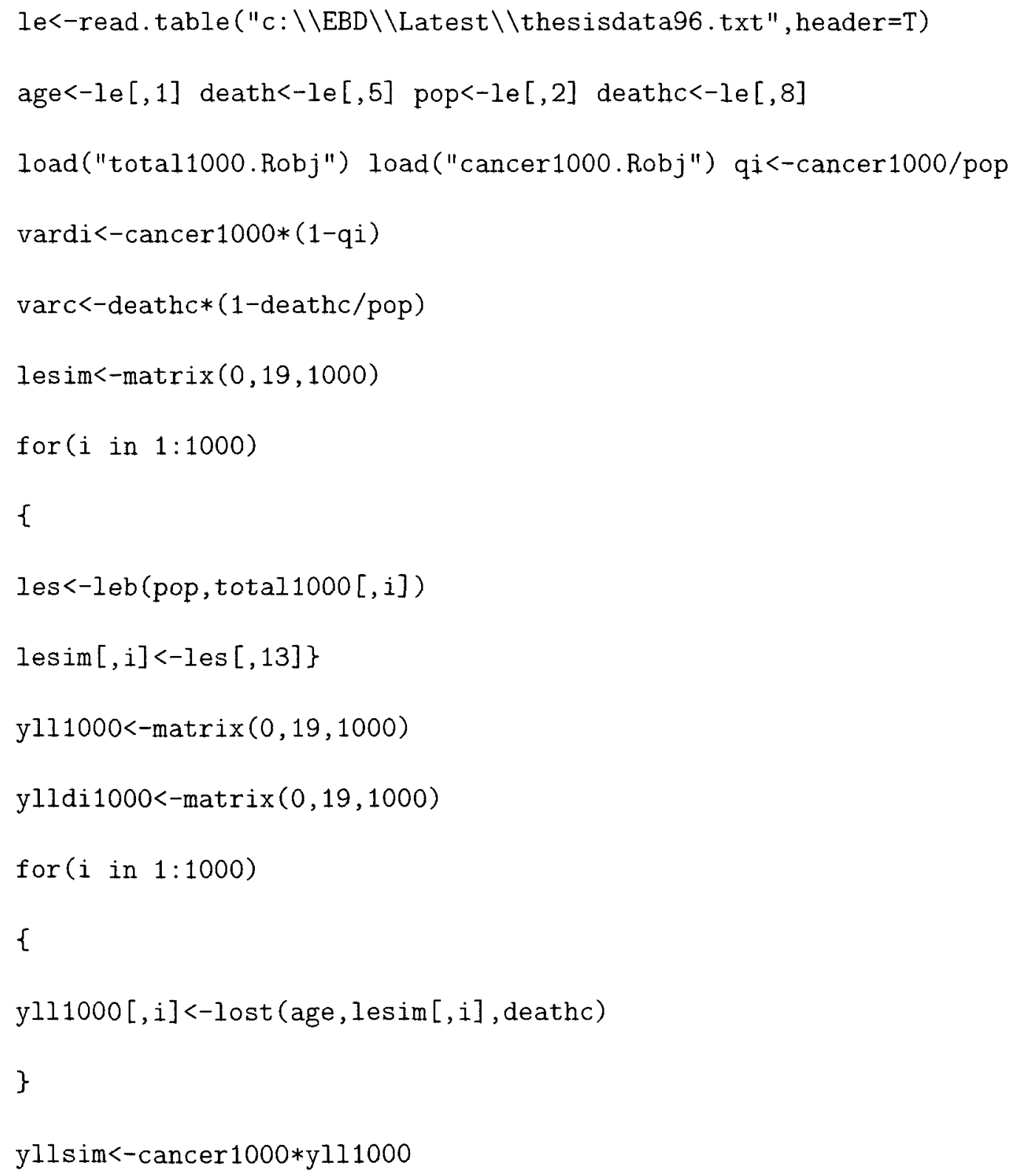




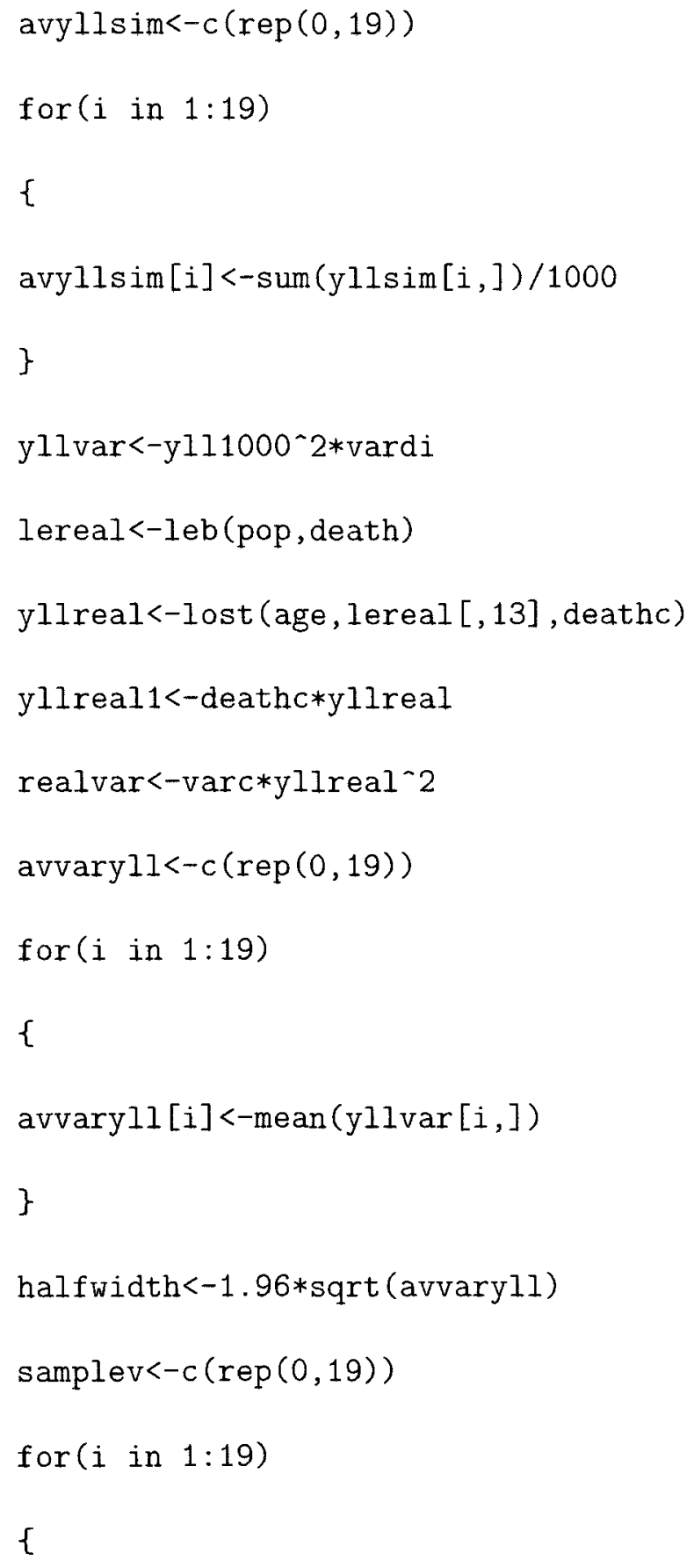




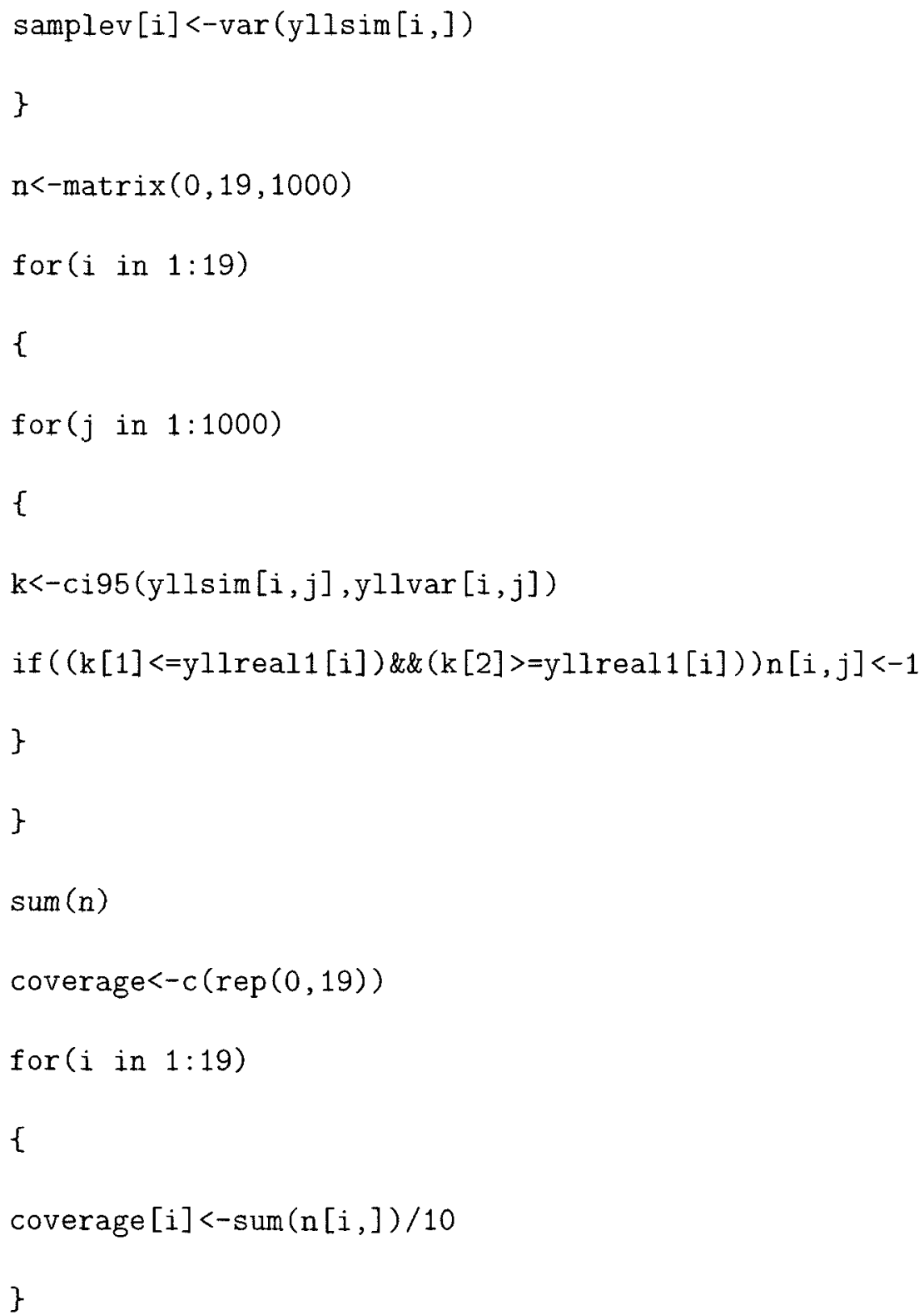




\section{A.6 YLL and Variance of YLL Calculations}

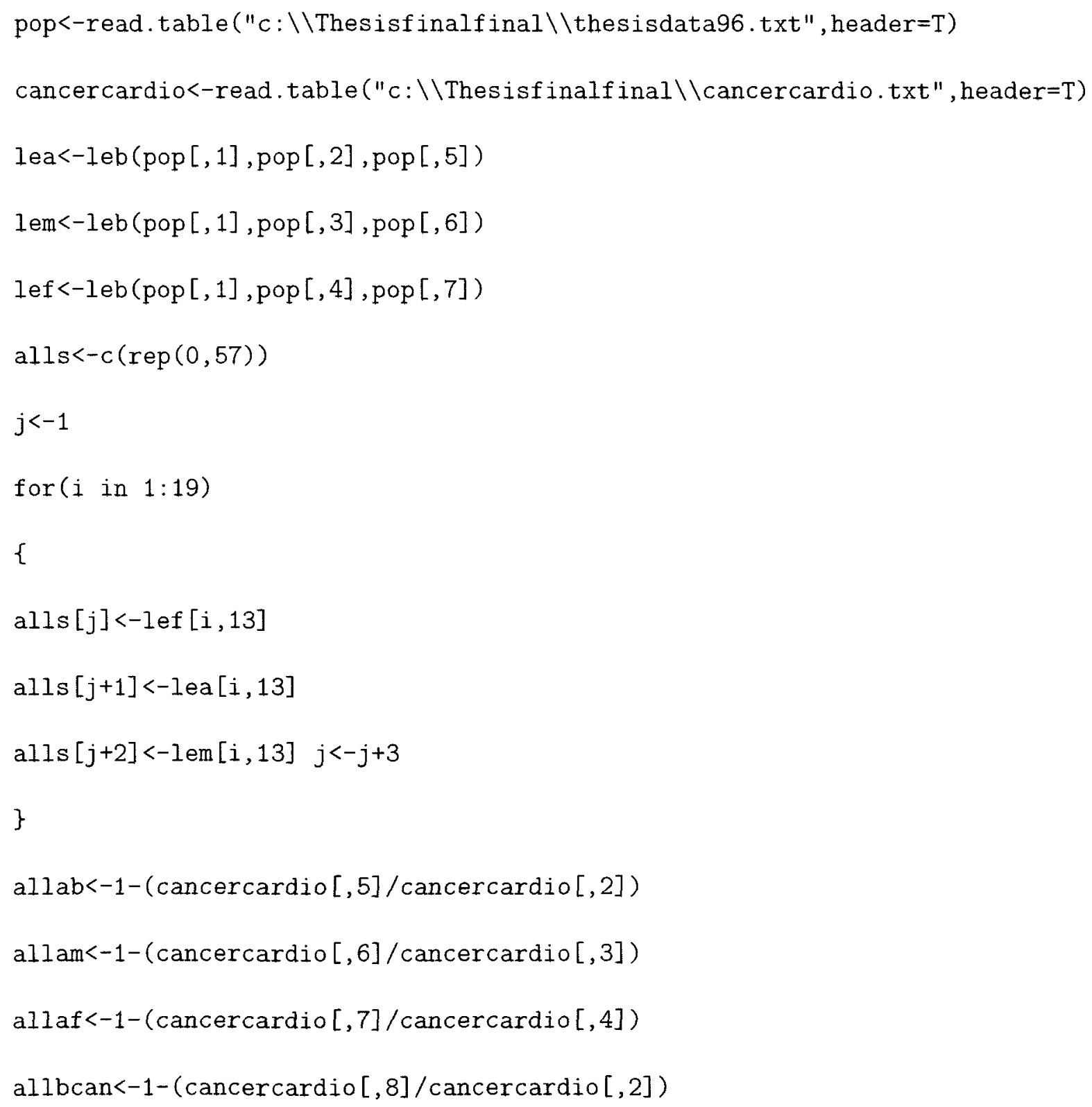




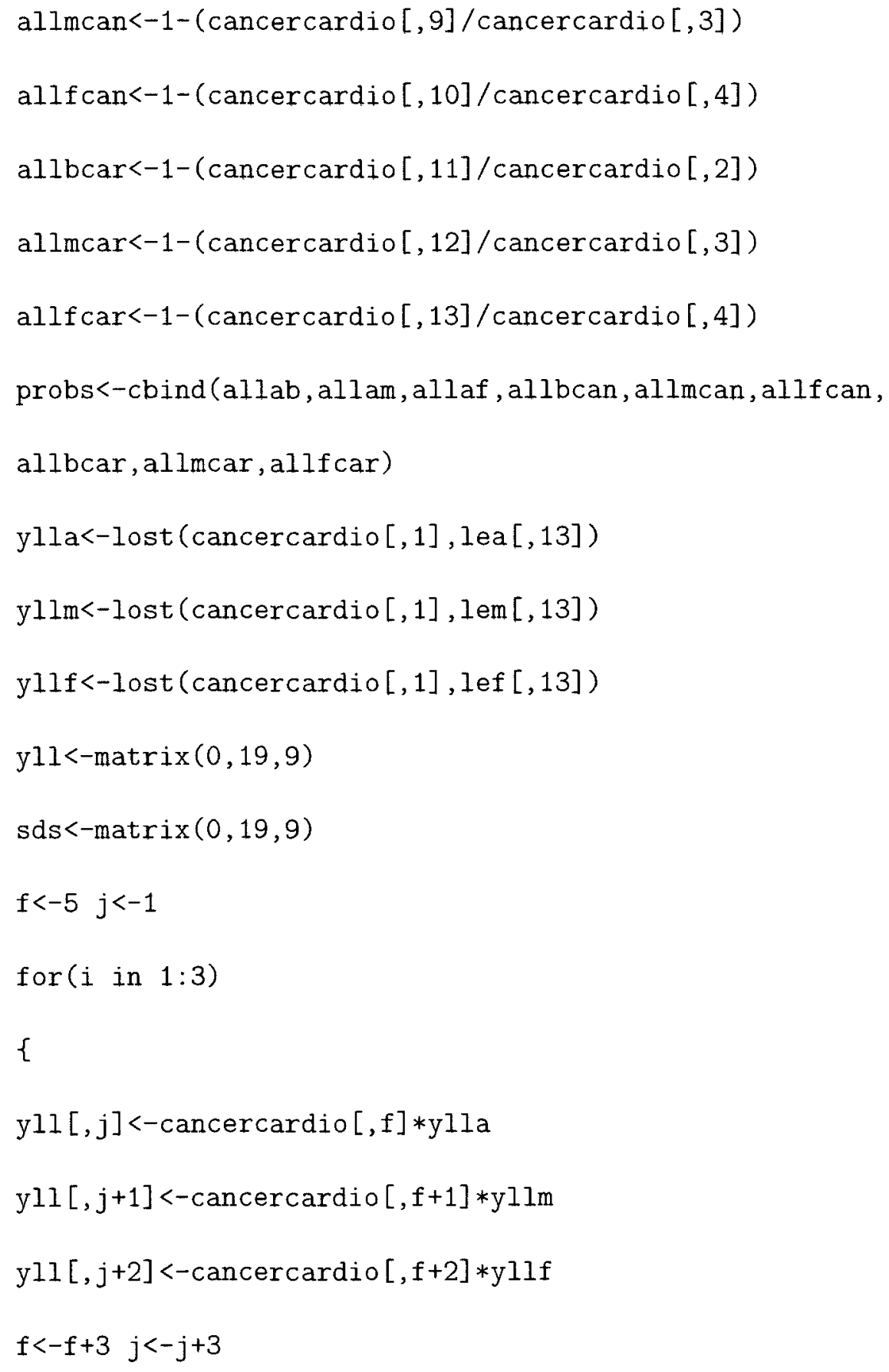




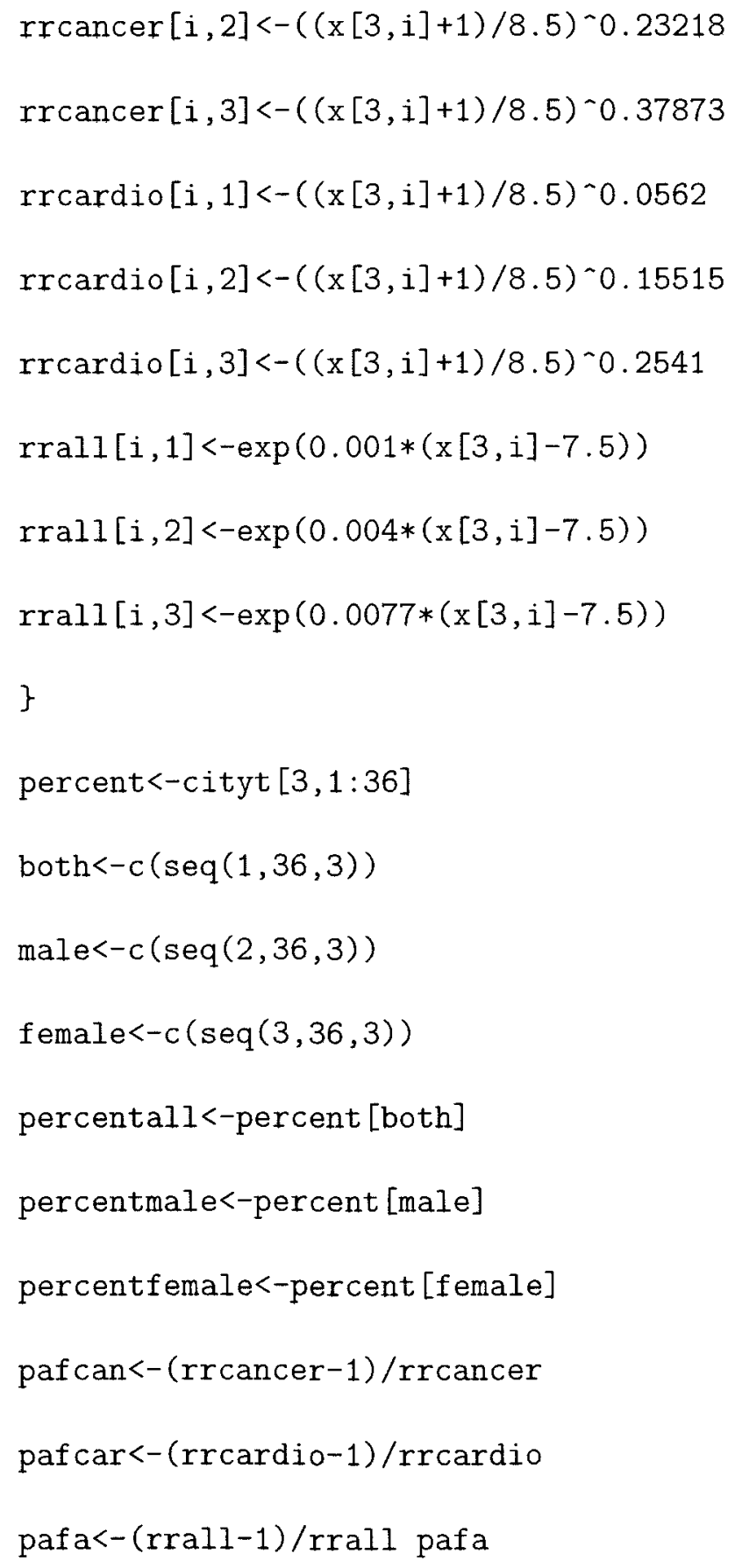




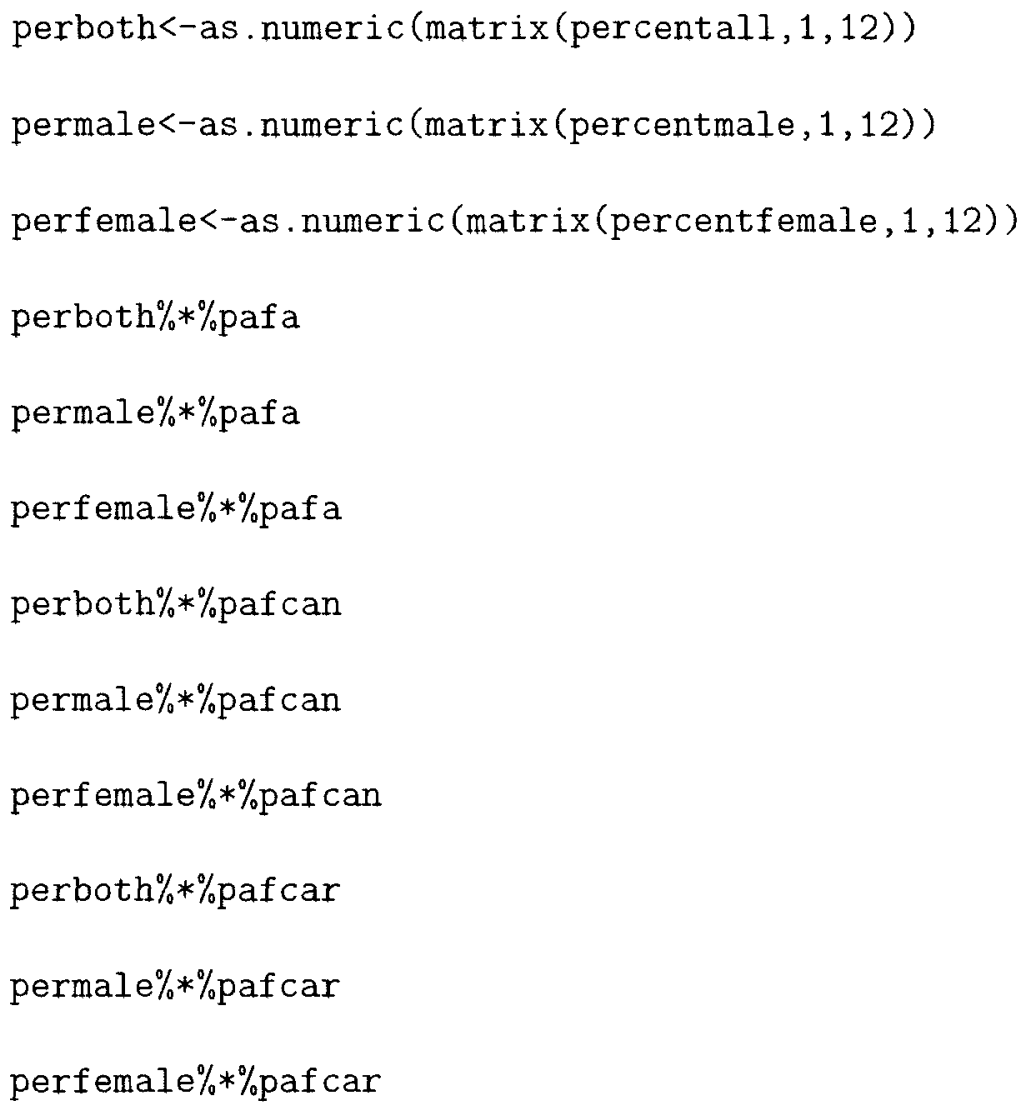

\section{A.8 Health Indicators Comparison}

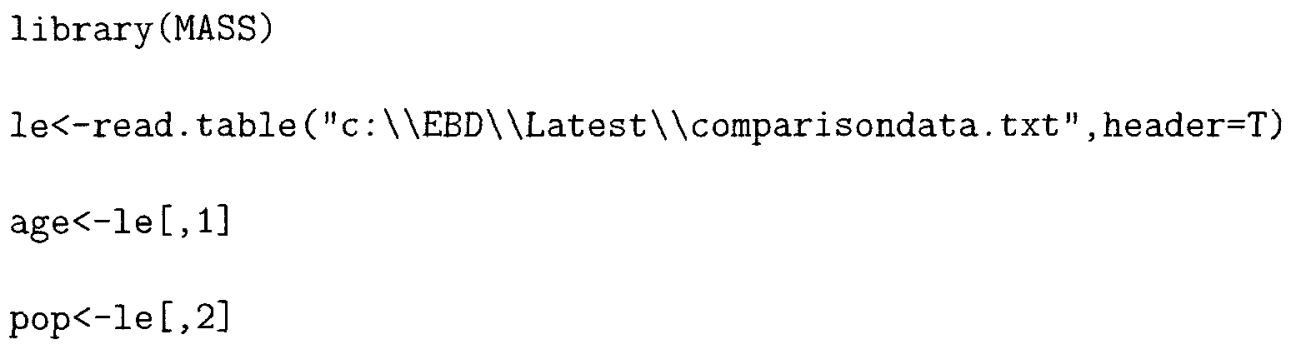




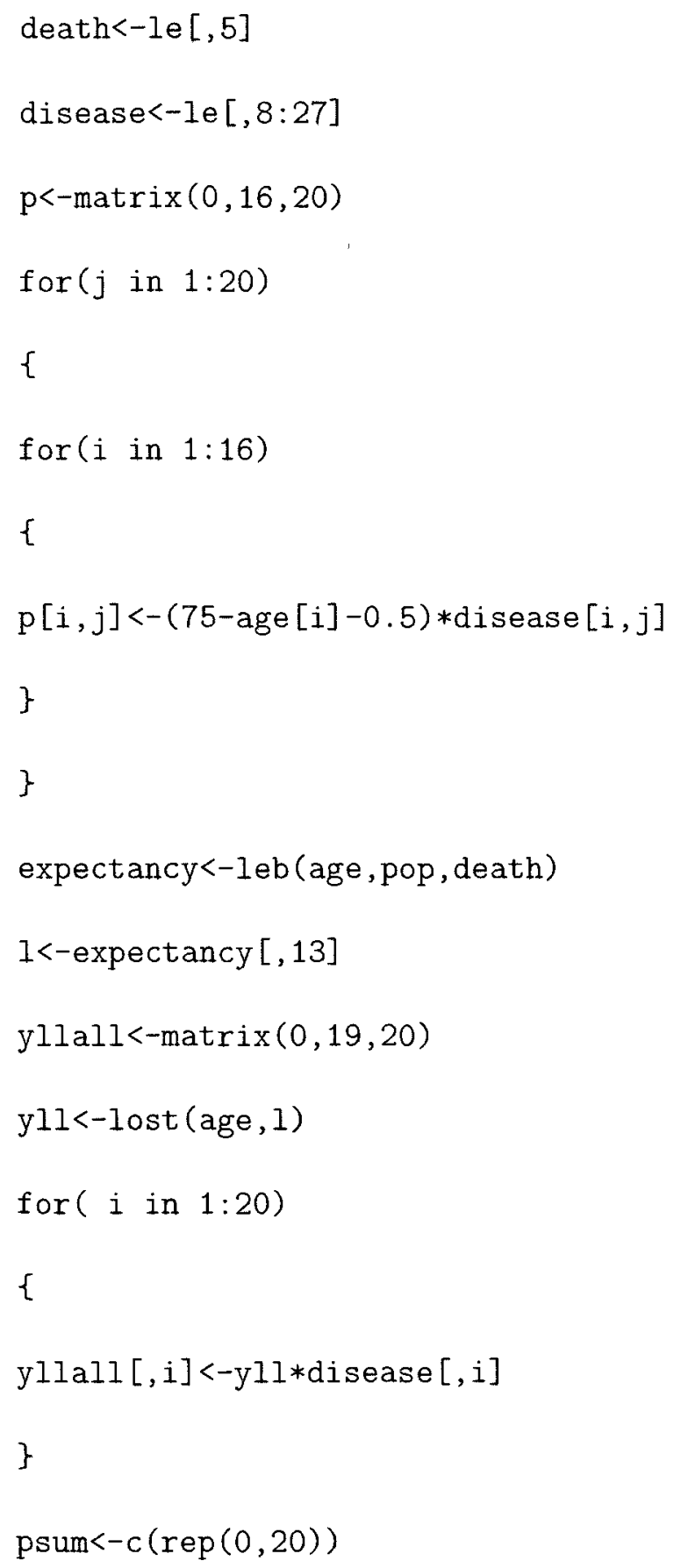




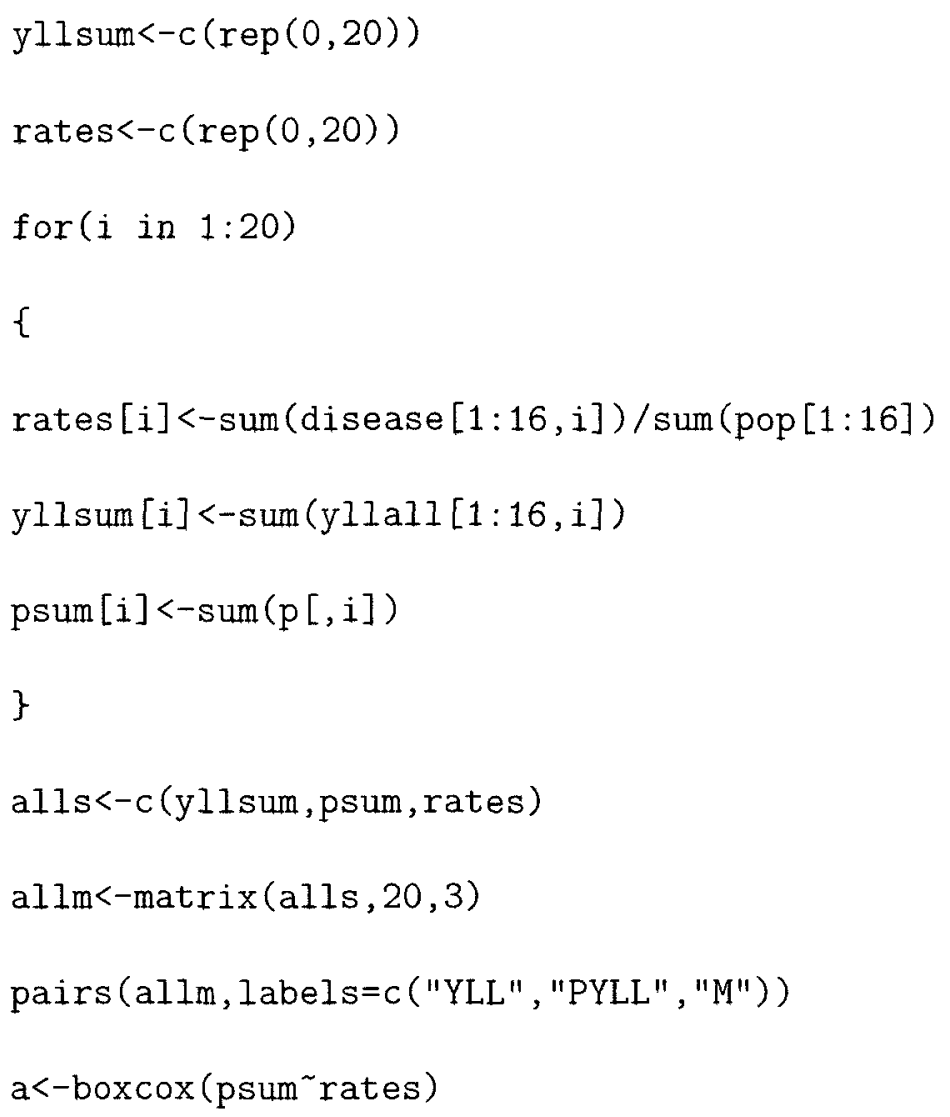


Appendix B

\section{Chapter 6 Data}

Source: Statistics Canada 
Table B 1. The 20 diseases used for the analvsis

\begin{tabular}{|c|c|}
\hline Discase & ICD- $9 \operatorname{cod} \mathrm{t}$ \\
\hline Lung $\mathrm{c}$ tnc: & 162 \\
\hline Lenhaemla & 204208 \\
\hline Live $x$ cancer $r$ & $155-156$ \\
\hline Heart fallure & 428 \\
\hline Carduac Dyurhotmas & 427 \\
\hline Chionx obstructive pulmonary discase & 490496 \\
\hline Accidents & E800 E949 \\
\hline Diabetes mellitur & 250 \\
\hline Pheuoma and influenza & $480-487$ \\
\hline Surcide & E950 E959 \\
\hline Chronue liver diseascs and carrheses & 571 \\
\hline HIV & 042044 \\
\hline Colon c ancer & $153+54$ \\
\hline Brcast cancer & 174 \\
\hline Pancicus cancer $r$ & 157 \\
\hline Huzditazs and degenciative diseases of the central nevous system & 330337 \\
\hline Alzheimer $s$ discase & 331 \\
\hline Psychoses & $200-299$ \\
\hline Neurotic disorders person silty disordus and orher nonpsevehorie mental disorders & 300316 \\
\hline Cancer of brain and contral nervous svatr $m$ & 191192 \\
\hline
\end{tabular}


Table B.2: Death for both genders combined from 10 diseases in the 1996

Canadian population

\begin{tabular}{|cccccccccc|}
\hline 162 & $204-208$ & $155-156$ & 428 & 427 & $490-496$ & E800-E949 & 250 & $480-487$ & E950-E959 \\
\hline 0 & 0 & 2 & 3 & 13 & 6 & 28 & 0 & 21 & 0 \\
0 & 25 & 2 & 2 & 5 & 3 & 130 & 1 & 15 & 0 \\
0 & 17 & 1 & 0 & 2 & 1 & 136 & 0 & 3 & 1 \\
0 & 19 & 0 & 0 & 2 & 3 & 102 & 0 & 1 & 40 \\
1 & 17 & 0 & 3 & 8 & 5 & 500 & 3 & 5 & 231 \\
2 & 24 & 3 & 0 & 4 & 9 & 568 & 3 & 8 & 350 \\
4 & 16 & 6 & 1 & 0 & 5 & 463 & 17 & 16 & 348 \\
22 & 27 & 8 & 2 & 17 & 5 & 557 & 24 & 15 & 419 \\
88 & 35 & 12 & 4 & 19 & 7 & 523 & 30 & 29 & 524 \\
231 & 55 & 32 & 5 & 31 & 17 & 193 & 55 & 45 & 479 \\
476 & 73 & 53 & 3 & 47 & 46 & 405 & 75 & 63 & 399 \\
800 & 88 & 69 & 14 & 49 & 77 & 367 & 127 & 91 & 305 \\
1240 & 111 & 102 & 37 & 84 & 186 & 285 & 210 & 100 & 203 \\
1949 & 154 & 160 & 79 & 138 & 410 & 308 & 366 & 172 & 153 \\
2746 & 223 & 221 & 189 & 251 & 862 & 358 & 605 & 285 & 156 \\
3071 & 291 & 295 & 375 & 362 & 1510 & 459 & 845 & 572 & 138 \\
2442 & 327 & 296 & 532 & 503 & 1847 & 602 & 926 & 925 & 89 \\
1611 & 269 & 240 & 907 & 655 & 2003 & 785 & 960 & 1464 & 60 \\
1025 & 304 & 203 & 2424 & 1339 & 2346 & 1594 & 1203 & 3644 & 46 \\
\hline
\end{tabular}


Table B.3: Death for both genders combined from 10 diseases in the 1996

Canadian population

\begin{tabular}{|ccccccccccc|}
\hline 571 & $042-044$ & $153-154$ & 174 & 157 & $330-337$ & 331 & $290-290$ & $300-316$ & $191-192$ \\
0 & 1 & 0 & 0 & 0 & 13 & 0 & 0 & 0 & 6 \\
0 & 5 & 0 & 0 & 0 & 11 & 0 & 0 & 0 & 18 \\
0 & 1 & 0 & 0 & 0 & 10 & 0 & 0 & 0 & 19 \\
0 & 1 & 0 & 0 & 0 & 6 & 0 & 1 & 0 & 20 \\
1 & 6 & 1 & 0 & 1 & 5 & 0 & 0 & 3 & 8 \\
0 & 10 & 1 & 0 & 0 & 4 & 0 & 1 & 5 & 12 \\
9 & 87 & 6 & 9 & 2 & 3 & 0 & 1 & 6 & 23 \\
20 & 265 & 26 & 45 & 5 & 8 & 0 & 0 & 26 & 35 \\
41 & 311 & 44 & 132 & 20 & 24 & 0 & 4 & 37 & 63 \\
113 & 241 & 83 & 253 & 35 & 22 & 1 & 8 & 58 & 73 \\
146 & 164 & 176 & 314 & 74 & 47 & 0 & 4 & 67 & 107 \\
180 & 105 & 287 & 388 & 116 & 58 & 3 & 8 & 73 & 98 \\
192 & 60 & 364 & 439 & 209 & 52 & 1 & 20 & 83 & 158 \\
262 & 24 & 548 & 473 & 290 & 157 & 30 & 44 & 87 & 167 \\
389 & 18 & 823 & 565 & 412 & 251 & 81 & 88 & 118 & 196 \\
353 & 5 & 994 & 661 & 526 & 482 & 186 & 208 & 120 & 209 \\
232 & 0 & 980 & 628 & 505 & 817 & 391 & 440 & 97 & 142 \\
110 & 2 & 846 & 538 & 425 & 1101 & 659 & 815 & 122 & 92 \\
67 & 0 & 979 & 629 & 371 & 1841 & 1336 & 2381 & 335 & 45 \\
\hline
\end{tabular}




\section{Appendix $\mathrm{C}$}

\section{World Regions}

Source: The World Health Organization website

\section{C.1 WHO Regions}

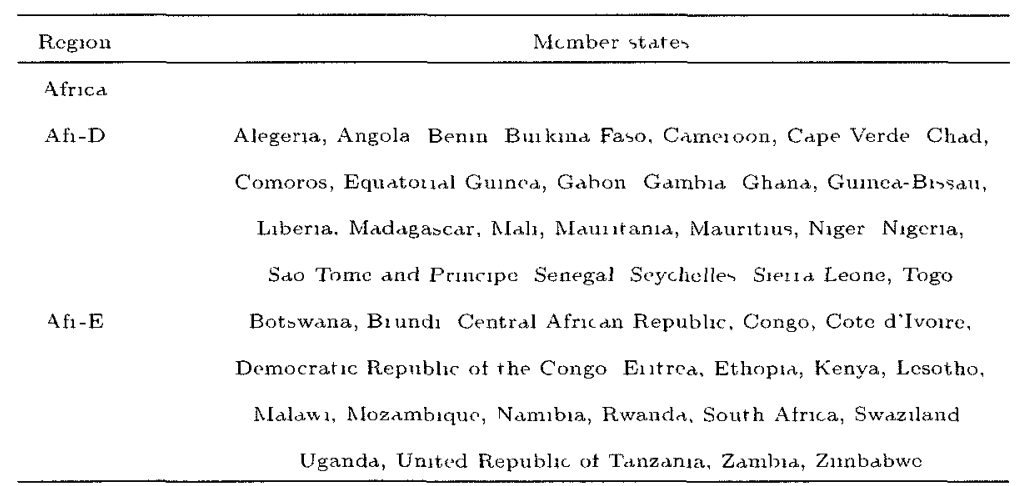




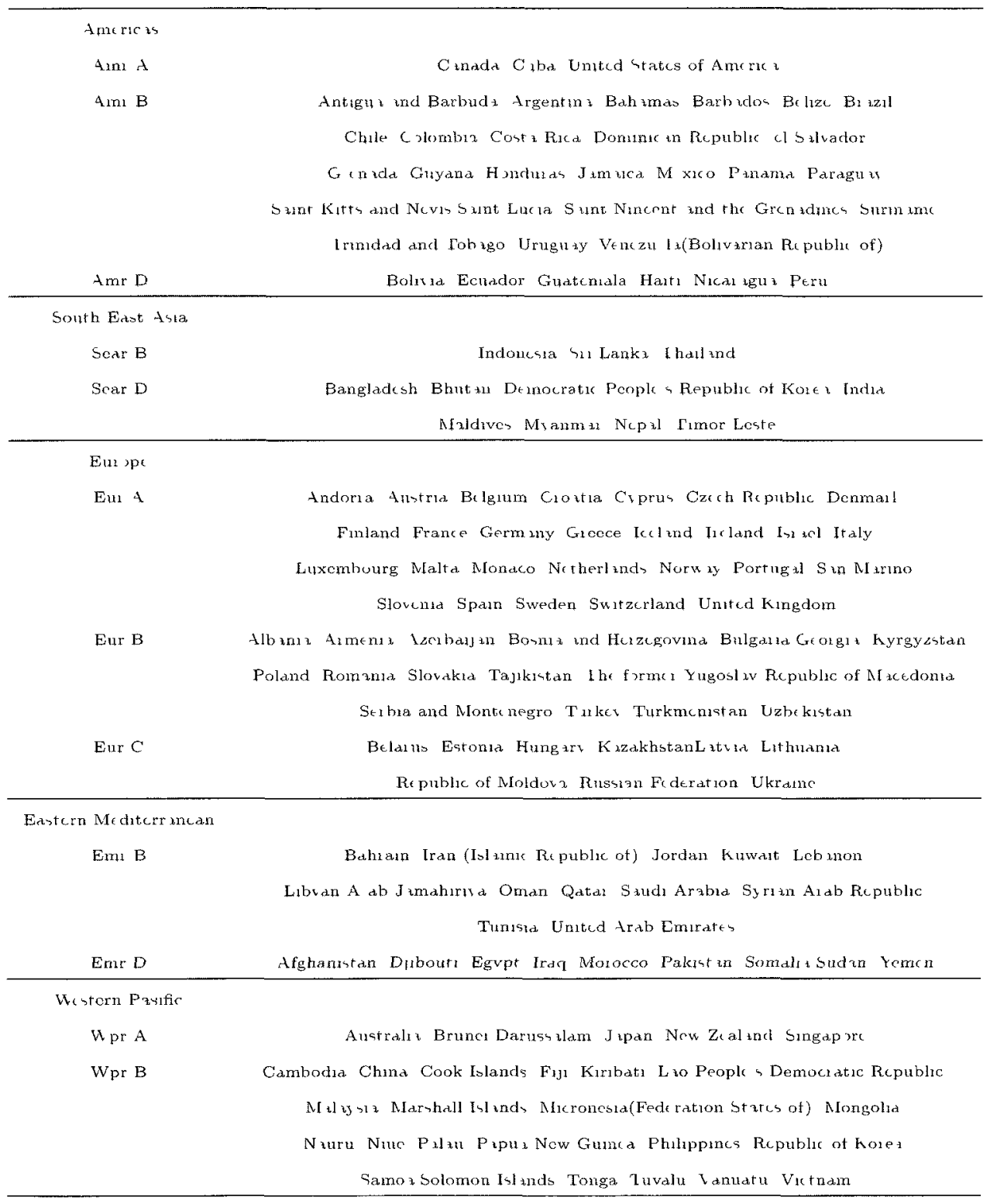




\section{C.2 World Bank Regions}

Source: World Bank website

\begin{tabular}{|c|c|c|c|c|c|}
\hline Afghanistan & Bangladesh & Benin & Burhina $\Gamma a>0$ & Bundu & Cambodia \\
\hline Cential Atrican Republe & Chad & Comoros & Congo, Dem Rep & Eratrez & Ethopla \\
\hline Gambla, The & Ghapa & Gusne & Gumed-Bissalu & Haxt & Kenya \\
\hline hored, Dem Rcp & Ky1guz Republic & Lao PDR & Liberia & Mrtdagascar & Malaw \\
\hline $\mathbf{M} \mathbf{z}_{1}$ & Mintutanic & Mozambique & Myanunal & $N_{c} p u$ & Nigel \\
\hline Rwanda & Senegal & Sienra & Lcone & Somalla & Tajukist un \\
\hline Tanzania & Togo & Ugancla & Uzbehintan & Vietnam & Ytunen, $R \in p$ \\
\hline Zambia. & Zambabwe & & & & \\
\hline
\end{tabular}


Lower middle income cconomxs

\begin{tabular}{|c|c|c|c|c|}
\hline Albanla & $\operatorname{lngol} i$ & Aı menta & Aza + baljan & Belizt \\
\hline Bł+ut uा & Bolivia & Cameroon & Cape Verde & China \\
\hline Cong, $R p$ & Cotc d Ivorre & Djibout & Ecu $\gtrsim d o t$ & Egypt Arab Rcp \\
\hline El \& ilvador & Geolgle & Guztcmala & Gur in? & Hondwis d. \\
\hline Indix & Indoncida & Irark lslamic Rep & $\operatorname{lr} x q_{1}$ & Jond an \\
\hline hutubtu & hosovo & Lesotho & Valdises & Marshall Irlands \\
\hline Mrooncsid Fed Srs & Noldor: & Mongolid & Morocco & Nicaragua \\
\hline Nigcria & Pihistan & reput & V w C mned & Paidaguav \\
\hline Philıppines & samo? & Sto Tome and Principe & Solomon folands & bri Lanka \\
\hline Sudan & Swazil ind & Syuan Arab Re public & Ih mlend & I mor Lest \\
\hline Toug $\mathrm{x}$ & Tunisit & Turkmenestan & Ukrain & Vanuatu \\
\hline \multicolumn{5}{|l|}{ Wo,t Bank and $G_{\exists z d}$} \\
\hline \multicolumn{5}{|c|}{ Uppos muddle meome coonomits } \\
\hline $4 \lg (11$ & Amcitir an Simoa & Argentina & Belirus & Bosmla and $\mathrm{H}$ lzegovma \\
\hline Borsw dnd & B: tzil & Bulguria & Chile & Colombia \\
\hline Cost $x$ Rica & Cuba & Domunied & Dominuc an Republic & \\
\hline$F_{1 y 1}$ & Grbon & Cl nada & Jamaica & K $₫$ zakhst in \\
\hline Latvia & I ebanon & Liby $x$ & Lithilarilat & Mrcedonla FYR \\
\hline Mal of size. & Murritius & Mayotte & Mcxico & Montenegro \\
\hline Namibla & $P \neq l \neq 1$ & Panam & Pulu & Pol ind \\
\hline Rom anıd & Russian & Foderition & Selbia & Scuchellen \\
\hline South Africa & St Kitts ind $N \in V_{1}$, & St Lucis & st Vuxernt & Surname \\
\hline & & & and the Grenuctines & \\
\hline Turkey & Urugux & Venezucla RB & & \\
\hline \multicolumn{5}{|l|}{ High ineome cconomis } \\
\hline Andoria & Antigu $*$ and Barbida & Arrubi & Austialix & Austrux \\
\hline Bahumas The & Bahı an & Barbados & Be $\lg 1 \mathrm{um}$ & Bermudz \\
\hline Brunt & Darussalam & Canada & Calam Islands & Channel Islunds \\
\hline Croctida & Cyprus & Cacch Republic & Denmark & Estonja \\
\hline Equ xt rual & Gunez & F z.eroc Inl $\neq$ uck & Finland & France \\
\hline French Polvatsid & Gurmany & Gruecl & Cretnland & Guam \\
\hline Hone Kong Chind & Hungary & Iccland & Ir $\in \mathrm{l}$ ind & Isle of Man \\
\hline I & It aly & J ipan & Kore a Rep & hux sut \\
\hline Licchtunstein & Luxembouts & Macao China & Malta & Mi jaaco \\
\hline \multirow[t]{2}{*}{ Ncihelands } & Netherl \pm nds Antille & New Caledonsa & New Zealand & N rrthor n Mallana \\
\hline & & & & Islands \\
\hline Noruav & On in & Poitriga.l & Puerto Rico & Qatar \\
\hline 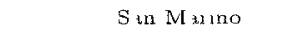 & Studi trabiat & $\operatorname{Sing} x$ xpor & Sl mak Rie public & hiorent \\
\hline Spain & Sweden & switzerland & T inid id and robagr & Unuted I ab Emurutes \\
\hline United Kingdom & Unuted $s t x t c s$ & Virgm laland ( $(\mathrm{C} \rightarrow)$ & & \\
\hline
\end{tabular}

